\title{
Fes? BASPENDER
}

Trascender, Contabilidad y Gestión. Vol. 6, Núm. 16 (enero - abril del 2021).

Universidad de Sonora. Departamento de Contabilidad. México.

ISSN: 2448-6388. Reserva de Derechos 04-2015-04172070800-203.

\section{Estudio histórico de evaluación: Cumplimiento de metas de la Secretaría de Hacienda, Secretaría de Economía y Secretaría de Desarrollo Social del Estado de Sonora del ejercicio 2015}

\author{
Historical evaluation study: Fulfillment of goals of the Secretary of Finance, Secretary of \\ Economy and Secretary of Social Development of the State of Sonora for the year 2015
}

\author{
Nallely Esther Villa Ruiz ${ }^{1}$
}

Recibido: 15 de octubre de 2020.

Aceptado: 18 de diciembre de 2020.

DOI: https://doi.org/10.36791/tcg.v0i16.91

JEL: H61. Presupuesto; Sistema presupuestario.

\section{Resumen}

En este artículo se realizara un estudio histórico del año 2015, para ello recurrimos a la información programática de la cuenta pública del poder ejecutivo de 2015, se tomaron como muestra de estudio 3 dependencias: la Secretaría de Hacienda, la Secretaría de Economía y la Secretaría de Desarrollo Social. Este análisis se realiza con el objetivo de Evaluar los programas públicos y lo indicadores para saber si las dependencias están cumpliendo las metas establecidas.

En este análisis podemos observar cómo se distribuye el presupuesto del poder ejecutivo a las Dependencias del sector Público, y como éstas, crean programas en relación a dicho presupuesto con la implementación de objetivos para cumplimento de metas y los diversos indicadores de evaluación para cada programa. El Ejecutivo del Estado es el que logró cumplir un mayor porcentaje de metas con un $78 \%$ equivalente a 29. En total el Poder Ejecutivo estableció 477 metas. La Secretaría de Agricultura,

\footnotetext{
${ }^{1}$ Nallely Esther Villa Ruiz. Licenciada en Contaduría Pública. Licenciada en Administración de Empresas. Maestra en Fiscalización y Control Gubernamental. Especialista en Contabilidad gubernamental, fiscalización, presupuesto y transparencia del sector público. Asistente contable en Progreso Fideicomiso. Correo: nallelyvillar@gmail.com. ORCID: 0000-0002-4143-1523
} 
Ganadería, Recursos Hidráulicos, Pesca y Acuacultura, es la Dependencia con menor porcentaje de metas cumplidas apenas alcanzó el 37\% de ellas.

En este análisis encontramos algunas metas inconclusas y deficiencias en los indicadores de los programas. Algunos de éstos programas no fueron efectuados, debido a cancelaciones de recursos por parte de la Secretaría de Hacienda, sin quedar claro a donde se redistribuyó dicho recurso. Aunado a esto los subejercicios registrados son de especial observancia, puesto que la sociedad siempre tendrá necesidades ilimitadas que cubrir, y se ve limitada de dicho recurso presupuestario.

Palabras clave: evaluación, cumplimiento, meta, presupuesto, programa.

\section{Abstract}

This article will carry out a historical study of the year 2015, for this we use the programmatic information of the public account of the executive branch of 2015, were taken as a sample of study 3 dependencies: the Secretary of Finance, the Secretary of Economy and the Secretary of Social Development. This analysis is carried out with the objective of Evaluating public programs and indicators to know if the units are meeting the established goals.

In this analysis we can see how the budget of the executive branch is distributed to the Public Sector Units, and like these, they create programs in relation to that budget with the implementation of objectives for meeting goals and the various evaluation indicators for each program. The State Executive is the one who managed to meet a higher percentage of targets with 78\% equivalent to 29. In total, the Executive Branch set 477 targets. The Ministry of Agriculture, Livestock, Hydraulic Resources, Fisheries and Aquaculture is the Unit with the lowest percentage of targets met barely reached $37 \%$ of them.

In this analysis we find some unfinished goals and deficiencies in program's indicators. Some of these programs were not carried out, due to cancellations of resources by the Secretary of Finance, without being clear where that resource was redistributed. In addition to this, registered sub-cycles are of particular observance, since society will always have unlimited needs to cover, and is limited in that budgetary resource.

Keywords: evaluation, compliance, goal, budget, program.

\section{Introducción}

Toda intervención pública tiene por objeto resolver un problema o atender una necesidad que sea de interés público. Los recursos de los que dispone el Estado deben ser utilizados de manera eficiente y eficaz, con la finalidad de maximizar el impacto de las políticas públicas sobre esos problemas. En este sentido, es una responsabilidad primordial de los gobiernos, es utilizar el gasto público como un instrumento para mejorar las condiciones de sus ciudadanos.

En este artículo se realizara un análisis histórico del año 2015, para ello necesitamos examinar la información programática de la cuenta pública del poder ejecutivo de ese mismo año, se tomaran como muestra 
de estudio 3 dependencias, para esto se eligieron: la Secretaría de Hacienda, la Secretaría de Economía y la Secretaría de Desarrollo Social, este análisis se realiza con el fin de Evaluar los programas públicos y lo indicadores para así, saber si las dependencias están realizando su cumplimiento de metas del año 2015.

Cada año a las dependencias se les asigna un presupuesto el cual debe administrarse de una manera eficaz y eficiente para cumplir un fin, para lograr este se crean programas públicos los cuales se deben planear en base a las necesidades de la sociedad para generar mejor calidad de vida, si estos no se planean eficazmente no se cumplirán y esto afectara económicamente ya que se asignó un presupuesto para llevar a cabo este programa $\mathrm{y}$ proyecto y si queda inconcluso generara gastos, además de no satisfacer las necesidades sociales.

En este estudio analizaremos las dependencias mencionadas con anterioridad y dictaminaremos si administraron sus recursos de manera correcta y si cumplieron o no con las metas que se establecieron, es decir, conocer si las dependencias cumplieron con sus objetivos, metas y atribuciones, y si ejercieron los recursos para el cual les fueron asignados, de manera eficaz, eficiente y con economía.

En relación a estas 3 dependencias analizadas podemos decir que no tienen sus objetivos muy claros, lo que hace que no cumplan sus metas establecidas, lo que se analizó de información relacionada al no cumplimiento de metas siempre hubo excusas por parte de los trabajadores para no llevar a cabo los indicadores y metas, creo que es necesario sancionar a las personas que no estén cumpliendo bien con su trabajo, ya que todo esto repercute en la economía y en la sociedad, estamos estancando programas de mucha utilidad, también es importante que con anticipación planeemos bien los programas, metas e indicadores, los cuales sean favorecedores para los sonorenses. Los programas tenían su recurso establecido algunas dependencias con más y otras con menos y eso no quiere decir o asegura que cumplirán con sus metas, además las dependencias se gastaron más del $98 \%$ de su presupuesto y no alcanzaron a lograr ni el 60\% de cumplimiento.

\section{Desarrollo}

A más de una década de implementación del Presupuesto basado en resultados y del Sistema de Evaluación del Desempeño en México, a la mayoría de los actores involucrados en la planeación, programación y presupuestación tienen clara la importancia de la evaluación y el seguimiento de las políticas y programas públicos por medio de los cuales se lleva a cabo el ejercicio del gasto en nuestro país. Es indispensable que los ejecutores del gasto y responsables de los programas presupuestarios tengan la voluntad de llevar a buen término las evaluaciones del desempeño y el cumplimiento de los Aspectos Susceptibles de Mejora que de estos deviene.

Toda intervención pública tiene por objeto resolver un problema o atender una necesidad que sea de interés público. Los recursos de los que dispone el Estado deben ser utilizados de manera eficiente y eficaz, con la finalidad de maximizar el impacto de las políticas públicas sobre esos problemas. En este sentido, es una responsabilidad primordial de los gobiernos, es utilizar el gasto público como un instrumento para mejorar las condiciones de sus ciudadanos.

Por ello, resulta vital que la agenda pública esté conformada por políticas y programas públicos que estén diseñados a partir de la identificación rigurosa acerca de las situaciones que intenta transformar, sus causas y efectos, la población objetivo o área de enfoque a los que va dirigido; que tenga claridad en los resultados esperados, los medios para lograrlo y los 
elementos a través de los cuales operarán; que demuestren que son capaces de lograr el propósito para el cual fueron creados, y que puedan identificar que sus resultados tienen el impacto esperado. La evaluación es una herramienta de política pública que hace una importante contribución para lograr esto.

El concepto de "evaluación” se ha entendido tradicionalmente como un medio para identificar los resultados o el impacto que genera una acción o conjunto de acciones. En el sector público, la evaluación suele vincularse a la identificación de las transformaciones generadas a partir de las políticas y programas públicos (Ballart, 1993). A partir de estas definiciones, es posible observar un claro enfoque de evaluación aplicado en las etapas finales de una acción, que justamente es cuando se hace posible apreciar dichos resultados o impactos, no antes.

Inicialmente, la evaluación fue considerada como una herramienta enfocada meramente en la medición de la eficacia. Más adelante, demostró su utilidad para la identificación y valoración de los efectos de la ejecución de políticas y programas (tomando en cuenta solamente el grado de impacto observado como consecuencia de su implementación, y no de otros factores externos).

Como indica Ballart (1993), la evaluación en el sector gubernamental puede abarcar todas las esferas del ciclo de una política o programa, desde su concepción hasta su impacto pasando por su implementación u operación.
Con esto, es importante esclarecer que el concepto de evaluación ha evolucionado paulatinamente para abarcar todas las etapas de una política o programa público, a fin de identificar e implementar acciones de mejora, no solo cuando los productos, servicios o acciones ya fueron entregados o ejecutados, o hasta que sea posible medir los resultados o impactos como sugieren los conceptos tradicionales, sino en etapas puntuales y bien definidas en todas las fases del ciclo de política pública que permitan reorientar los cursos de acción.

De esta manera, la evaluación no solo analiza si alguna intervención pública fue o no efectiva, sino que proporciona información para determinar si es la alternativa más adecuada y si existen elementos para prever que logrará sus objetivos.

De acuerdo con Roth (2010), parte de esta confusión se debe a la imprecisión de la lengua castellana para traducir una tradición científica y académica que encuentra sus orígenes en la cultura anglosajona. Para demostrar lo anterior, el autor define, a partir del Diccionario de la Real Academia Española (XXII edición) estos tres conceptos. Se remite, asimismo, a la definición del Diccionario de Oxford para la consulta en inglés de las definiciones. Como resultado, indica que este idioma parece mucho más preciso por el hecho de que permite vincular coherentemente un concepto con otro, tal y como se muestra en la figura 1. 


\section{Figura 1}

Definición de política, programa y proyecto

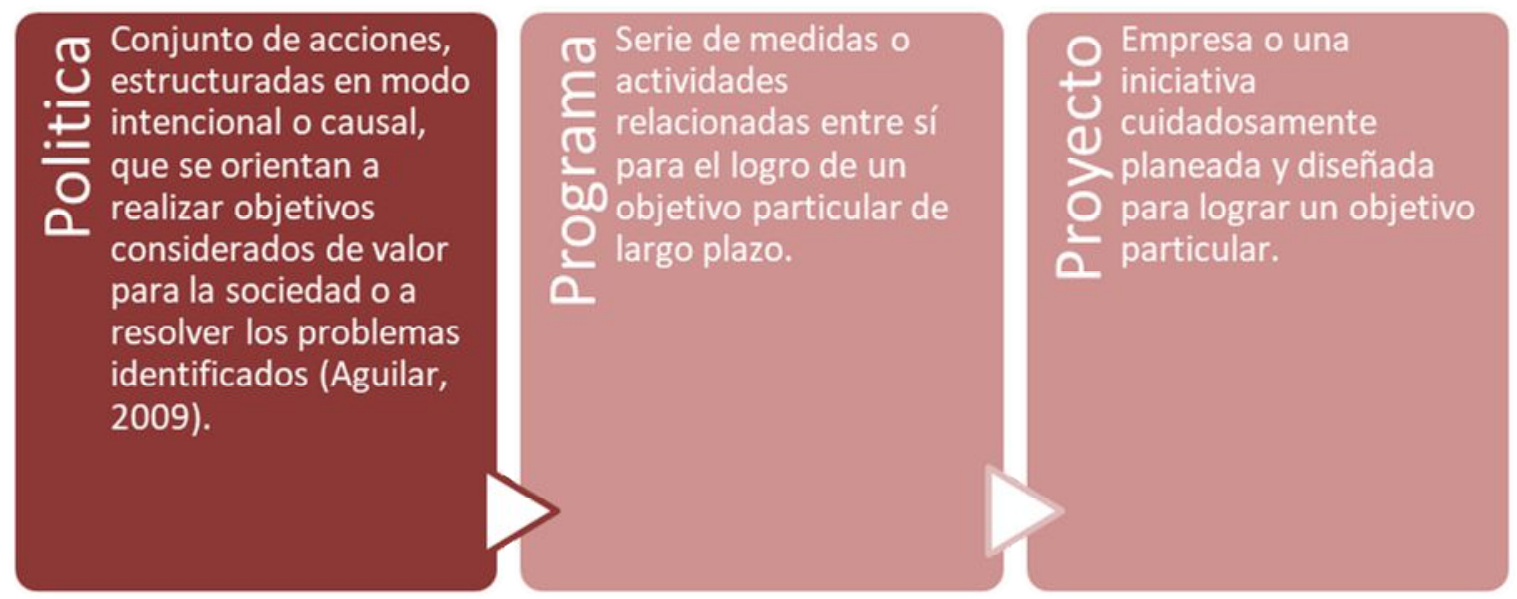

Fuente: Elaboración propia.

\section{Objetivos}

\section{Objetivo General}

Analizar la información programática de las dependencias del Poder Ejecutivo del Gobierno del Estado de Sonora del año 2015 y determinar el cumplimiento de sus metas.

\section{Objetivo específico}

Evaluar cumplimiento de metas del año 2015 de la Secretaría de Desarrollo Social, Secretaría de Economía y Secretaría de Hacienda.

\section{Planteamiento del Problema}

El principal objetivo del artículo es realizar un análisis de la información programática, en específico de la evaluación del cumplimiento de metas por Dependencia del Poder Ejecutivo del Gobierno del Estado de Sonora para la cuenta pública 2015 presentada.
En el presente estudio analizaremos en específico la Secretaría de Desarrollo Social, Secretaría de Economía y Secretaría de Hacienda. El propósito es evaluar si cumplieron o no con las metas que se establecieron, es decir, conocer si las dependencias cumplieron con sus objetivos, metas y atribuciones, y si ejercieron los recursos para el cual les fueron asignados, de manera eficaz, eficiente y con economía

\section{Pregunta de Investigación}

¿En el año 2015 la Secretaría de Desarrollo Social, Secretaría de Economía y Secretaría de Hacienda cumplieron con sus metas establecidas?

Es fundamental que las dependencias cumplan sus metas, ya que estas fueron establecidas para contribuir y mejorar nuestro estado, además de que se destina un presupuesto para lograr este fin, lo ideal sería que se cumplieran las metas. 
Año con año nuestro estado va teniendo más necesidades, es por eso que las dependencias deben adaptarse a dichas necesidades y crear nuevos programas públicos para ayudar a que la sociedad tenga una mejor calidad de vida, para crear programas públicos eficientes y eficaces es necesario hacer un estudio basado en las necesidades de la sociedad sonorense y medir su alcance, todo esto se lleva a cabo

con una buena planeación y programación, estableciendo metas, objetivos e indicadores alcanzables, para que así se establezca un presupuesto y poder cumplir con el programa, proyecto, meta, objetivo e indicador.

\section{Metodología}

Supuesto de investigación, figura 2

\section{Figura 2}

Supuesto de investigación

\section{Determinar si la Secretaría de Desarrollo Social, Secretaría de Fconomía y Secretaría de Hacienda, cumplen con sus metas y objetivos 2015.}

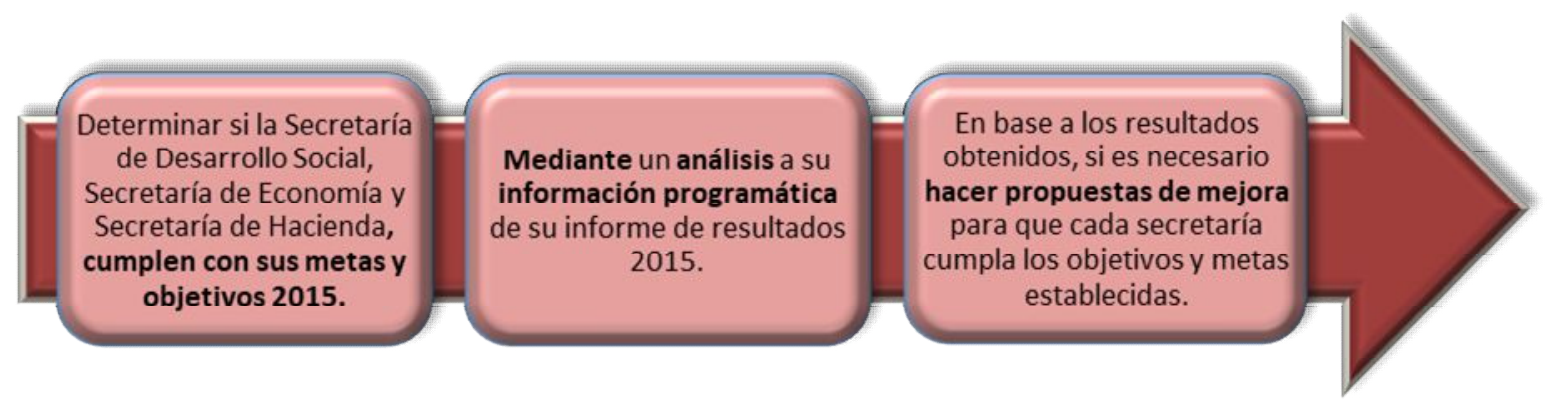

Fuente: Elaboración propia.

Elementos de investigación, figura 3

\section{Figura 3}

Elementos de investigación

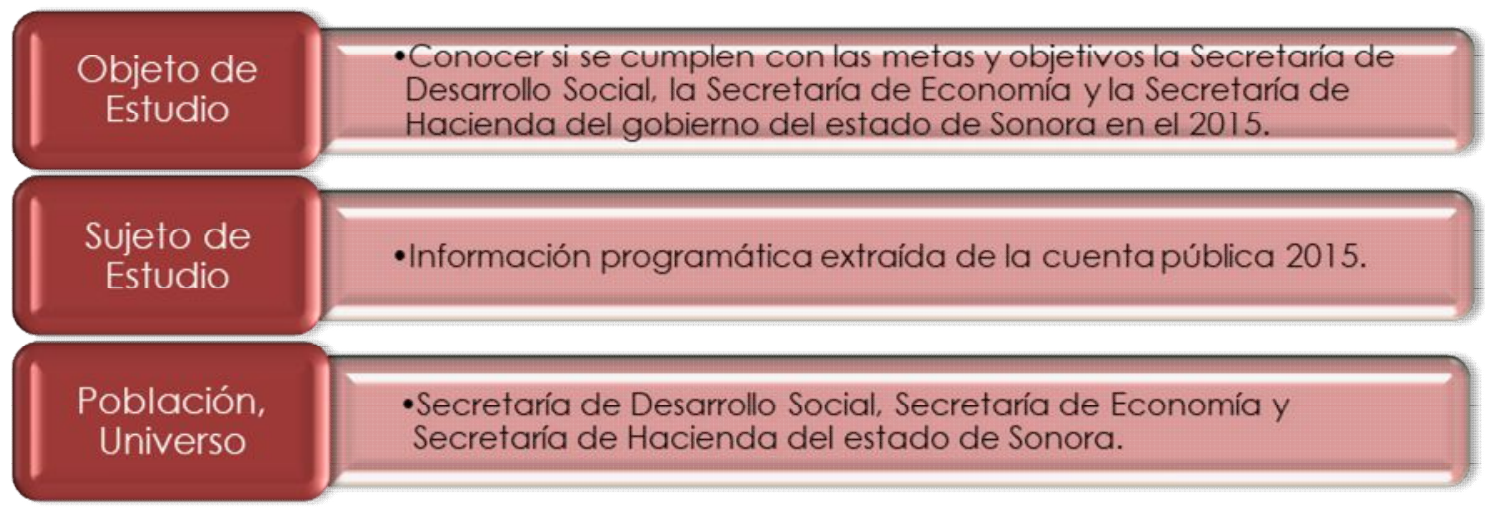

Fuente: Elaboración propia. 
Metodología, figura 4

\section{Figura 4}

\section{Metodología}

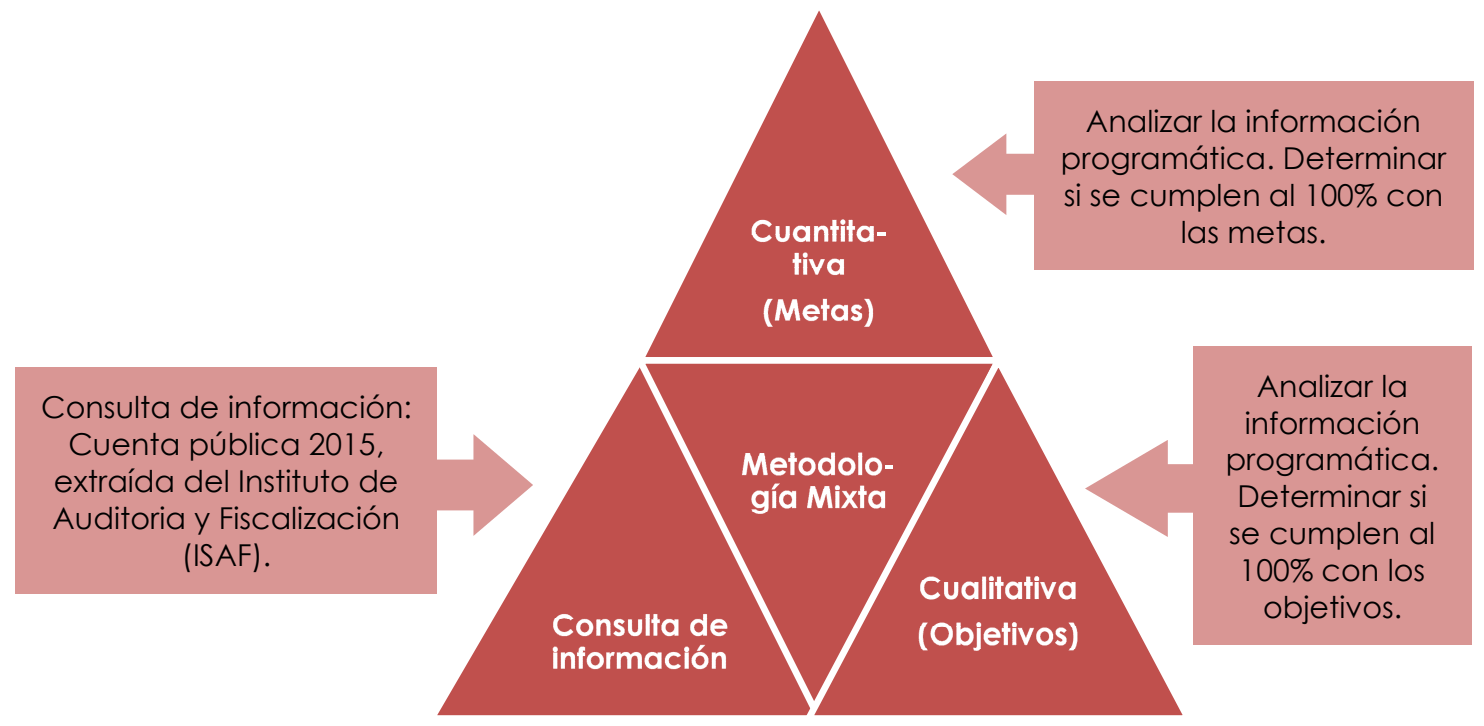

Fuente: Elaboración propia.

\section{Descripción de la Información}

Este trabajo se realizara con ayuda de la Cuenta Pública correspondiente al ejercicio fiscal de 2015, en el cual se analizaran sus resultados generales como información presupuestaria y programática (resultados por Dependencia de sus programas e indicadores en el sistema de evaluación estatal) de las siguientes dependencias que forman parte del poder ejecutivo: Ejecutivo del Estado, Secretaría de Gobierno, Secretaría de Salud Pública, Secretaría del Trabajo, Secretaría de Salud Pública, Secretaría de Infraestructura y Desarrollo
Urbano, Secretaría de la Contraloría General, Secretaría de Desarrollo Social, Secretaría de Economía, Secretaría de Hacienda, Oficialía Mayor, Procuraduría General de Justicia, Secretaría de Educación y Cultura y Secretaría de Agricultura, Ganadería, Recursos Hidráulicos, Pesca y Acuacultura. Se tomaran como muestra de estudio 3 dependencias, para esto se eligieron: la Secretaría de Hacienda, la Secretaría de Economía y la Secretaría de Desarrollo Social, este análisis se realiza con el fin de Evaluar los programas públicos y lo indicadores para así, saber si las dependencias están realizando su 
cumplimiento de metas del año 2015. En este estudio analizaremos las dependencias mencionadas con anterioridad y dictaminaremos si administraron sus recursos de manera correcta y si cumplieron o no con las metas que se establecieron, es decir, conocer si las dependencias cumplieron con sus objetivos, metas y atribuciones, y si ejercieron los recursos para el cual les fueron asignados, de manera eficaz, eficiente y con economía, la intervención pública tiene por objeto resolver un problema o atender una necesidad que sea de interés público. Los recursos de los que dispone el Estado deben ser utilizados de manera eficiente y eficaz, con la finalidad de maximizar el impacto de las políticas públicas sobre esos problemas. En este sentido, es una responsabilidad primordial de los gobiernos, es utilizar el gasto público como un instrumento para mejorar las condiciones de sus ciudadanos.

\section{Análisis de la Información}

En este apartado analizaremos la información programática de la cuenta pública proporcionada por el Poder Ejecutivo de Estado de Sonora referente al ejercicio 2015, poniendo especial énfasis en las metas establecidas por las dependencias y su nivel de desempeño, así como los presupuestos otorgados y los montos ejercidos al finalizar su ejercicio fiscal.

Anualmente las dependencias gubernamentales implementan programas sociales para contribuir al desarrollo de nuestro país, estos programas manejan indicadores para evaluar su cumplimiento y desarrollo, aunado a los programas se establecen metas para poder alcanzar los objetivos de los mismos; enfocándonos específicamente en las metas establecidas podemos apoyarnos en la tabla 1 en la cual nos muestra los datos cuantificables del total de metas establecidas por dependencias del poder ejecutivo y los porcentajes de las cuales lograron cumplirse y las que no se lograron consolidar.

En esta tabla podemos observar que se establecieron un total de 477 metas correspondientes a todas las Dependencias del Poder Ejecutivo, separando las metas que se cumplieron al $100 \%$ o más; las que cumplieron con menos de $100 \%$ y más de $80 \%$; y la que cumplieron con menos del $80 \%$.

Las 3 dependencias con mayor ranking fueron:

El Ejecutivo del estado de Sonora se posicionó en el puesto número uno, logrando obtener el mayor ranking de metas alcanzadas, las metas que se cumplieron con más del 100\% fueron 29 de las 37 establecidas equivalentes al $78 \%$ de su totalidad.

La Secretaría de Gobierno se posicionó en el puesto número dos, considerando las metas que se cumplieron dentro del rango más del 100\%, fueron 14 las metas alcanzadas las que se cumplieron de 21 metas establecidas, estas equivalentes al $67 \%$ del total que estableció esta dependencia.

La Secretaría de Salud Pública se posicionó en el puesto número tres, considerando las metas que se cumplieron dentro del rango más del 100\%, fueron 17 las metas alcanzadas las que se cumplieron de 27 metas establecidas, estas equivalentes al 63\% del total que estableció esta dependencia.

Por otro lado, se muestra en el último lugar a la Secretaría de Agricultura, Ganadería, Recursos Hidráulicos, Pesca y Acuacultura, considerando las metas que se cumplieron dentro del rango de más del $100 \%$, fueron solo 13 las metas alcanzadas las que se cumplieron de 35 metas establecidas, estas equivalentes a solo el $37 \%$ de su totalidad. En el rango de cumplimiento de menos del $80 \%$ fueron 15 metas, equivalentes al $43 \%$ del total de las metas que estableció esta dependencia. 
Cumplimiento de Metas por Dependencia, tabla 1

\section{Tabla 1}

Metas por dependencia

\begin{tabular}{|c|c|c|c|c|c|c|c|}
\hline \multirow[b]{2}{*}{ DEPENDENCIAS } & \multicolumn{7}{|c|}{ METAS } \\
\hline & $\begin{array}{l}\text { TOTAL } \\
\text { DE } \\
\text { METAS }\end{array}$ & $\begin{array}{c}\text { AL } \\
100 \% \text { Y } \\
\text { MÁs }\end{array}$ & $\%$ & $\begin{array}{l}\text { MENOS } \\
\text { DEL 100\% } \\
\text { Y MÁS } \\
\text { DEL } 80 \%\end{array}$ & $\%$ & $\begin{array}{l}\text { MENOS } \\
\text { DEL } \mathbf{8 0} \%\end{array}$ & $\%$ \\
\hline EJECUTIVO DEL ESTADO & 37 & 29 & $78 \%$ & 3 & $8 \%$ & 5 & $14 \%$ \\
\hline $\begin{array}{l}\text { SECRETARÍA DE } \\
\text { GOBIERNO }\end{array}$ & 21 & 14 & $67 \%$ & 4 & $19 \%$ & 3 & $14 \%$ \\
\hline $\begin{array}{l}\text { SECRETARÍA DE SALUD } \\
\text { PÚBLICA }\end{array}$ & 27 & 17 & $63 \%$ & 2 & $7 \%$ & 8 & $30 \%$ \\
\hline $\begin{array}{l}\text { SECRETARÍA DEL } \\
\text { TRABAJO }\end{array}$ & 42 & 26 & $62 \%$ & 1 & $2 \%$ & 15 & $36 \%$ \\
\hline $\begin{array}{l}\text { SECRETARÍA DE } \\
\text { SEGURIDAD PÚBLICA }\end{array}$ & 28 & 17 & $61 \%$ & 5 & $18 \%$ & 6 & $21 \%$ \\
\hline $\begin{array}{l}\text { SECRETARÍA DE } \\
\text { INFRAESTRUCTURA Y } \\
\text { DESARROLLO URBANO }\end{array}$ & 38 & 23 & $61 \%$ & 8 & $21 \%$ & 7 & $18 \%$ \\
\hline $\begin{array}{l}\text { SECRETARÍA DE LA } \\
\text { CONTRALORÍA GENERAL }\end{array}$ & 25 & 15 & $60 \%$ & 8 & $32 \%$ & 2 & $8 \%$ \\
\hline
\end{tabular}




\section{Tabla 1}

\section{Continuación...}

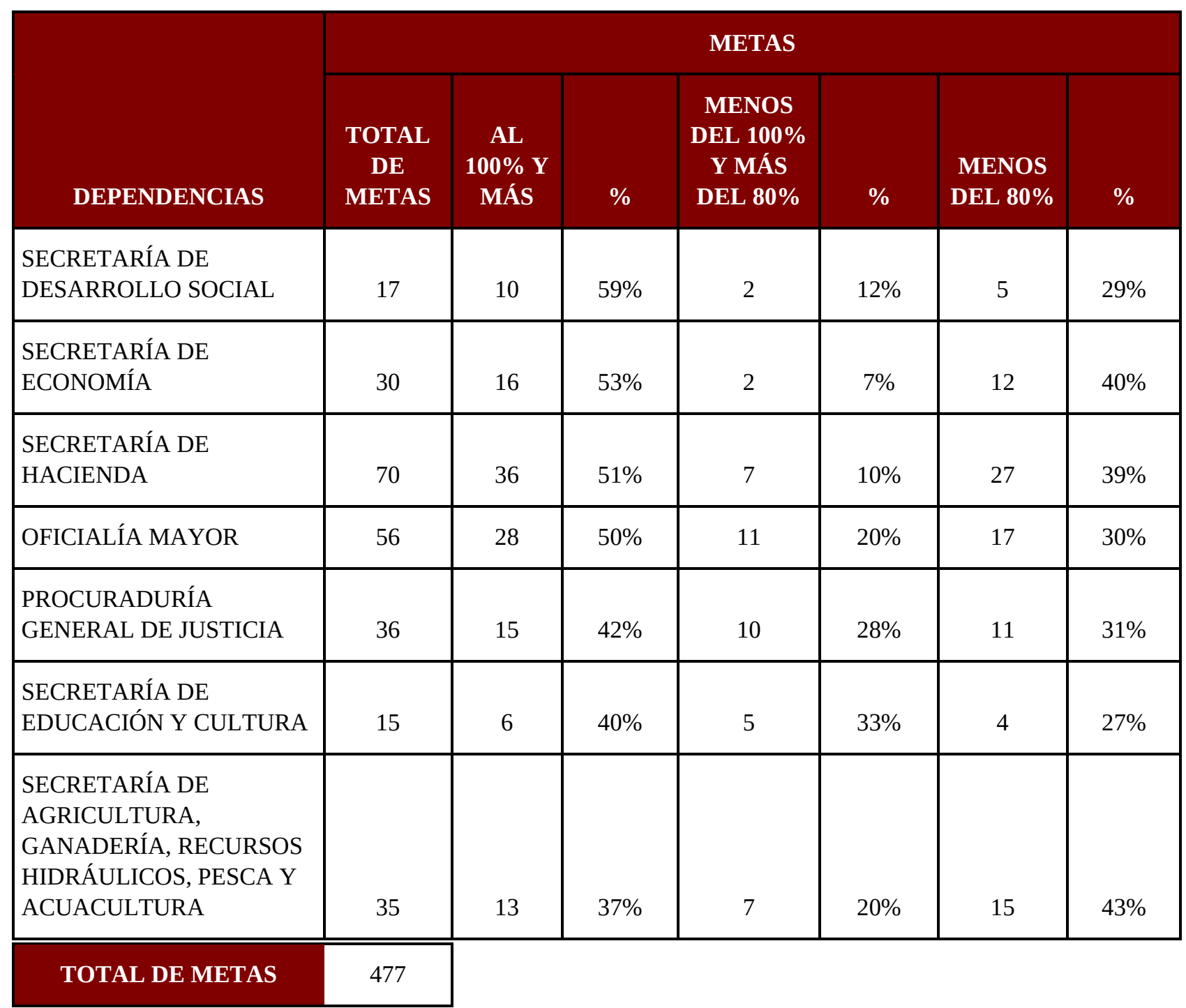

Fuente: Elaboración propia. 
Terminando el comparativo de las metas alcanzadas y no logradas, pasaremos a la cuestión presupuestaria con relación específica a las metas obtenidas; en la tabla 2 se muestras los presupuestos ejercidos por dependencia del Poder Ejecutivo del año 2015.

Las 3 dependencias con mayor presupuesto otorgado fueron: En primer lugar la Secretaría de Educación con un total de \$16, 335 millones de pesos, en segundo la Secretaría de Hacienda con $\$ 13,620$ millones de pesos y en tercero la Secretaría de Salud \$5,118 millones de pesos. El subejercicio de estas mismas dependencias fue por: $\$ 94,888$ millones de pesos para la Secretaría de Educación, 22,336 millones de pesos para la Secretaría de Hacienda y \$18,301 millones de pesos para la Secretaría de Salud, prácticamente el subejercicio es el presupuesto que las dependencias no gastaron durante ese ejercicio fiscal.

El presupuesto se les asigna a las dependencias con el fin de cumplir sus objetivos y así contribuir a la mejora de nuestros estados y municipios, como por ejemplo contribuir con la educación, salud, empleo, economía, infraestructura (Escuelas, hospitales, carreteras, etc.) etc. es por eso que se crean programas públicos específicos dentro de las dependencias adecuándose a la actividad que desempeña cada una de estas dependencias que junto con metas e indicadores ayudan al cumplimiento de sus objetivos. Es muy importante administrar con eficiencia y eficacia el presupuesto que está destinado para cada programa público, ya que si no se administra bien ese recurso podrían no cumplirse las metas que se tienen establecidas y afectar a los posibles beneficiarios del programa; prosiguiendo con la tabla 2 se ve reflejado que la Dependencia de Desarrollo Urbano reflejó el mayor monto de subejercicio, con un total de \$268 millones de pesos correspondiendo al 6.1\% de subejercido (Presupuesto no gastado); así mismo, podemos observar que la Procuraduría General de Justicia no presentó subejercicios (Eso quiere decir que se gastó todo el presupuesto que se le asignó pero no cumplió al $100 \%$ con las metas establecidas como se puede ver en la tabla 1 ).

Presupuesto Ejercido por Dependencia en Pesos, tabla 2

\section{Tabla 2}

Presupuesto subejercido por dependencia 2015 en pesos

\begin{tabular}{|l|c|c|c|}
\hline \multicolumn{1}{|c|}{ DEPENDENCIA } & $\begin{array}{c}\text { PRESUPUESTO } \\
\text { MODIFICADO }\end{array}$ & SUBEJERCICIO & \% DE LA VARIACIÓN \\
\hline EJECUTIVO DEL ESTADO & $\$ 375,939,227.17$ & $\$ 5,819,499.61$ & $1.5 \%$ \\
\hline $\begin{array}{l}\text { SECRETARÍA DE } \\
\text { GOBIERNO }\end{array}$ & $\$ 604,258,283.94$ & $\$ 4,369,752.08$ & $0.7 \%$ \\
\hline
\end{tabular}




\section{Tabla 2}

Continuación...

\begin{tabular}{|l|c|c|c|}
\hline \multicolumn{1}{|c|}{ DEPENDENCIA } & $\begin{array}{c}\text { PRESUPUESTO } \\
\text { MODIFICADO }\end{array}$ & SUBEJERCICIO & \% DE LA VARIACIÓN \\
\hline $\begin{array}{l}\text { SECRETARÍA DE SALUD } \\
\text { PÚBLICA }\end{array}$ & $\$ 5,118,189,329.22$ & $\$ 18,301,631.76$ & $0.4 \%$ \\
\hline $\begin{array}{l}\text { SECRETARÍA DEL } \\
\text { TRABAJO }\end{array}$ & $\$ 121,288,778.80$ & $\$ 360,254.81$ & $0.3 \%$ \\
\hline $\begin{array}{l}\text { SECRETARÍA DE } \\
\text { SEGURIDAD PÚBLICA }\end{array}$ & $\$ 1,792,976,879.78$ & $\$ 34,551,118.60$ & $1.9 \%$ \\
\hline $\begin{array}{l}\text { SECRETARÍA DE } \\
\text { INFRAESTRUCTURA Y } \\
\text { DESARROLLO URBANO }\end{array}$ & $\$ 4,372,818,080.80$ & $\$ 268,295,007.99$ & $2.1 \%$ \\
\hline $\begin{array}{l}\text { SECRETARÍA DE LA } \\
\text { CONTRALORÍA GENERAL }\end{array}$ & $\$ 104,173,664.09$ & $\$ 2,922,860.32$ & $0.0 \%$ \\
\hline $\begin{array}{l}\text { SECRETARÍA DE } \\
\text { DESARROLLO SOCIAL }\end{array}$ & $\$ 381,867,525.08$ & $\$ 2,783,233.37$ & $0.7 \%$ \\
\hline $\begin{array}{l}\text { SECRETARÍA DE } \\
\text { ECONOMÍA }\end{array}$ & $\$ 662,600,029.11$ & $\$ 14,731,304.37$ & $2.2 \%$ \\
\hline $\begin{array}{l}\text { SECRETARÍA DE } \\
\text { HACIENDA }\end{array}$ & $\$ 13,620,936,739.13$ & $\$ 22,336,363.74$ & $0.0 \%$ \\
\hline $\begin{array}{l}\text { OFICIALÍA MAYOR } \\
\text { GENERAL DE JUSTICIA }\end{array}$ & $\$ 966,957,213.12$ & & \\
\hline
\end{tabular}




\section{Tabla 2}

Continuación...

\begin{tabular}{|c|c|c|c|}
\hline DEPENDENCIA & $\begin{array}{l}\text { PRESUPUESTO } \\
\text { MODIFICADO }\end{array}$ & SUBEJERCICIO & \% DE LA VARIACIÓN \\
\hline $\begin{array}{l}\text { SECRETARÍA DE } \\
\text { EDUCACIÓN Y CULTURA }\end{array}$ & $\$ 16,335,369,418.85$ & $\$ 94,888,382.77$ & $0.6 \%$ \\
\hline $\begin{array}{l}\text { SECRETARÍA DE } \\
\text { AGRICULTURA, } \\
\text { GANADERÍA, RECURSOS } \\
\text { HIDRÁULICOS, PESCA Y } \\
\text { ACUACULTURA }\end{array}$ & $\$ 1,504,815,245.67$ & $\$ 3,738,064.86$ & $0.2 \%$ \\
\hline
\end{tabular}

Fuente: Elaboración propia.

Presupuesto Ejercido por Dependencia en metas cumplidas y no cumplidas, además de saber en Porcentajes porcentaje cuánto fue el presupuesto ejercido y sobrante de cada una de las dependencias del ejercicio 2015.

En la tabla 3 podemos analizar en porcentajes las

\section{Tabla 3}

Presupuesto subejercido por dependencia en porcentajes

\begin{tabular}{|l|c|c|c|c|}
\hline \multicolumn{1}{|c|}{ DEPENDENCIA } & $\begin{array}{c}\text { \% NO } \\
\text { CUMPLIMIENTO } \\
\text { DE METAS }\end{array}$ & $\begin{array}{c}\text { \% DE } \\
\text { CUMPLIMIENTO } \\
\text { DE METAS }\end{array}$ & $\begin{array}{c}\text { \% DE LA } \\
\text { VARIACIÓN }\end{array}$ & $\begin{array}{c}\text { \% DE RECURSOS } \\
\text { EJERCIDOS EN } \\
\text { RELACIÓN A LO } \\
\text { PRESUPUESTADO }\end{array}$ \\
\hline $\begin{array}{l}\text { EJECUTIVO DEL } \\
\text { ESTADO }\end{array}$ & $21.6 \%$ & $78.4 \%$ & $1.5 \%$ & $98.5 \%$ \\
\hline $\begin{array}{l}\text { SECRETARÍA DE } \\
\text { GOBIERNO }\end{array}$ & $33.3 \%$ & $66.7 \%$ & $0.7 \%$ & $99.3 \%$ \\
\hline
\end{tabular}




\section{Tabla 3}

Continuación...

\begin{tabular}{|c|c|c|c|c|}
\hline DEPENDENCIA & $\begin{array}{c}\text { \% NO } \\
\text { CUMPLIMIENTO } \\
\text { DE METAS }\end{array}$ & $\begin{array}{c}\% \text { DE } \\
\text { CUMPLIMIENTO } \\
\text { DE METAS }\end{array}$ & $\begin{array}{c}\% \text { DE LA } \\
\text { VARIACIÓN }\end{array}$ & $\begin{array}{c}\text { \% DE RECURSOS } \\
\text { EJERCIDOS EN } \\
\text { RELACIÓN A LO } \\
\text { PRESUPUESTADO }\end{array}$ \\
\hline $\begin{array}{l}\text { SECRETARÍA DE } \\
\text { SALUD PÚBLICA }\end{array}$ & $37.0 \%$ & $63.0 \%$ & $0.4 \%$ & $99.6 \%$ \\
\hline $\begin{array}{l}\text { SECRETARÍA DEL } \\
\text { TRABAJO }\end{array}$ & $38.1 \%$ & $61.9 \%$ & $0.3 \%$ & $99.7 \%$ \\
\hline $\begin{array}{l}\text { SECRETARÍA DE } \\
\text { SEGURIDAD } \\
\text { PÚBLICA }\end{array}$ & $39.3 \%$ & $60.7 \%$ & $1.9 \%$ & $98.1 \%$ \\
\hline $\begin{array}{l}\text { SECRETARÍA DE } \\
\text { INFRAESTRUCTURA } \\
\text { Y DESARROLLO } \\
\text { URBANO }\end{array}$ & $39.5 \%$ & $60.5 \%$ & $6.1 \%$ & $93.9 \%$ \\
\hline $\begin{array}{l}\text { SECRETARÍA DE LA } \\
\text { CONTRALORÍA } \\
\text { GENERAL }\end{array}$ & $36.0 \%$ & $64.0 \%$ & $2.8 \%$ & $97.2 \%$ \\
\hline $\begin{array}{l}\text { SECRETARÍA DE } \\
\text { DESARROLLO } \\
\text { SOCIAL }\end{array}$ & $41.2 \%$ & $58.8 \%$ & $0.7 \%$ & $99.3 \%$ \\
\hline $\begin{array}{l}\text { SECRETARÍA DE } \\
\text { ECONOMÍA }\end{array}$ & $46.7 \%$ & $53.3 \%$ & $2.2 \%$ & $97.8 \%$ \\
\hline $\begin{array}{l}\text { SECRETARÍA DE } \\
\text { HACIENDA }\end{array}$ & $48.6 \%$ & $51.4 \%$ & $0.2 \%$ & $99.8 \%$ \\
\hline OFICIALÍA MAYOR & $50.0 \%$ & $50.0 \%$ & $4.5 \%$ & $95.5 \%$ \\
\hline
\end{tabular}




\section{Tabla 3}

Continuación...

\begin{tabular}{|c|c|c|c|c|}
\hline DEPENDENCIA & $\begin{array}{c}\% \text { NO } \\
\text { CUMPLIMIENTO } \\
\text { DE METAS }\end{array}$ & $\begin{array}{c}\text { \% DE } \\
\text { CUMPLIMIENTO } \\
\text { DE METAS }\end{array}$ & $\begin{array}{c}\text { \% DE LA } \\
\text { VARIACIÓN }\end{array}$ & $\begin{array}{c}\text { \% DE RECURSOS } \\
\text { EJERCIDOS EN } \\
\text { RELACIÓN A LO } \\
\text { PRESUPUESTADO }\end{array}$ \\
\hline $\begin{array}{l}\text { PROCURADURÍA } \\
\text { GENERAL DE } \\
\text { JUSTICIA }\end{array}$ & $58.3 \%$ & $41.7 \%$ & $0.0 \%$ & $100.0 \%$ \\
\hline $\begin{array}{l}\text { SECRETARÍA DE } \\
\text { EDUCACIÓN Y } \\
\text { CULTURA }\end{array}$ & $60.0 \%$ & $40.0 \%$ & $0.6 \%$ & $99.4 \%$ \\
\hline $\begin{array}{l}\text { SECRETARÍA DE } \\
\text { AGRICULTURA, } \\
\text { GANADERIIA, } \\
\text { RECURSOS } \\
\text { HIDRÁULICOS, } \\
\text { PESCA Y } \\
\text { ACUACULTURA }\end{array}$ & $62.9 \%$ & $37.1 \%$ & $0.2 \%$ & $99.8 \%$ \\
\hline
\end{tabular}

Fuente: Elaboración propia.

Para tener una mejor idea del presupuesto final se muestra en la gráfica 1 . 


\section{Gráfica 1}

Presupuesto modificado (Presupuesto final)

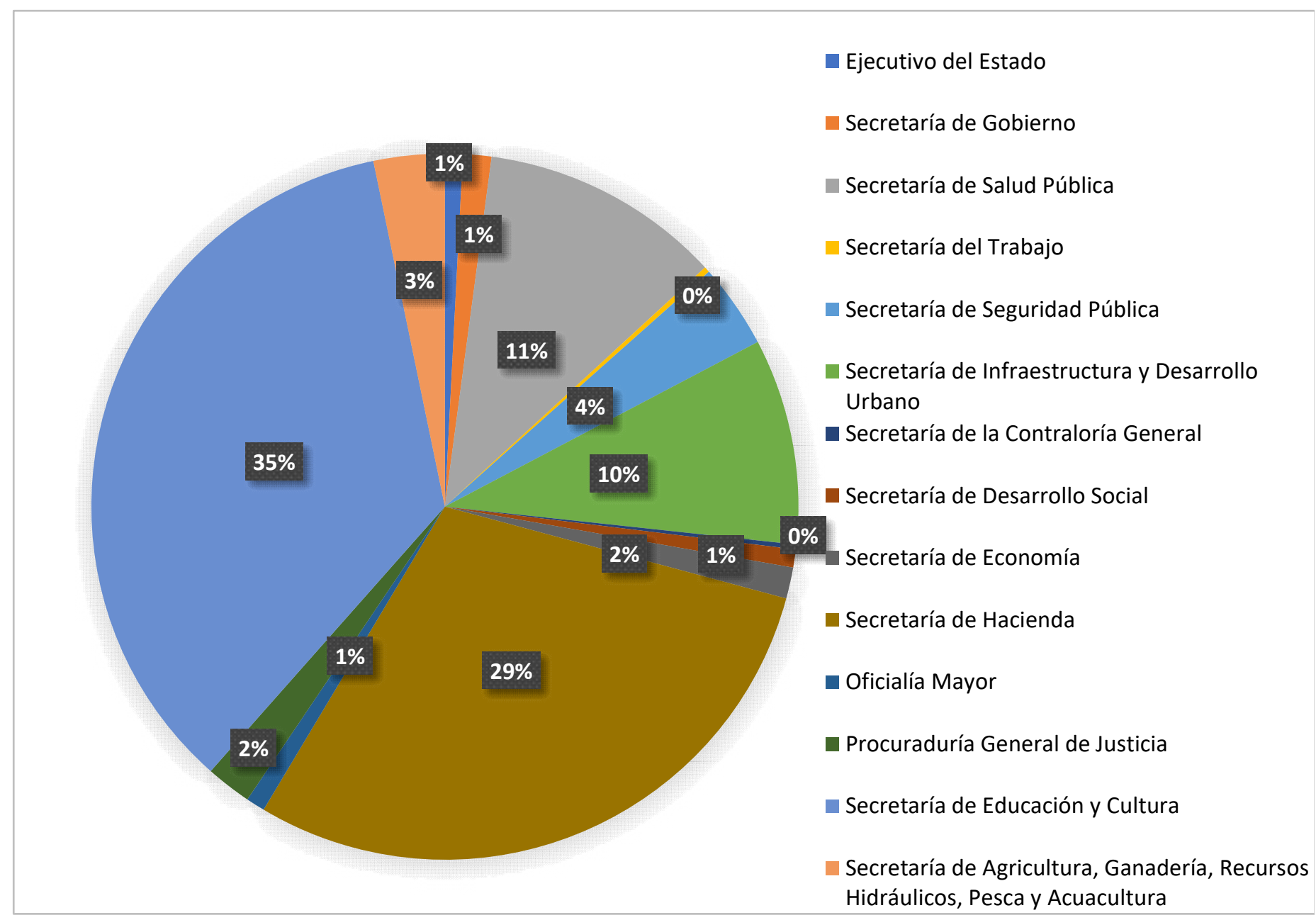

Fuente: Elaboración propia.

Hablando de las 3 dependencias del Poder Ejecutivo con mayor presupuesto asignado (tabla 2), observaremos en la gráfica 1 la distribución del presupuesto total, el mayor presupuesto se le asignó a Secretaría de Educación y cultura que equivale al 35\% del presupuesto total, continúa la Secretaría de Hacienda con 29\%, Secretaría de Salud Pública 11\% , le continúa Secretaría Salud con 11\%.

\section{Dependencias Analizadas}

A continuación, analizaremos más a detalle la información programática de la Cuenta Pública Estatal del año 2015 presentada por el Poder Ejecutivo del Estado de Sonora, analizaremos el proyecto/proceso, objetivo, 
resultado esperado, indicador, meta, resultado y presupuesto otorgado todos estos puntos se analizaran para saber si las dependencias están cumpliendo con sus metas y objetivos con ayuda del presupuesto que se les asigno. Esta prueba se hará tomando una muestra, seleccionaron al azar tres Dependencias: Secretaría de Desarrollo Social, Secretaría de Economía y Secretaría de Hacienda.

\section{Secretaría de Desarrollo Social (SEDESOL)}

Para entender mejor hacia donde van encaminados los programas de esta Dependencia comenzaremos mencionando su misión y visión.

Su Misión en pocas palabras es ayudar a la población para que no tenga carencias, hacer que las personas excluidas, inadaptadas e incomprendidas tengan inclusión en la sociedad para así conducir a nuestro Estado a un desarrollo social integral.

La visión seria ayudar y apoyar a los sonorenses que no cuentan con los recursos necesarios pero tienen las capacidades y talentos, ofreciéndoles mejores oportunidades de crecimiento, desarrollo y apoyo para tener una mejor calidad de vida.

Una vez conociendo su misión y visión, podemos inferir que los programas y por consecuencia los indicadores que se utilizan para medir y evaluar, deben estar enfocados en reducir la pobreza en la población sonorense y direccionar la política social.

\section{Programa 1: Sonora Solidario}

- Proyecto/procesos 1: Dirección, coordinación y planeación del desarrollo social

- Proyectos/procesos 2: Corresponsabilidad social

- Proyecto/procesos 3: Crecer con más infraestructura/Seguimiento y evaluación de inversión social

- Proyecto/procesos 4: Impulsar al desarrollo social 06A

- Proyectos/procesos 5: Impulsar al desarrollo social 05D

- Proyectos/procesos 6: Control y seguimiento administrativo para el desarrollo social

Programa 2: Impulso al Federalismo y al Desarrollo Municipal

- Proyectos/procesos 1: Fortalecimiento al desarrollo social regional y municipal

A continuación, se presenta una evaluación de los proyectos o procesos correspondientes a los 2 programas de la SEDESOL, con esta se determinara si el presupuesto ejercido de los mismos está bien dirigido y si dichos programas han cumplido con las metas establecidas en los indicadores.

\section{Programa 1: Sonora Solidario}

$\checkmark$ Proyecto/procesos 1: Dirección, coordinación y planeación del desarrollo social, tabla 4. 
TRASCENDER, CONTABILIDAD Y GESTIÓN

\section{Tabla 4}

Dirección, coordinación y planeación del desarrollo social

\begin{tabular}{|c|c|c|c|c|c|c|c|c|}
\hline $\begin{array}{l}\text { PROYECTO O } \\
\text { PROCESO }\end{array}$ & OBJETIVO & RESULTADO ESPERADO & $\begin{array}{l}\text { NOMBRE DEL IN- } \\
\text { DICADOR }\end{array}$ & $\begin{array}{c}\text { ME- } \\
\text { TA } \\
\text { ANU } \\
\text { AL }\end{array}$ & $\begin{array}{l}\text { MODI- } \\
\text { FICA- } \\
\text { CIÓN }\end{array}$ & $\begin{array}{l}\text { RE- } \\
\text { SUL- } \\
\text { TADO }\end{array}$ & SEMÁFORO & $\begin{array}{c}\text { PRESU- } \\
\text { PUESTO } \\
\text { OTORGADO }\end{array}$ \\
\hline \multirow{2}{*}{$\begin{array}{l}\text { DIRECCIÓN, } \\
\text { COORDINA- } \\
\text { CIÓN Y PLA- } \\
\text { NEACIÓN DEL } \\
\text { DESARROLLO } \\
\text { SOCIAL }\end{array}$} & \multirow{2}{*}{$\begin{array}{l}\text { ESTABLECER } \\
\text { LOS PROGRA- } \\
\text { MAS Y ESTRA- } \\
\text { TEGIAS ENFO- } \\
\text { CADAS A CUM- } \\
\text { PLIR CON LOS } \\
\text { LINEAMIENTOS } \\
\text { DE LA POLÍTI- } \\
\text { CA SOCIAL } \\
\text { ESTATAL }\end{array}$} & $\begin{array}{l}\text { INSTRUMENTAR LA POLÍTICA SO- } \\
\text { CIAL MEDIANTE PROGRAMAS Y } \\
\text { ACCIONES ENFOCADAS A ELEVAR } \\
\text { LOS NIVELES DE CALIDAD DE VI- } \\
\text { DA DE LA POBLACIÓN EN SITUA- } \\
\text { CIÓN DE POBREZA MULTIDIMEN- } \\
\text { SIONAL EXTREMA }\end{array}$ & $\begin{array}{l}\text { ÍNDICE DE PRO- } \\
\text { GRAMAS, ESTRA- } \\
\text { TEGIAS Y ACCIO- } \\
\text { NES DE DESARRO- } \\
\text { LLO SOCIAL EJECU- } \\
\text { TADAS }\end{array}$ & 100 & 0 & 130.00 & & \multirow{2}{*}{$\$ 44,097,807$} \\
\hline & & $\begin{array}{l}\text { LLEVAR A CABO LA EVALUACIÓN } \\
\text { Y SEGUIMIENTO DE LA INSTRU- } \\
\text { MENTACIÓN DE PROGRAMAS Y } \\
\text { ESTRATEGIAS SOCIALES, CONTRI- } \\
\text { BUYENDO DE ESA MANERA A GE- } \\
\text { NERAR UNA RETROALIMENTA- } \\
\text { CIÓN DE LOS MISMOS }\end{array}$ & $\begin{array}{l}\text { ÍNDICE DE SEGUI- } \\
\text { MIENTO DE PRO- } \\
\text { GRAMAS Y ESTRA- } \\
\text { TEGIAS SOCIALES }\end{array}$ & 100 & 0 & 137.50 & & \\
\hline
\end{tabular}




\section{Tabla 4}

Continuación...

\begin{tabular}{|c|c|c|c|c|c|c|c|c|}
\hline $\begin{array}{l}\text { PROYECTO O } \\
\text { PROCESO }\end{array}$ & OBJETIVO & RESULTADO ESPERADO & $\begin{array}{l}\text { NOMBRE DEL IN- } \\
\text { DICADOR }\end{array}$ & $\begin{array}{l}\text { META } \\
\text { ANUAL }\end{array}$ & $\begin{array}{l}\text { MODI- } \\
\text { FICA- } \\
\text { CIÓN }\end{array}$ & $\begin{array}{l}\text { RESUL- } \\
\text { TADO }\end{array}$ & $\begin{array}{l}\text { SEMÁ- } \\
\text { FORO }\end{array}$ & $\begin{array}{l}\text { PRESU- } \\
\text { PUESTO } \\
\text { OTORGADO }\end{array}$ \\
\hline \multirow{2}{*}{$\begin{array}{l}\text { DIRECCIÓN, } \\
\text { COORDINA- } \\
\text { CIÓN Y PLA- } \\
\text { NEACIÓN DEL } \\
\text { DESARROLLO } \\
\text { SOCIAL }\end{array}$} & \multirow{2}{*}{$\begin{array}{l}\text { ESTABLECER } \\
\text { LOS PROGRA- } \\
\text { MAS Y ESTRA- } \\
\text { TEGIAS ENFO- } \\
\text { CADAS A CUM- } \\
\text { PLIR CON LOS } \\
\text { LINEAMIENTOS } \\
\text { DE LA POLÍTI- } \\
\text { CA SOCIAL } \\
\text { ESTATAL }\end{array}$} & $\begin{array}{l}\text { ALCANZAR UNA GESTIÓN EFI- } \\
\text { CIENTE QUE GENERE RESPUESTAS } \\
\text { Y ACCIONES EN TIEMPO Y FORMA } \\
\text { ANTE LAS DEMANDAS RECIBIDAS } \\
\text { DE LA POBLACIÓN EN CONDICIO- } \\
\text { NES DE MARGINACIÓN Y POBRE- } \\
\text { ZA }\end{array}$ & $\begin{array}{l}\text { ÍNDICE DE ATEN- } \\
\text { CIÓN A SOLICITU- } \\
\text { DES DE APOYOS } \\
\text { SOCIALES }\end{array}$ & 100 & 0 & 91.67 & & \multirow{2}{*}{$\$ 44,097,807$} \\
\hline & & $\begin{array}{l}\text { LOGRAR QUE LOS PROGRAMAS, } \\
\text { ESTRATEGIAS Y ACCIONES QUE } \\
\text { COORDINA LA SECRETARÍA, SE } \\
\text { EJECUTEN EN BASE A LA OBSER- } \\
\text { VANCIA DE LAS NORMAS JURÍDI- } \\
\text { CAS APLICABLES EN MATERIA DE } \\
\text { DESARROLLO SOCIAL }\end{array}$ & $\begin{array}{l}\text { ÍNDICE DE ATEN- } \\
\text { CIÓN A LA NORMA- } \\
\text { TIVIDAD JURÍDICA }\end{array}$ & 100 & 0 & 500.00 & & \\
\hline
\end{tabular}




\section{Tabla 4}

Continuación...

\begin{tabular}{|c|c|c|c|c|c|c|c|c|}
\hline $\begin{array}{c}\text { PROYECTO O } \\
\text { PROCESO }\end{array}$ & OBJETIVO & RESULTADO ESPERADO & $\begin{array}{l}\text { NOMBRE DEL IN- } \\
\text { DICADOR }\end{array}$ & $\begin{array}{l}\text { META } \\
\text { ANUAL }\end{array}$ & $\begin{array}{l}\text { MODI- } \\
\text { FICA- } \\
\text { CIÓN }\end{array}$ & $\begin{array}{l}\text { RESUL- } \\
\text { TADO }\end{array}$ & $\begin{array}{l}\text { SEMÁ- } \\
\text { FORO }\end{array}$ & $\begin{array}{l}\text { PRESU- } \\
\text { PUESTO } \\
\text { OTORGADO }\end{array}$ \\
\hline \multirow{3}{*}{$\begin{array}{l}\text { DIRECCIÓN, } \\
\text { COORDINA- } \\
\text { CIÓN Y PLA- } \\
\text { NEACIÓN DEL } \\
\text { DESARROLLO } \\
\text { SOCIAL }\end{array}$} & \multirow{3}{*}{$\begin{array}{l}\text { ESTABLECER } \\
\text { LOS PROGRA- } \\
\text { MAS Y ESTRA- } \\
\text { TEGIAS ENFO- } \\
\text { CADAS A CUM- } \\
\text { PLIR CON LOS } \\
\text { LINEAMIENTOS } \\
\text { DE LA POLIITI- } \\
\text { CA SOCIAL } \\
\text { ESTATAL }\end{array}$} & $\begin{array}{l}\text { ALCANZAR UNA GESTIÓN EFI- } \\
\text { CIENTE QUE GENERE RESPUESTAS } \\
\text { Y ACCIONES EN TIEMPO Y FORMA } \\
\text { ANTE LAS DEMANDAS RECIBIDAS } \\
\text { DE LA POBLACIÓN EN CONDICIO- } \\
\text { NES DE MARGINACIÓN Y POBRE- } \\
\text { ZA }\end{array}$ & $\begin{array}{l}\text { ÍNDICE DE ATEN- } \\
\text { CIÓN A SOLICITU- } \\
\text { DES DE APOYOS } \\
\text { SOCIALES }\end{array}$ & 100 & 0 & 91.67 & & \multirow{3}{*}{$\$ 44,097,807$} \\
\hline & & $\begin{array}{l}\text { LOGRAR QUE LOS PROGRAMAS, } \\
\text { ESTRATEGIAS Y ACCIONES QUE } \\
\text { COORDINA LA SECRETARÍA, SE } \\
\text { EJECUTEN EN BASE A LA OBSER- } \\
\text { VANCIA DE LAS NORMAS JURÍDI- } \\
\text { CAS APLICABLES EN MATERIA DE } \\
\text { DESARROLLO SOCIAL }\end{array}$ & $\begin{array}{l}\text { ÍNDICE DE ATEN- } \\
\text { CIÓN A LA NORMA- } \\
\text { TIVIDAD JURÍDICA }\end{array}$ & 100 & 0 & 500.00 & & \\
\hline & & $\begin{array}{l}\text { RESPONDERENTIEMPOYFORMAA- } \\
\text { LACIUDADANÍAQUESOLICITEIN- } \\
\text { FORMACIÓNATRAVÉSDELPOR- } \\
\text { TALDE TRANSPARENCIA }\end{array}$ & $\begin{array}{l}\text { ÍNDICE DE ATEN- } \\
\text { CIÓN A SOLICITU- } \\
\text { DES DE INFORMA- } \\
\text { CIÓN PÚBLICA. }\end{array}$ & 100 & 0 & 230.56 & & \\
\hline
\end{tabular}

Fuente: Elaboración propia en base Secretaría de Hacienda y Credito Público Sonora (2016). 
En el proyecto que establece los programas y estrategias enfocadas a la política social estatal se destinaron $\$ 44,097,807$ pesos, como se puede apreciar los 5 indicadores tienen resultados satisfactorios, sólo el índice de atención a solicitudes de apoyos sociales no alcanzó el 100\% de la meta, sin embargo, tiene un buen resultado $91.67 \%$ de la meta cumplida. Según el CONEVAL Sonora es una de las entidades federativas con menos porcentaje de la población en pobreza (2014), lo que nos lleva a pensar que es un proyecto del programa "Sonora Solidario", que si está cumpliendo sus metas pero que tal vez, parte del recurso destinado se puede re direccionar a otros sectores de la población sonorense que necesiten de una mayor inversión.

$\checkmark$ Proyecto/procesos 2: Corresponsabilidad social, tabla 5.

\section{Tabla 5}

Corresponsabilidad social

\begin{tabular}{|c|c|c|c|c|c|c|c|c|}
\hline $\begin{array}{c}\text { PROYECTO O } \\
\text { PROCESO }\end{array}$ & OBJETIVO & $\begin{array}{c}\text { RESULTADO ESPERA- } \\
\text { DO }\end{array}$ & $\begin{array}{l}\text { NOMBRE DEL } \\
\text { INDICADOR }\end{array}$ & $\begin{array}{l}\text { META } \\
\text { ANUAL }\end{array}$ & $\begin{array}{l}\text { MODIFI- } \\
\text { CACIÓN }\end{array}$ & $\begin{array}{l}\text { RESUL- } \\
\text { TADO }\end{array}$ & $\begin{array}{l}\text { SEMÁ- } \\
\text { FORO }\end{array}$ & $\begin{array}{c}\text { PRESU- } \\
\text { PUESTO } \\
\text { OTORGA- } \\
\text { DO }\end{array}$ \\
\hline $\begin{array}{l}\text { CORRESPON- } \\
\text { SABILIDAD } \\
\text { SOCIAL }\end{array}$ & $\begin{array}{l}\text { INTERVENIR EN LA DEFINI- } \\
\text { CIÓN E INSTRUMENTACIÓN DE } \\
\text { PROGRAMAS, ACCIONES Y } \\
\text { ACTIVIDADES ORIENTADAS A } \\
\text { FORTALECER INCENTIVAR LOS } \\
\text { SISTEMAS Y PROCESOS DE } \\
\text { CORRESPONSABILIDAD SO- } \\
\text { CIAL DE LA POBLACIÓN EN } \\
\text { CONDICIÓN DE POBREZA Y } \\
\text { MARGINACIÓN }\end{array}$ & $\begin{array}{l}\text { LOGRAR UNA MAYOR } \\
\text { PARTICIPACIÓN CIU- } \\
\text { DADANA EN LA DEFI- } \\
\text { NICIÓN, INSTRUMEN- } \\
\text { TACIÓN Y EVALUA- } \\
\text { CIÓN DE LOS PRO- } \\
\text { GRAMAS SOCIALES }\end{array}$ & $\begin{array}{l}\text { ÍNDICE DE CA- } \\
\text { PACITACIÓN } \\
\text { SOCIAL }\end{array}$ & 100 & 0 & 165.73 & & $\$ 6,915,596$ \\
\hline
\end{tabular}




\section{Tabla 5}

Continuación...

\begin{tabular}{|c|c|c|c|c|c|c|c|c|}
\hline $\begin{array}{l}\text { PROYECTO O } \\
\text { PROCESO }\end{array}$ & OBJETIVO & $\begin{array}{l}\text { RESULTADO ESPERA- } \\
\text { DO }\end{array}$ & $\begin{array}{l}\text { NOMBRE DEL } \\
\text { INDICADOR }\end{array}$ & $\begin{array}{l}\text { META } \\
\text { ANUAL }\end{array}$ & $\begin{array}{l}\text { MODIFI- } \\
\text { CACIÓN }\end{array}$ & $\begin{array}{l}\text { RESUL- } \\
\text { TADO }\end{array}$ & $\begin{array}{l}\text { SEMÁ- } \\
\text { FORO }\end{array}$ & $\begin{array}{c}\text { PRESU- } \\
\text { PUESTO } \\
\text { OTORGA- } \\
\text { DO }\end{array}$ \\
\hline $\begin{array}{l}\text { CORRESPON- } \\
\text { SABILIDAD } \\
\text { SOCIAL }\end{array}$ & $\begin{array}{l}\text { INTERVENIR EN LA DEFINI- } \\
\text { CIÓN E INSTRUMENTACIÓN DE } \\
\text { PROGRAMAS, ACCIONES Y } \\
\text { ACTIVIDADES ORIENTADAS A } \\
\text { FORTALECER INCENTIVAR LOS } \\
\text { SISTEMAS Y PROCESOS DE } \\
\text { CORRESPONSABILIDAD SO- } \\
\text { CIAL DE LA POBLACIÓN EN } \\
\text { CONDICIÓN DE POBREZA Y } \\
\text { MARGINACIÓN }\end{array}$ & $\begin{array}{l}\text { LOGRAR LA VINCULA- } \\
\text { CIÓN DE LAS ORGANI- } \\
\text { ZACIONES DE LA SO- } \\
\text { CIEDAD CIVIL EN LA } \\
\text { PLANEACIÓN, EJECU- } \\
\text { CIÓN Y EVALUACIÓN } \\
\text { DE LOS PROGRAMAS } \\
\text { SOCIALES QUE COOR- } \\
\text { DINA LA SECRETARÍA }\end{array}$ & $\begin{array}{l}\text { ÍNDICE DE CA- } \\
\text { PACITACIÓN } \\
\text { SOCIAL }\end{array}$ & 100 & 0 & 396.43 & & $\$ 6,915,596$ \\
\hline
\end{tabular}

Fuente: Elaboración propia en base Secretaría de Hacienda y Credito Público Sonora (2016).

Al proyecto Corresponsabilidad Social en el cual se impartieron 425 talleres de capacitación, 111 asesorías a organizaciones sociales, visitas a Dependencias, Entidades, entre otros; se le otorgaron recursos que ascienden a $\$ 6,915,596$ pesos, los 2 indicadores sobrepasaron la meta establecida.
Consideramos que invertir en educación, tiene un mayor impacto social para erradicar la pobreza, que proporcionar bienes a la población.

$\checkmark$ Proyecto/procesos 3: Crecer con más infraestructura/Seguimiento y evaluación de inversión social, tabla 6. 
Tabla 6

Crecer con más infraestructura/Seguimiento y evaluación de inversión social

\begin{tabular}{|c|c|c|c|c|c|c|c|c|}
\hline $\begin{array}{c}\text { PROYECTO O } \\
\text { PROCESO }\end{array}$ & OBJETIVO & RESULTADO ESPERADO & $\begin{array}{l}\text { NOMBRE DEL } \\
\text { INDICADOR }\end{array}$ & $\begin{array}{l}\text { META } \\
\text { ANUAL }\end{array}$ & $\begin{array}{l}\text { MODI- } \\
\text { FICA- } \\
\text { CIÓN }\end{array}$ & $\begin{array}{l}\text { RE- } \\
\text { SUL- } \\
\text { TADO }\end{array}$ & $\begin{array}{c}\text { SE- } \\
\text { MÁ- } \\
\text { FORO }\end{array}$ & $\begin{array}{c}\text { PRESU- } \\
\text { PUESTO } \\
\text { OTORGADO }\end{array}$ \\
\hline $\begin{array}{l}\text { CRECER CON MÁS } \\
\text { INFRAESTRUCTU- } \\
\text { RA }\end{array}$ & $\begin{array}{l}\text { DOTAR DE INFRAES- } \\
\text { TRUCTURA Y EQUIPA- } \\
\text { MIENTO SOCIAL A LOS } \\
\text { MUNICIPIOS QUE SE EN- } \\
\text { CUENTRAN EN ZONAS } \\
\text { PRIORITARIAS CON EL } \\
\text { FIN DE ELEVAR LA CA- } \\
\text { LIDAD DE VIDA DE LA } \\
\text { POBLACIÓN EN SITUA- } \\
\text { CIÓN DE VULNERABILI- } \\
\text { DAD SOCIAL }\end{array}$ & $\begin{array}{l}\text { LOGRAR LA EJECUCIÓN } \\
\text { DE LAS OBRAS Y ACCIO- } \\
\text { NES QUE CONTRIBUYEN A } \\
\text { ABATIR LOS REZAGOS Y } \\
\text { MEJORAR LA CALIDAD Y } \\
\text { EL INCREMENTO DE LOS } \\
\text { SERVICIOS PÚBLICOS BÁ- } \\
\text { SICOS E INFRAESTRUC- } \\
\text { TURA SOCIAL BÁSICA }\end{array}$ & $\begin{array}{l}\text { ÍNDICE DE CUM- } \\
\text { PLIMIENTO DE } \\
\text { LA EJECUCIÓN } \\
\text { DE OBRAS Y AC- } \\
\text { CIONES DE IN- } \\
\text { FRAESTRUCTURA } \\
\text { Y EQUIPAMIEN- } \\
\text { TO SOCIAL }\end{array}$ & 100 & 0 & 87.26 & & $\$ 171,068,907$ \\
\hline
\end{tabular}




\section{Tabla 6}

Continuación...

\begin{tabular}{|c|c|c|c|c|c|c|c|c|}
\hline $\begin{array}{c}\text { PROYECTO O } \\
\text { PROCESO }\end{array}$ & OBJETIVO & RESULTADO ESPERADO & $\begin{array}{l}\text { NOMBRE DEL } \\
\text { INDICADOR }\end{array}$ & $\begin{array}{l}\text { META } \\
\text { ANUAL }\end{array}$ & $\begin{array}{l}\text { MODI- } \\
\text { FICA- } \\
\text { CIÓN }\end{array}$ & $\begin{array}{l}\text { RE- } \\
\text { SUL- } \\
\text { TADO }\end{array}$ & $\begin{array}{l}\text { SE- } \\
\text { MÁ- } \\
\text { FORO }\end{array}$ & $\begin{array}{c}\text { PRESU- } \\
\text { PUESTO } \\
\text { OTORGADO }\end{array}$ \\
\hline $\begin{array}{l}\text { SEGUIMIENTO Y } \\
\text { EVALUACIÓN DE } \\
\text { INVERSIÓN SOCIAL }\end{array}$ & $\begin{array}{l}\text { INSTRUMENTAR Y PRO- } \\
\text { MOVER PROGRAMAS Y } \\
\text { ESTRATEGIAS QUE } \\
\text { CONTRIBUYEN ALCAN- } \\
\text { ZAR MEJORES NIVELES } \\
\text { DE VIDA DE LA POBLA- } \\
\text { CIÓN EN SITUACIÓN DE } \\
\text { POBREZA Y MARGINA- } \\
\text { CIÓN SOCIAL CONTRI- } \\
\text { BUYENDO A UN DESA- } \\
\text { RROLLO SOCIAL INTE- } \\
\text { GRAL DEL ESTADO }\end{array}$ & $\begin{array}{l}\text { COADYUVAR EN LA IN- } \\
\text { TEGRACIÓN DOCUMEN- } \\
\text { TAL DEL SEGUIMIENTO Y } \\
\text { EVALUACIÓN DEL GASTO } \\
\text { DE INVERSIÓN SOCIAL }\end{array}$ & $\begin{array}{l}\text { ÍNDICE DE CUM- } \\
\text { PLIMIENTO DEL } \\
\text { SEGUIMIENTO Y } \\
\text { EVALUACIÓN DE } \\
\text { INVERSIÓN SO- } \\
\text { CIAL. }\end{array}$ & 100 & 0 & $4,083.33$ & & $\$ 171,068,907$ \\
\hline
\end{tabular}

Fuente: Elaboración propia en base Secretaría de Hacienda y Credito Público Sonora (2016).

Se observó que el proyecto Crecer con más Infraestructura no alcanzó la meta anual establecida, logró el alcanzar el 87.26\% equivalente a 1,850 obras, en comparación con las 2,120 programadas. Sin embargo, es una calificación aceptable, en este programa se ejecutaron obras como: introducción y ampliación del servicio de alcantarillado, desarrollo y restitución de vías de agua potable, obras de infraestructura deportiva, programa de construcción de baños, programa de ampliación de vivienda, entre otros. El incremento del 4,083.33\% del proyecto Seguimiento y Evaluación de Inversión Social, se 
debió a la generación de 490 documentos de una meta programada de 12 , dichos documentos se refieren a proyectos ejecutivos de obras; en el último trimestre se tuvo una ampliación de recursos presupuestales en varios fondos.
La inversión que genera la obra tiene un efecto multiplicador positivo y muy grande en la población, por lo que se considera que los \$171,068,907 pesos están siendo bien dirigidos.

$\checkmark$ Proyecto/procesos 4: Impulsar al desarrollo social 06A, tabla 7.

\section{Tabla 7}

Impulsar al desarrollo social 06A

\begin{tabular}{|c|c|c|c|c|c|c|c|c|}
\hline $\begin{array}{c}\text { PROYECTO O } \\
\text { PROCESO }\end{array}$ & OBJETIVO & RESULTADO ESPERADO & $\begin{array}{l}\text { NOMBRE DEL } \\
\text { INDICADOR }\end{array}$ & $\begin{array}{l}\text { META } \\
\text { ANUAL }\end{array}$ & $\begin{array}{l}\text { MODI- } \\
\text { FICA- } \\
\text { CIÓN }\end{array}$ & $\begin{array}{l}\text { RESUL- } \\
\text { TADO }\end{array}$ & $\begin{array}{l}\text { SEMÁ- } \\
\text { FORO }\end{array}$ & $\begin{array}{c}\text { PRESUPUESTO } \\
\text { OTORGADO }\end{array}$ \\
\hline $\begin{array}{l}\text { IMPULSAR AL } \\
\text { DESARROLLO } \\
\text { SOCIAL CLA- } \\
\text { VE: 06A }\end{array}$ & $\begin{array}{l}\text { INSTRUMENTAR Y PRO- } \\
\text { MOVER PROGRAMAS Y } \\
\text { ESTRATEGIAS QUE CON- } \\
\text { TRIBUYAN A ALCANZAR } \\
\text { MEJORES NIVELES DE } \\
\text { VIDA DE LA POBLACIÓN } \\
\text { EN SITUACIÓN DE PO- } \\
\text { BREZA Y MARGINACIÓN } \\
\text { SOCIAL CONTRIBUYENDO } \\
\text { A UN DESARROLLO SO- } \\
\text { CIAL INTEGRAL DEL ES- } \\
\text { TADO }\end{array}$ & $\begin{array}{l}\text { CONTRIBUIR A MEJORAR } \\
\text { ELEVAR LA CALIDAD DE } \\
\text { VIDA DE LAS PERSONAS } \\
\text { ADULTAS MAYORES } \\
\text { QUE SE ENCUENTRAN } \\
\text { EN CONDICIONES DE } \\
\text { POBREZA, MEDIANTE EL } \\
\text { OTORGAMIENTO DE } \\
\text { APOYOS }\end{array}$ & $\begin{array}{l}\text { ÍNDICE DE CO- } \\
\text { BERTURA DEL } \\
\text { PROGRAMA DE } \\
\text { APOYO A ADUL- } \\
\text { TOS MAYORES }\end{array}$ & 100 & 0 & 0 & & $\$ 37,385,981$ \\
\hline
\end{tabular}


Tabla 7

Continuación...

\begin{tabular}{|c|c|c|c|c|c|c|c|c|}
\hline $\begin{array}{c}\text { PROYECTO O } \\
\text { PROCESO }\end{array}$ & OBJETIVO & RESULTADO ESPERADO & $\begin{array}{l}\text { NOMBRE DEL } \\
\text { INDICADOR }\end{array}$ & $\begin{array}{l}\text { META } \\
\text { ANUAL }\end{array}$ & $\begin{array}{l}\text { MODI- } \\
\text { FICA- } \\
\text { CIÓN }\end{array}$ & $\begin{array}{l}\text { RESUL- } \\
\text { TADO }\end{array}$ & $\begin{array}{l}\text { SEMÁ- } \\
\text { FORO }\end{array}$ & $\begin{array}{c}\text { PRESUPUESTO } \\
\text { OTORGADO }\end{array}$ \\
\hline \multirow[b]{2}{*}{$\begin{array}{l}\text { IMPULSAR AL } \\
\text { DESARROLLO } \\
\text { SOCIAL CLA- } \\
\text { VE: 06A }\end{array}$} & \multirow{2}{*}{$\begin{array}{l}\text { INSTRUMENTAR Y PRO- } \\
\text { MOVER PROGRAMAS Y } \\
\text { ESTRATEGIAS QUE CON- } \\
\text { TRIBUYAN A ALCANZAR } \\
\text { MEJORES NIVELES DE } \\
\text { VIDA DE LA POBLACIÓN } \\
\text { EN SITUACIÓN DE PO- } \\
\text { BREZA Y MARGINACIÓN } \\
\text { SOCIAL CONTRIBUYENDO } \\
\text { A UN DESARROLLO SO- } \\
\text { CIAL INTEGRAL DEL ES- } \\
\text { TADO }\end{array}$} & $\begin{array}{l}\text { CONTRIBUIR A MEJORAR } \\
\text { LA CALIDAD DE VIDA DE } \\
\text { LAS MADRES JEFAS DE } \\
\text { FAMILIA EN SITUACIÓN } \\
\text { DE POBREZA }\end{array}$ & $\begin{array}{l}\text { ÍNDICE DE CO- } \\
\text { BERTURA DEL } \\
\text { PROGRAMA DE } \\
\text { APOYO A MA- } \\
\text { DRES JEFAS DE } \\
\text { FAMILIA }\end{array}$ & 100 & 0 & 0 & & \multirow[b]{2}{*}{$\$ 37,385,981$} \\
\hline & & $\begin{array}{l}\text { REGISTRAR Y EVALUAR } \\
\text { EL OTORGAMIENTO DE } \\
\text { FINANCIAMIENTO A LA } \\
\text { POBLACIÓN EN SITUA- } \\
\text { CIÓN DE POBREZA, QUE } \\
\text { PRESENTE SOLICITUDES } \\
\text { DE CRÉDITO PARA LA } \\
\text { IMPLEMENTACIÓN O } \\
\text { CONSOLIDACIÓN DE } \\
\text { PROYECTOS PRODUCTI- } \\
\text { VOS }\end{array}$ & $\begin{array}{l}\text { ÍNDICE DE } \\
\text { ATENCIÓN A LAS } \\
\text { SOLICITUDES DE } \\
\text { CRÉDITO PARA } \\
\text { PROYECTOS } \\
\text { PRODUCTIVOS }\end{array}$ & 100 & 0 & 2.96 & & \\
\hline
\end{tabular}


Tabla 7

Continuación...

\begin{tabular}{|c|c|c|c|c|c|c|c|c|}
\hline $\begin{array}{c}\text { PROYECTO O } \\
\text { PROCESO }\end{array}$ & OBJETIVO & RESULTADO ESPERADO & $\begin{array}{l}\text { NOMBRE DEL } \\
\text { INDICADOR }\end{array}$ & $\begin{array}{r}\text { META } \\
\text { ANUAL }\end{array}$ & $\begin{array}{l}\text { MODI- } \\
\text { FICA- } \\
\text { CIÓN }\end{array}$ & $\begin{array}{l}\text { RESUL- } \\
\text { TADO }\end{array}$ & $\begin{array}{l}\text { SEMÁ- } \\
\text { FORO }\end{array}$ & $\begin{array}{l}\text { PRESUPUESTO } \\
\text { OTORGADO }\end{array}$ \\
\hline $\begin{array}{l}\text { IMPULSAR AL } \\
\text { DESARROLLO } \\
\text { SOCIAL CLA- } \\
\text { VE: 06A }\end{array}$ & $\begin{array}{l}\text { INSTRUMENTAR Y PRO- } \\
\text { MOVER PROGRAMAS Y } \\
\text { ESTRATEGIAS QUE CON- } \\
\text { TRIBUYAN A ALCANZAR } \\
\text { MEJORES NIVELES DE } \\
\text { VIDA DE LA POBLACIÓN } \\
\text { EN SITUACIÓN DE PO- } \\
\text { BREZA Y MARGINACIÓN } \\
\text { SOCIAL CONTRIBUYENDO } \\
\text { A UN DESARROLLO SO- } \\
\text { CIAL INTEGRAL DEL ES- } \\
\text { TADO }\end{array}$ & $\begin{array}{l}\text { CONTRIBUIR A MEJORAR } \\
\text { LA CALIDAD DE VIDA DE } \\
\text { LA POBLACIÓN EN SI- } \\
\text { TUACIÓN DE POBREZA Y } \\
\text { MARGINACIÓN SOCIAL A } \\
\text { TRAVÉS DE APOYOS Y } \\
\text { SERVICIOS OTORGADOS } \\
\text { EN LAS BRIGADAS CO- } \\
\text { MUNITARIAS QUE SE } \\
\text { REALIZAN }\end{array}$ & $\begin{array}{l}\text { ÍNDICE DE CUM- } \\
\text { PLIMIENTO DE } \\
\text { LA REALIZACIÓN } \\
\text { DE BRIGADAS } \\
\text { COMUNITARIAS }\end{array}$ & 100 & 0 & 40.00 & & $\$ 37,385,981$ \\
\hline
\end{tabular}

Fuente: Elaboración propia en base Secretaría de Hacienda y Credito Público Sonora (2016). 
El proyecto Impulsar al Desarrollo Social establece 4 indicadores, los cuales ninguno logró alcanzar la meta; 2 de ellos el Índice de Cobertura del Programa de Apoyo a Adultos Mayores (asignación aprobada 50 millones de pesos, padrón de beneficiarios 32,880 personas adultas)y el Programa de Apoyo a Madres Jefas de Familia no tienen ningún avance, debido a una serie de medidas de racionalidad y limitación en la administración del presupuesto y falta de liquidez por parte de la Secretaría de Hacienda no se pudieron otorgar a tiempo esos recursos que ya estaban autorizados. Los \$37,385,981 pesos otorgados a este proyecto se destinaron a cubrir el indicador Índice de Cumplimiento de la Realización de Brigadas Comunitarias.

$\checkmark$ Proyecto/procesos 5: Impulso al desarrollo social 05D, tabla 8.

\section{Tabla 8}

Impulso al desarrollo social 05D

\begin{tabular}{|c|c|c|c|c|c|c|c|c|}
\hline $\begin{array}{c}\text { PROYECTO O } \\
\text { PROCESO }\end{array}$ & OBJETIVO & $\begin{array}{c}\text { RESULTADO } \\
\text { ESPERADO }\end{array}$ & $\begin{array}{l}\text { NOMBRE DEL } \\
\text { INDICADOR }\end{array}$ & $\begin{array}{l}\text { META } \\
\text { ANUAL }\end{array}$ & $\begin{array}{l}\text { MODIFI- } \\
\text { CACIÓN }\end{array}$ & $\begin{array}{l}\text { RESUL- } \\
\text { TADO }\end{array}$ & $\begin{array}{l}\text { SEMÁ- } \\
\text { FORO }\end{array}$ & $\begin{array}{l}\text { PRESU- } \\
\text { PUESTO } \\
\text { OTORGA- } \\
\text { DO }\end{array}$ \\
\hline $\begin{array}{l}\text { IMPULSO AL } \\
\text { DESARROLLO } \\
\text { SOCIAL CLA- } \\
\text { VE: 05D }\end{array}$ & $\begin{array}{l}\text { INSTRUMENTAR Y PROMOVER PRO- } \\
\text { GRAMAS Y ESTRATEGIAS QUE CONTRI- } \\
\text { BUYAN A ALCANZAR MEJORES NIVE-- } \\
\text { LES DE VIDA DE LA POBLACIÓN EN SI- } \\
\text { TUACIÓN DE POBREZA Y MARGINA- } \\
\text { CIÓN SOCIAL CONTRIBUYENDO A UN } \\
\text { DESARROLLO SOCIAL INTEGRAL DEL } \\
\text { ESTADO }\end{array}$ & $\begin{array}{l}\text { INCREMEN- } \\
\text { TAR LA CALI- } \\
\text { DAD DE VIDA } \\
\text { DE LAS FAMI- } \\
\text { LIAS BENEFI- } \\
\text { CIADAS CON } \\
\text { DEL PRO- } \\
\text { GRAMA }\end{array}$ & $\begin{array}{l}\text { ÍNDICE DE CO- } \\
\text { BERTURA DEL } \\
\text { PROGRAMA } \\
\text { CRESER CON } \\
\text { BIENESTAR }\end{array}$ & 100 & 0 & 72.57 & & $\$ 25,388,539$ \\
\hline
\end{tabular}

Fuente: Elaboración propia en base Secretaría de Hacienda y Credito Público Sonora (2016). 
El proceso Impulso al Desarrollo Social cuenta con el indicador Índice de Cobertura del Programa Crecer con Bienestar el cual no logró alcanzar el 100\% de la meta establecida (atender a 23,000 familias), a pesar de que contó con un presupuesto de $\$ 25,388,539$ pesos. El proyecto no plantea buenos indicadores para medir las acciones para fortalecer las medidas autogestivas de la población en desventaja social; no está clara la manera en la que se medirá el impacto o cambio en la formación del capital humano.

$\checkmark$ Proyecto/procesos 6: Control y seguimiento administrativo para el desarrollo social, tabla 9.

\section{Tabla 9}

Control y seguimiento administrativo para el desarrollo social

\begin{tabular}{|c|c|c|c|c|c|c|c|c|}
\hline $\begin{array}{c}\text { PROYECTO } \\
\text { O PROCE- } \\
\text { SO }\end{array}$ & OBJETIVO & RESULTADO ESPERADO & $\begin{array}{l}\text { NOMBRE } \\
\text { DEL INDI- } \\
\text { CADOR }\end{array}$ & $\begin{array}{l}\text { META } \\
\text { ANUAL }\end{array}$ & $\begin{array}{l}\text { MODI- } \\
\text { FICA- } \\
\text { CIÓN }\end{array}$ & $\begin{array}{c}\text { RE- } \\
\text { SUL- } \\
\text { TADO }\end{array}$ & $\begin{array}{l}\text { SEMÁ- } \\
\text { FORO }\end{array}$ & $\begin{array}{c}\text { PRESU- } \\
\text { PUESTO } \\
\text { OTORGADO }\end{array}$ \\
\hline \begin{tabular}{|l} 
CONTROL Y \\
SEGUI- \\
MIENTO \\
ADMINIS- \\
TRATIVO \\
PARA EL \\
DESARRO- \\
LLO SOCIAL
\end{tabular} & $\begin{array}{l}\text { INSTRUMENTAR ACCIONES } \\
\text { ORIENTADAS A LOGRAR LA AD- } \\
\text { MINISTRACIÓN DE LOS RECUR- } \\
\text { SOS MATERIALES, HUMANOS Y } \\
\text { FINANCIEROS ASIGNADOS A ES- } \\
\text { TA DEPENDENCIA Y PROVEER } \\
\text { LOS DIVERSOS SERVICIOS GENE- } \\
\text { RALES, CON CALIDAD, EFICIEN- } \\
\text { CIA, EFICACIA Y TRANSPAREN- } \\
\text { CIA PARA CONTRIBUIR A LA EJE- } \\
\text { CUCIÓN DE LOS PROGRAMAS Y } \\
\text { ESTRATEGIAS DE IMPACTO SO- } \\
\text { CIAL }\end{array}$ & $\begin{array}{l}\text { CONTRIBUIR A UNA ADMINIS- } \\
\text { TRACIÓN EFICIENTE Y TRANS- } \\
\text { PARENTE DE LOS RECURSOS } \\
\text { ASIGNADOS A ESTA SECRETA- } \\
\text { RÍA QUE PERMITA EL CUM- } \\
\text { PLIMIENTO DE LOS PROPÓSI- } \\
\text { TOS Y OBJETIVOS DE LOS } \\
\text { PROGRAMAS Y ESTRATEGIAS } \\
\text { DE IMPACTO SOCIAL }\end{array}$ & $\begin{array}{l}\text { ÍNDICE DE } \\
\text { OPERA- } \\
\text { CIÓN DE } \\
\text { SISTEMAS } \\
\text { ADMINIS- } \\
\text { TRATIVOS }\end{array}$ & 100 & 0 & 125.00 & & $\$ 81,806,169$ \\
\hline
\end{tabular}


Tabla 9

Continuación...

\begin{tabular}{|c|c|c|c|c|c|c|c|c|}
\hline $\begin{array}{c}\text { PROYECTO } \\
\text { O PROCE- } \\
\text { SO }\end{array}$ & OBJETIVO & RESULTADO ESPERADO & $\begin{array}{l}\text { NOMBRE } \\
\text { DEL INDI- } \\
\text { CADOR }\end{array}$ & $\begin{array}{l}\text { META } \\
\text { ANUAL }\end{array}$ & $\begin{array}{l}\text { MODI- } \\
\text { FICA- } \\
\text { CIÓN }\end{array}$ & $\begin{array}{l}\text { RE- } \\
\text { SUL- } \\
\text { TADO }\end{array}$ & $\begin{array}{l}\text { SEMÁ- } \\
\text { FORO }\end{array}$ & $\begin{array}{c}\text { PRESU- } \\
\text { PUESTO } \\
\text { OTORGADO }\end{array}$ \\
\hline $\begin{array}{l}\text { CONTROL Y } \\
\text { SEGUI- } \\
\text { MIENTO } \\
\text { ADMINIS- } \\
\text { TRATIVO } \\
\text { PARA EL } \\
\text { DESARRO- } \\
\text { LLO SOCIAL }\end{array}$ & $\begin{array}{l}\text { INSTRUMENTAR ACCIONES } \\
\text { ORIENTADAS A LOGRAR LA AD- } \\
\text { MINISTRACIÓN DE LOS RECUR- } \\
\text { SOS MATERIALES, HUMANOS Y } \\
\text { FINANCIEROS ASIGNADOS A ES- } \\
\text { TA DEPENDENCIA Y PROVEER } \\
\text { LOS DIVERSOS SERVICIOS GENE- } \\
\text { RALES, CON CALIDAD, EFICIEN- } \\
\text { CIA, EFICACIA Y TRANSPAREN- } \\
\text { CIA PARA CONTRIBUIR A LA EJE- } \\
\text { CUCIÓN DE LOS PROGRAMAS Y } \\
\text { ESTRATEGIAS DE IMPACTO SO- } \\
\text { CIAL }\end{array}$ & $\begin{array}{l}\text { CUMPLIR EN TIEMPO Y FORMA } \\
\text { CON LOS CALENDARIOS DE } \\
\text { ENTREGA DE LOS INFORMES Y } \\
\text { REPORTES SOLICITADOS POR } \\
\text { LAS DIVERSAS DEPENDENCIAS } \\
\text { Y ORGANISMOS DE FISCALI- } \\
\text { ZACIÓN }\end{array}$ & $\begin{array}{l}\text { PORCENTA- } \\
\text { JE DE CUM- } \\
\text { PLIMIENTO } \\
\text { DE EVA- } \\
\text { LUACIÓN } \\
\text { PROGRA- } \\
\text { MÁTICA } \\
\text { INSTITU- } \\
\text { CIONAL }\end{array}$ & 100 & 0 & 250.00 & & $\$ 81,806,169$ \\
\hline
\end{tabular}

Fuente: Elaboración propia en base Secretaría de Hacienda y Credito Público Sonora (2016).

Los 2 indicadores del proceso Control y Seguimiento Administrativo para el Desarrollo Social sobrepasaron al $100 \%$ de las metas establecidas, al cual se le otorgaron $\$ 81,806,169$, cumpliendo con las metas establecidas.

\section{Programa 2: Impulso al Federalismo y al Desarrollo Municipal}

$\checkmark$ Proyecto/procesos 1: Fortalecimiento al desarrollo social regional y municipal, tabla 10. 


\section{Tabla 10}

Fortalecimiento al desarrollo social regional y municipal

\begin{tabular}{|c|c|c|c|c|c|c|c|c|}
\hline $\begin{array}{l}\text { PROYECTO O } \\
\text { PROCESO }\end{array}$ & OBJETIVO & $\begin{array}{l}\text { RESULTADO ESPE- } \\
\text { RADO }\end{array}$ & $\begin{array}{l}\text { NOMBRE } \\
\text { DEL INDI- } \\
\text { CADOR }\end{array}$ & $\begin{array}{l}\text { META } \\
\text { ANUAL }\end{array}$ & $\begin{array}{l}\text { MODIFICA- } \\
\text { CIÓN }\end{array}$ & $\begin{array}{l}\text { RESULTA- } \\
\text { DO }\end{array}$ & SEMÁFORO | & $\begin{array}{c}\text { PRESUPUES- } \\
\text { TO OTORGA- } \\
\text { DO }\end{array}$ \\
\hline $\begin{array}{l}\text { FORTALECIMIEN- } \\
\text { TO AL DESARRO- } \\
\text { LLO SOCIAL RE- } \\
\text { GIONAL Y MUNICI- } \\
\text { PAL }\end{array}$ & $\begin{array}{l}\text { LOGRAR LA EJE- } \\
\text { CUCIÓN DE PRO- } \\
\text { GRAMAS Y ES- } \\
\text { TRATEGIAS QUE } \\
\text { IMPULSEN UN } \\
\text { DESARROLLO } \\
\text { EQUILIBRADO DE } \\
\text { LAS REGIONES Y } \\
\text { MUNICIPIOS } \\
\text { PRIORITARIOS } \\
\text { CONTRIBUYEN- } \\
\text { DO A UN DESA- } \\
\text { RROLLO SOCIAL } \\
\text { INTEGRAL }\end{array}$ & $\begin{array}{l}\text { EJECUCIÓN DE } \\
\text { PROGRAMAS Y AC- } \\
\text { CIONES ORIENTA- } \\
\text { DAS A MODERNI- } \\
\text { ZAR Y CONSOLIDAR } \\
\text { A LOS GOBIERNOS Y } \\
\text { ADMINISTRACIO- } \\
\text { NES PÚBLICAS DE } \\
\text { LOS MUNICIPIOS } \\
\text { DEL ESTADO }\end{array}$ & $\begin{array}{l}\text { PORCENTAJE } \\
\text { DE COBER- } \\
\text { TURA DE } \\
\text { ESTRATE- } \\
\text { GIAS Y AC- } \\
\text { CIONES DE } \\
\text { DESARRO- } \\
\text { LLO MUNICI- } \\
\text { PAL }\end{array}$ & 100 & 0 & 214.80 & & $\$ 12,421,292$ \\
\hline
\end{tabular}

Fuente: Elaboración propia en base Secretaría de Hacienda y Credito Público Sonora (2016). 
Este programa solo cuenta con un proyecto nombrado Fortalecimiento al Desarrollo Social Regional y Municipal, y un indicador, el cual sobrepasó el 100\% de la meta pactada, la cual consistía en realizar 757 acciones referentes a asesorías de interpretación jurídica a los municipios del Estado, formulación y entrega de documentos como reglamento interior, reglamento de administración, acuerdos de creación de organismos municipales, asesoría en la formulación del Plan de Desarrollo Municipal, entre otros. El gobierno debe canalizar esfuerzos para aminorar el rezago que presentan los municipios en todos los sectores y sobre todo en cumplir con la normatividad que les aplica.

\section{Secretaría de Economía (SE)}

Como ya lo mencionamos para evaluar la gestión de una Dependencia primeramente es necesario conocer su razón de ser y las aspiraciones de la misma.

La misión es apoyar el desarrollo económico de Sonora para crear políticas que garanticen mercados más eficientes, eficaces y competitivos, que incentiven el bienestar de los consumidores, además de apoyar la innovación de las empresas y el crecimiento de la economía, todo esto con el objetivo de poder generar nuevos empleos, aumentar la entrada de dinero y mejorar la calidad de vida de los sonorenses.

La Visión es ser una entidad transparente con buenas políticas públicas eficientes y eficaces que permitan el crecimiento económico de Sonora para ser reconocidos a nivel nacional, además de generar empleos y mejorar la economía de nuestro estado.
A continuación, analizaremos los programas 2015 de la SE:

Programa 1: Sonora competitivo

- Proyecto/procesos 1: Dirección y coordinación de las políticas para el desarrollo económico y la competitividad

- Proyecto/procesos 2: Difundir disposiciones jurídicas

- Proyecto/procesos 3: Analizar y proponer modificaciones a instrumentos que contengan actos jurídicos

- Proyecto/procesos 4: Apoyar acciones para lograr un desarrollo económico sustentable e infraestructura competitiva

- Proyecto/procesos 5: Evaluación de los procesos operativos y administrativos de la dependencia

- Proyecto/procesos 6: Administración y control de recursos

- Proyecto/procesos 7: Atención a solicitudes de acceso a la información pública

- Proyecto/procesos 8: Coordinar y Dar seguimiento a la ejecución de los proyectos detonadores del desarrollo económico del estado

- Proyecto/procesos 9: Operar el programa de distribución de uniformes y zapatos escolares

- Proyecto/procesos 10: Formación de capital humano para cubrir necesidades del sector industrial 
- Proyecto/procesos 11: Incentivos a la inversión y generación de empleos en Sonora

- Proyecto/procesos 12: Reingeniería de trámites y servicios empresariales

Programa 2: Sonora competitivo y Modernización comercial

- Proyecto/procesos 1: Sonora competitivo

- Proyecto/procesos 2: Modernización comercial

Programa 3: Innovación y desarrollo tecnológico

- Proyecto/procesos 1: Programa estatal para el fortalecimiento de empresas de tecnología de la información

- Proyecto/procesos 2: Atención de solicitudes de apoyo al fondo mixto de fomento a la investigación científica y tecnológica CONACYT gobierno del estado de sonora / fomento a la investigación científica y tecnológica CONACYT
- Proyecto/procesos 3: Programa estatal para el fortalecimiento de empresas de tecnología de la información (PROSOFT)

Programa 4: Promoción internacional y comercio exterior

- Proyecto/procesos 1: Impulso a la diversificación de mercados

Programa 5: Fomento a la minería

- Proyecto/procesos 1: Atención de gestión

- Proyecto/procesos 2: Asistencia técnica a pequeños mineros

- Proyecto/procesos 3: Impulso a la minería

- Proyecto/procesos 4: Curso de capacitación

$\checkmark$ Programa 1: Sonora competitivo

A continuación, se presenta una evaluación de los proyectos o procesos correspondientes a los 5 programas de la SE, con esta se determinara si el presupuesto ejercido de los mismos está bien dirigido y si dichos programas han cumplido con las metas establecidas en los indicadores. Tabla 11. 


\section{Tabla 11}

Sonora competitivo

\begin{tabular}{|c|c|c|c|c|c|c|c|c|}
\hline $\begin{array}{l}\text { PROYECTO O } \\
\text { PROCESO }\end{array}$ & OBJETIVO & \begin{tabular}{|} 
RESULTADO ESPERA- \\
DO
\end{tabular} & $\begin{array}{l}\text { NOMBRE DEL } \\
\text { INDICADOR }\end{array}$ & $\begin{array}{l}\text { META } \\
\text { ANUAL }\end{array}$ & $\begin{array}{l}\text { MODI- } \\
\text { FICA- } \\
\text { CIÓN }\end{array}$ & $\begin{array}{l}\text { RESUL- } \\
\text { TADO }\end{array}$ & $\begin{array}{l}\text { SEMÁ- } \\
\text { FORO }\end{array}$ & $\begin{array}{c}\text { PRESU- } \\
\text { PUESTO } \\
\text { OTORGADO }\end{array}$ \\
\hline $\begin{array}{l}\text { DIRECCION Y } \\
\text { COORDINACION DE } \\
\text { LAS POLITICAS PA- } \\
\text { RA EL DESARRO- } \\
\text { LLO ECONOMICO Y } \\
\text { LA COMPETITIVI- } \\
\text { DAD }\end{array}$ & $\begin{array}{l}\text { CREAR LAS CONDICIO- } \\
\text { NES OPTIMAS PARA IM- } \\
\text { PULSAR EL DESARROLLO } \\
\text { DE LAS REGIONES DE } \\
\text { SONORA, GENERAR EM- } \\
\text { PLEOS BIEN REMUNERA- } \\
\text { DOS Y PRODUCIR BIENES } \\
\text { Y SERVICIOS DE ALTO } \\
\text { VALOR AGREGADO }\end{array}$ & $\begin{array}{l}\text { SE CREAN LAS CONDI- } \\
\text { CIONES OPTIMAS PARA } \\
\text { IMPULSAR EL DESA- } \\
\text { RROLLO DE LAS RE- } \\
\text { GIONES DE SONORA, } \\
\text { GENERANDO EMPLEOS } \\
\text { BIEN REMUNERADOS Y } \\
\text { PRODUCIENDO BIENES } \\
\text { Y SERVICIOS DE ALTO } \\
\text { VALOR AGREGADO }\end{array}$ & $\begin{array}{l}\text { VARIACION DE } \\
\text { ASUNTOS } \\
\text { ATENDIDOS } \\
\text { SATISFACTORIA } \\
\text { Y OPORTUNA- } \\
\text { MENTE }\end{array}$ & 100 & 100 & 100 & & $\$ 11,389,618$ \\
\hline
\end{tabular}




\section{Tabla 11}

Continuación...

\begin{tabular}{|c|c|c|c|c|c|c|c|c|}
\hline $\begin{array}{l}\text { PROYECTO O } \\
\text { PROCESO }\end{array}$ & OBJETIVO & $\begin{array}{c}\text { RESULTADO ESPERA- } \\
\text { DO }\end{array}$ & $\begin{array}{l}\text { NOMBRE DEL } \\
\text { INDICADOR }\end{array}$ & $\begin{array}{l}\text { META } \\
\text { ANUAL }\end{array}$ & $\begin{array}{l}\text { MODI- } \\
\text { FICA- } \\
\text { CIÓN }\end{array}$ & $\begin{array}{l}\text { RESUL- } \\
\text { TADO }\end{array}$ & $\begin{array}{l}\text { SEMÁ- } \\
\text { FORO }\end{array}$ & $\begin{array}{c}\text { PRESU- } \\
\text { PUESTO } \\
\text { OTORGADO }\end{array}$ \\
\hline $\begin{array}{l}\text { DIFUNDIR DISPOSI- } \\
\text { CIONES JURÍDICAS }\end{array}$ & $\begin{array}{l}\text { ACTUALIZACIÓN DEL } \\
\text { MARCO JURÍDICO DE AC- } \\
\text { TUACIÓN DE LA DEPEN- } \\
\text { DENCIA }\end{array}$ & $\begin{array}{l}\text { SE CUENTA CON AC- } \\
\text { TUALIZACIÓN DEL } \\
\text { MARCO JURÍDICO DE } \\
\text { ACTUACIÓN DE LA } \\
\text { DEPENDENCIA }\end{array}$ & $\begin{array}{l}\text { ÍNDICE DE } \\
\text { COMPILACIÓN } \\
\text { Y DIFUSIÓN DE } \\
\text { DISPOSICIONES } \\
\text { JURÍDICA }\end{array}$ & 80 & 251.3 & 251.3 & & \\
\hline $\begin{array}{l}\text { ANALIZAR Y PRO- } \\
\text { PONER MODIFICA- } \\
\text { CIONES A INSTRU- } \\
\text { MENTOS QUE CON- } \\
\text { TENGAN ACTOS } \\
\text { JURÍDICOS }\end{array}$ & $\begin{array}{l}\text { QUE SUS ACTOS CUM- } \\
\text { PLAN CON LA NORMATI- } \\
\text { VIDAD QUE RESULTE } \\
\text { APLICABLE }\end{array}$ & $\begin{array}{l}\text { LOS ACTOS DE LA DE- } \\
\text { PENDENCIA CUMPLEN } \\
\text { CON LA NORMATIVI- } \\
\text { DAD APLICABLE }\end{array}$ & $\begin{array}{l}\text { ATENCIÓN Y } \\
\text { TRÁMITE }\end{array}$ & 100 & 85.5 & 85.5 & & $\$ 1,106,577$ \\
\hline
\end{tabular}




\section{Tabla 11}

Continuación...

\begin{tabular}{|c|c|c|c|c|c|c|c|c|}
\hline $\begin{array}{l}\text { PROYECTO O } \\
\text { PROCESO }\end{array}$ & OBJETIVO & $\begin{array}{c}\text { RESULTADO ESPERA- } \\
\text { DO }\end{array}$ & $\begin{array}{l}\text { NOMBRE DEL } \\
\text { INDICADOR }\end{array}$ & $\begin{array}{l}\text { META } \\
\text { ANUAL }\end{array}$ & $\begin{array}{l}\text { MODI- } \\
\text { FICA- } \\
\text { CIÓN }\end{array}$ & $\begin{array}{l}\text { RESUL- } \\
\text { TADO }\end{array}$ & $\begin{array}{l}\text { SEMÁ- } \\
\text { FORO }\end{array}$ & $\begin{array}{l}\text { PRESU- } \\
\text { PUESTO } \\
\text { OTORGADO }\end{array}$ \\
\hline $\begin{array}{l}\text { APOYAR ACCIONES } \\
\text { PARA LOGRAR UN } \\
\text { DESARROLLO ECO- } \\
\text { NÓMICO SUSTEN- } \\
\text { TABLE E INFRAES- } \\
\text { TRUCTURA COM- } \\
\text { PETITIVA }\end{array}$ & $\begin{array}{l}\text { OPERAR EN EL MARCO } \\
\text { DE LA LEGALIDAD CON } \\
\text { INSTRUMENTOS JURÍDI- } \\
\text { COS ENCAMINADOS AL } \\
\text { LOGRO DE LOS OBJETI- } \\
\text { VOS DE LA SECRETARÍA }\end{array}$ & $\begin{array}{l}\text { SE OPERA EN EL MAR- } \\
\text { CO DE LA LEGALIDAD } \\
\text { CON INSTRUMENTOS } \\
\text { JURÍDICOS ENCAMI- } \\
\text { NADOS AL LOGRO DE } \\
\text { LOS OBJETIVOS DE LA } \\
\text { SECRETARÍA }\end{array}$ & $\begin{array}{l}\text { VARIACIÓN DE } \\
\text { CONVENIOS } \\
\text { CONCRETADOS }\end{array}$ & 100 & 100 & 100 & & $\$ 1,106,577$ \\
\hline $\begin{array}{l}\text { EVALUACIÓN DE } \\
\text { LOS PROCESOS } \\
\text { OPERATIVOS Y } \\
\text { ADMINISTRATIVOS } \\
\text { DE LA DEPENDEN- } \\
\text { CIA }\end{array}$ & $\begin{array}{l}\text { CONTAR CON UNA EVA- } \\
\text { LUACIÓN PERIÓDICA DE } \\
\text { LOS PROCESOS INTERNOS } \\
\text { DE LA SECRETARÍA }\end{array}$ & $\begin{array}{l}\text { SE CUENTA CON UNA } \\
\text { EVALUACIÓN PERIÓ- } \\
\text { DICA DE LOS PROCE- } \\
\text { SOS INTERNOS DE LA } \\
\text { SECRETARÍA }\end{array}$ & $\begin{array}{l}\text { INDICE DE IN- } \\
\text { FORMES DE } \\
\text { REVISIÓN Y } \\
\text { ACTUALIZA- } \\
\text { CIÓN DE MA- } \\
\text { NUALES ADMI- } \\
\text { NISTRATIVOS }\end{array}$ & 100 & 100 & 100 & & $\$ 1,862,770$ \\
\hline
\end{tabular}




\section{Tabla 11}

Continuación...

\begin{tabular}{|c|c|c|c|c|c|c|c|c|}
\hline $\begin{array}{l}\text { PROYECTO O } \\
\text { PROCESO }\end{array}$ & OBJETIVO & $\begin{array}{c}\text { RESULTADO ESPERA- } \\
\text { DO }\end{array}$ & $\begin{array}{l}\text { NOMBRE DEL } \\
\text { INDICADOR }\end{array}$ & $\begin{array}{l}\text { META } \\
\text { ANUAL }\end{array}$ & $\begin{array}{l}\text { MODI- } \\
\text { FICA- } \\
\text { CIÓN }\end{array}$ & $\begin{array}{l}\text { RESUL- } \\
\text { TADO }\end{array}$ & $\begin{array}{l}\text { SEMÁ- } \\
\text { FORO }\end{array}$ & $\begin{array}{c}\text { PRESU- } \\
\text { PUESTO } \\
\text { OTORGADO }\end{array}$ \\
\hline $\begin{array}{l}\text { ADMINISTRACIÓN } \\
\text { Y CONTROL DE RE- } \\
\text { CURSOS }\end{array}$ & $\begin{array}{l}\text { GESTIONAR RECURSOS } \\
\text { PARA PROGRAMAS Y } \\
\text { PROYECTOS DE LA SE- } \\
\text { CRETARÍA }\end{array}$ & $\begin{array}{l}\text { SE GESTIONAN RECUR- } \\
\text { SOS PARA PROGRAMAS } \\
\text { Y PROYECTOS DE LA } \\
\text { SECRETARÍA Y SE LO- } \\
\text { GRA UNA ADMINIS- } \\
\text { TRACIÓN EFICIENTE DE } \\
\text { LOS RECURSOS CON } \\
\text { QUE CUENTA LA DE- } \\
\text { PENDENCIA PARA SU } \\
\text { OPERATIVIDAD }\end{array}$ & $\begin{array}{l}\text { ÍNDICE DE EFI- } \\
\text { CIENCIA EN EL } \\
\text { EJERCICIO DEL } \\
\text { GASTO }\end{array}$ & 100 & 115 & 115 & & $\$ 1,862,770$ \\
\hline $\begin{array}{l}\text { ATENCIÓN A SOLI- } \\
\text { CITUDES DE ACCE- } \\
\text { SO A LA INFORMA- } \\
\text { CIÓN PÚBLICA }\end{array}$ & $\begin{array}{l}\text { CONTAR CON UNA EVA- } \\
\text { LUACIÓN PERIÓDICA DE } \\
\text { LA ATENCIÓN Y SEGUI- } \\
\text { MIENTO A SOLICITUDES } \\
\text { DE ACCESO A LA INFOR- } \\
\text { MACIÓN PÚBLICA }\end{array}$ & $\begin{array}{l}\text { SE CUENTA CON UNA } \\
\text { EVALUACIÓN PERIÓ- } \\
\text { DICA DE LA ATENCIÓN } \\
\text { Y SEGUIMIENTO A SO- } \\
\text { LICITUDES DE ACCESO } \\
\text { A LA INFORMACIÓN } \\
\text { PÚBLICA }\end{array}$ & $\begin{array}{l}\text { INDICE DE } \\
\text { ATENCIÓN A } \\
\text { SOLICITUDES } \\
\text { DE ACCESO }\end{array}$ & 100 & 100 & 100 & & \\
\hline
\end{tabular}




\section{Tabla 11}

Continuación...

\begin{tabular}{|c|c|c|c|c|c|c|c|c|}
\hline $\begin{array}{l}\text { PROYECTO O } \\
\text { PROCESO }\end{array}$ & OBJETIVO & \begin{tabular}{|} 
RESULTADO ESPERA- \\
DO
\end{tabular} & $\begin{array}{l}\text { NOMBRE DEL } \\
\text { INDICADOR }\end{array}$ & $\begin{array}{l}\text { META } \\
\text { ANUAL }\end{array}$ & $\begin{array}{l}\text { MODI- } \\
\text { FICA- } \\
\text { CIÓN }\end{array}$ & $\begin{array}{l}\text { RESUL- } \\
\text { TADO }\end{array}$ & $\begin{array}{l}\text { SEMÁ- } \\
\text { FORO }\end{array}$ & $\begin{array}{c}\text { PRESU- } \\
\text { PUESTO } \\
\text { OTORGADO }\end{array}$ \\
\hline $\begin{array}{l}\text { COORDINAR Y DAR } \\
\text { SEGUIMIENTO A LA } \\
\text { EJECUCION DE LOS } \\
\text { PROYECTOS DETO- } \\
\text { NADORES DEL } \\
\text { DESARROLLO ECO- } \\
\text { NOMICO DEL ES- } \\
\text { TADO }\end{array}$ & $\begin{array}{l}\text { DESARROLLO ECONÓMI- } \\
\text { CO SUSTENTABLE Y SOS- } \\
\text { TENIDO }\end{array}$ & $\begin{array}{l}\text { LOGRAR UN DESARRO- } \\
\text { LLO ECONÓMICO SUS- } \\
\text { TENTABLE Y SOSTENI- } \\
\text { DO }\end{array}$ & INFORMES & 100 & 100 & 100 & & \\
\hline $\begin{array}{l}\text { OPERAR EL PRO- } \\
\text { GRAMA DE DISTRI- } \\
\text { BUCIÓN DE UNI- } \\
\text { FORMES Y ZAPA- } \\
\text { TOS ESCOLARES }\end{array}$ & $\begin{array}{l}\text { HACER LLEGAR LOS UNI- } \\
\text { FORMES Y ZAPATOS ES- } \\
\text { COLARES A TODAS LAS } \\
\text { ESCUELAS PÚBLICAS DE } \\
\text { EDUCACIÓN BASICA DEL } \\
\text { ESTADO, PARA SU EN- } \\
\text { TREGA A LOS ALUMNOS } \\
\text { BENEFICIADOS }\end{array}$ & $\begin{array}{l}\text { SE HACEN LLEGAR LOS } \\
\text { UNIFORMES Y ZAPA- } \\
\text { TOS ESCOLARES A TO- } \\
\text { DAS LAS ESCUELAS } \\
\text { PÚBLICAS DE EDUCA- } \\
\text { CIÓN BASICA DEL ES- } \\
\text { TADO, PARA SU EN- } \\
\text { TREGA A LOS ALUM- } \\
\text { NOS BENEFICIADOS }\end{array}$ & $\begin{array}{l}\text { ALUMNOS BE- } \\
\text { NEFICIADOS }\end{array}$ & 100 & 97.1 & 29.2 & & $\$ 12,202,881$ \\
\hline
\end{tabular}




\section{Tabla 11}

Continuación...

\begin{tabular}{|c|c|c|c|c|c|c|c|c|}
\hline $\begin{array}{l}\text { PROYECTO O } \\
\text { PROCESO }\end{array}$ & OBJETIVO & $\begin{array}{c}\text { RESULTADO ESPERA- } \\
\text { DO }\end{array}$ & $\begin{array}{l}\text { NOMBRE DEL } \\
\text { INDICADOR }\end{array}$ & $\begin{array}{l}\text { META } \\
\text { ANUAL }\end{array}$ & $\begin{array}{l}\text { MODI- } \\
\text { FICA- } \\
\text { CIÓN }\end{array}$ & $\begin{array}{l}\text { RESUL- } \\
\text { TADO }\end{array}$ & $\begin{array}{l}\text { SEMÁ- } \\
\text { FORO }\end{array}$ & $\begin{array}{c}\text { PRESU- } \\
\text { PUESTO } \\
\text { OTORGADO }\end{array}$ \\
\hline $\begin{array}{l}\text { OPERAR EL PRO- } \\
\text { GRAMA DE DISTRI- } \\
\text { BUCIÓN DE UNI- } \\
\text { FORMES Y ZAPA- } \\
\text { TOS ESCOLARES }\end{array}$ & $\begin{array}{l}\text { HACER LLEGAR LOS UNI- } \\
\text { FORMES Y ZAPATOS ES- } \\
\text { COLARES A TODAS LAS } \\
\text { ESCUELAS PÚBLICAS DE } \\
\text { EDUCACIÓN BASICA DEL } \\
\text { ESTADO, PARA SU EN- } \\
\text { TREGA A LOS ALUMNOS } \\
\text { BENEFICIADOS }\end{array}$ & $\begin{array}{l}\text { SE HACEN LLEGAR LOS } \\
\text { UNIFORMES Y ZAPA- } \\
\text { TOS ESCOLARES A TO- } \\
\text { DAS LAS ESCUELAS } \\
\text { PÚBLICAS DE EDUCA- } \\
\text { CIÓN BASICA DEL ES- } \\
\text { TADO, PARA SU EN- } \\
\text { TREGA A LOS ALUM- } \\
\text { NOS BENEFICIADOS }\end{array}$ & $\begin{array}{l}\text { ALUMNOS BE- } \\
\text { NEFICIADOS }\end{array}$ & 100 & 97.1 & 29.2 & & $\$ 12,202,881$ \\
\hline
\end{tabular}




\section{Tabla 11}

Continuación...

\begin{tabular}{|c|c|c|c|c|c|c|c|c|}
\hline $\begin{array}{l}\text { PROYECTO O } \\
\text { PROCESO }\end{array}$ & OBJETIVO & $\begin{array}{l}\text { RESULTADO ESPERA- } \\
\text { DO }\end{array}$ & $\begin{array}{l}\text { NOMBRE DEL } \\
\text { INDICADOR }\end{array}$ & $\begin{array}{l}\text { META } \\
\text { ANUAL }\end{array}$ & $\begin{array}{l}\text { MODI- } \\
\text { FICA- } \\
\text { CIÓN }\end{array}$ & $\begin{array}{l}\text { RESUL- } \\
\text { TADO }\end{array}$ & $\begin{array}{l}\text { SEMÁ- } \\
\text { FORO }\end{array}$ & $\begin{array}{c}\text { PRESU- } \\
\text { PUESTO } \\
\text { OTORGADO }\end{array}$ \\
\hline $\begin{array}{l}\text { FORMACIÓN DE } \\
\text { CAPITAL HUMANO } \\
\text { PARA CUBRIR NE- } \\
\text { CESIDADES DEL } \\
\text { SECTOR INDUS- } \\
\text { TRIAL }\end{array}$ & $\begin{array}{l}\text { IMPULSAR LA GENERA- } \\
\text { CIÓN DE UNA MASA CRÍ- } \\
\text { TICA DE TÉCNICOS PRO- } \\
\text { FESIONALES ALTAMENTE } \\
\text { COMPETENTES EN PRO- } \\
\text { CESOS INDUSTRIALES } \\
\text { ESPECÍFICOS, NECESA- } \\
\text { RIOS PARA EL DESARRO- } \\
\text { LLO DE LA INDUSTRIA DE } \\
\text { ALTA TECNOLOGÍA }\end{array}$ & $\begin{array}{l}\text { TENER EGRESADOS } \\
\text { TÉCNICOS UNIVERSI- } \\
\text { TARIOS CON UN VA- } \\
\text { LOR AGREGADO A SU } \\
\text { PROFESIÓN, SIENDO } \\
\text { ESTE SEGÚN LAS NE- } \\
\text { CESIDADES QUE PRE- } \\
\text { SENTE EL SECTOR IN- } \\
\text { DUSTRIAL EN EL ES- } \\
\text { TADO }\end{array}$ & $\begin{array}{l}\text { INDICE DE CA- } \\
\text { PACITACIONES }\end{array}$ & 100 & 100 & 100 & & $\$ 4,347,095$ \\
\hline $\begin{array}{l}\text { INCENTIVOS A LA } \\
\text { INVERSIÓN Y GE- } \\
\text { NERACIÓN DE EM- } \\
\text { PLEOS EN SONORA }\end{array}$ & $\begin{array}{l}\text { CONSERVAR Y GENERAR } \\
\text { EMPRESAS DE CALIDAD } \\
\text { MUNDIAL Y DE INNOVA- } \\
\text { CIÓN TECNOLÓGICA PA- } \\
\text { RA GENERAR EMPLEOS } \\
\text { MEJOR REMUNERADOS }\end{array}$ & $\begin{array}{l}\text { OTORGAR INCENTIVOS } \\
\text { FISCALES Y NO FISCA- } \\
\text { LES A LAS EMPRESAS } \\
\text { EN SONORA, PARA IM- } \\
\text { PULSAR EL DESARRO- } \\
\text { LLO ECONÓMICO }\end{array}$ & $\begin{array}{l}\text { INDICE DE } \\
\text { OTORGAMIEN- } \\
\text { TO DE INCEN- } \\
\text { TIVOS FISCA- } \\
\text { LES Y NO FIS- } \\
\text { CALES }\end{array}$ & 100 & 25 & 25 & & $\$ 1,291,509$ \\
\hline
\end{tabular}




\section{Tabla 11}

Continuación...

\begin{tabular}{|c|c|c|c|c|c|c|c|c|}
\hline $\begin{array}{l}\text { PROYECTO O } \\
\text { PROCESO }\end{array}$ & OBJETIVO & $\begin{array}{l}\text { RESULTADO ESPERA- } \\
\text { DO }\end{array}$ & $\begin{array}{l}\text { NOMBRE DEL } \\
\text { INDICADOR }\end{array}$ & $\begin{array}{l}\text { META } \\
\text { ANUAL }\end{array}$ & $\begin{array}{l}\text { MODI- } \\
\text { FICA- } \\
\text { CIÓN }\end{array}$ & $\begin{array}{l}\text { RESUL- } \\
\text { TADO }\end{array}$ & $\begin{array}{l}\text { SEMÁ- } \\
\text { FORO }\end{array}$ & $\begin{array}{c}\text { PRESU- } \\
\text { PUESTO } \\
\text { OTORGADO }\end{array}$ \\
\hline \multirow[t]{2}{*}{$\begin{array}{l}\text { REINGENIERÍA DE } \\
\text { TRÁMITES Y SER- } \\
\text { VICIOS EMPRESA- } \\
\text { RIALES }\end{array}$} & \multirow{2}{*}{$\begin{array}{l}\text { FACILITAR AL EMPRESA- } \\
\text { RIO EN TODOS LOS TRÁ- } \\
\text { MITES Y SERVICIOS DE } \\
\text { LOS TRES NIVELES DE } \\
\text { GOBIERNO }\end{array}$} & \multirow[t]{2}{*}{$\begin{array}{l}\text { TRÁMITES Y SERVI- } \\
\text { CIOS MEJORADOS }\end{array}$} & $\begin{array}{l}\text { CAPACITACIÓN } \\
\text { A LOS CENTROS } \\
\text { DE APERTURA } \\
\text { RÁPIDA DE EM- } \\
\text { PRESAS DEL } \\
\text { ESTADO }\end{array}$ & 100 & 133.3 & 133.3 & & \multirow[t]{2}{*}{$\$ 3,136,454$} \\
\hline & & & $\begin{array}{l}\text { ÍNDICE DE } \\
\text { TRÁMITES } \\
\text { ATENDIDOS }\end{array}$ & 100 & 75.6 & 75.6 & & \\
\hline
\end{tabular}

Fuente: Elaboración propia en base Secretaría de Hacienda y Credito Público Sonora (2016). 
El programa Sonora Competitivo contiene 12 proyectos y 13 indicadores de los cuales 9 alcanzaron las metas establecidas. Uno de los proyectos a los cuales se les asignó mayor presupuesto es el de Dirección y Coordinación de las Políticas para el Desarrollo Económico y la Competitividad, dicho recurso ascendió a \$11 millones de pesos este indicador midió 1,180 asuntos relacionados con el fomento a la economía en Sonora, participar en programas como "Nuevas Naves Industriales", "Bacanora en Sonora", "Sonora Networking", entre otros.

Los proyectos Coordinar y dar Seguimiento a la Ejecución de los Proyectos Detonadores del Desarrollo Económico del Estado y Operar el Programa de Distribución de Uniformes y Zapatos Escolares obtuvieron recursos por \$12 millones de pesos, el primero se alcanzó la meta al 100\% midiéndose con un indicador que establecía el número de informes realizados con respecto a la revisión y valoración de la operación de los programas y procesos estratégicos a cargo de la SE como son "Construcción del Gasoducto", "Instalación del Primer Laboratorio Nanotecnológico", "Investigaciones de los empleos creados por los proyectos tanto informales como formales, entre otros. El segundo proyecto sólo logró el $29.2 \%$ de la meta establecida, el informe de cuenta pública menciona que no fue posible alcanzar la meta debido a que el fabricante no inició la fabricación de los uniformes escolares, argumentando que la SEC no pago a tiempo, dejando de beneficiar al $70.8 \%$ de un total de 514,467 alumnos.

Por otro lado los indicadores Índice de Incentivos Fiscales y no Fiscales a las Empresas en Sonora, para Impulsar el Desarrollo Económico e Índice de Trámites Atendidos no obtuvieron resultados satisfactorios, a pesar de que tuvieron un recurso por más de $\$ 1$ millones de pesos.

Programa 2: Sonora competitivo y modernización comercial, tabla 12. 


\section{Tabla 12}

Sonora competitivo y modernización comercial

\begin{tabular}{|c|c|c|c|c|c|c|c|c|c|}
\hline $\begin{array}{l}\text { PRO- } \\
\text { GRAMA }\end{array}$ & $\begin{array}{l}\text { PROYECTO } \\
\text { O PROCESO }\end{array}$ & OBJETIVO & $\begin{array}{c}\text { RESULTADO } \\
\text { ESPERADO }\end{array}$ & $\begin{array}{l}\text { NOMBRE } \\
\text { DEL INDI- } \\
\text { CADOR }\end{array}$ & $\begin{array}{r}\text { META } \\
\text { ANUAL }\end{array}$ & $\begin{array}{l}\text { MODI- } \\
\text { FICA- } \\
\text { CIÓN }\end{array}$ & $\begin{array}{l}\text { RE- } \\
\text { SUL- } \\
\text { TADO }\end{array}$ & $\begin{array}{l}\text { SEMÁ- } \\
\text { FORO }\end{array}$ & $\begin{array}{c}\text { PRESUPUES- } \\
\text { TO OTORGA- } \\
\text { DO }\end{array}$ \\
\hline $\begin{array}{l}\text { SONORA } \\
\text { COMPETI- } \\
\text { TIVO }\end{array}$ & $\begin{array}{l}\text { PROGRAMA } \\
\text { DE APOYO A } \\
\text { CÁMARAS Y } \\
\text { ORGANIS- } \\
\text { MOS EMPRE- } \\
\text { SARIALES }\end{array}$ & $\begin{array}{l}\text { IMPULSAR UNA POLITICA DE } \\
\text { DESARROLLO ECONÓMICO Y } \\
\text { PRODUCTIVIDAD, MEDIANTE LA } \\
\text { COORDINACIÓN Y CONCERTA- } \\
\text { CIÓN DE ACCIONES ENTRE OR- } \\
\text { GANISMOS EMPRESARIALES, } \\
\text { ATRAVÉS DE ACCIONES O PRO- } \\
\text { YECTOS QUE PROMUEVAN ESTOS } \\
\text { ORGAMISMOS, IMPULSANDO EL } \\
\text { CRECIMIENTO SOSTENIDO DE LA } \\
\text { ACTIVIDAD INDUSTRIAL, CO- } \\
\text { MERCIAL Y DE SERVICIOS QUE } \\
\text { DEMANDAN LAS EMPRESAS } \\
\text { AGREMIADAS }\end{array}$ & \begin{tabular}{|l} 
BENEFICIAR \\
AL MAYOR \\
NÚMERO DE \\
EMPRESAS DE \\
TODOS LOS \\
SECTORES \\
PRODUCTIVOS \\
AGREMIADOS \\
A CÁMARAS Y \\
ORGANISMOS \\
EMPRESARIA- \\
LES
\end{tabular} & $\begin{array}{l}\text { EMPRESAS } \\
\text { BENEFICIA- } \\
\text { DAS DE TO- } \\
\text { DOS LOS } \\
\text { SECTORES } \\
\text { PRODUCTI- } \\
\text { VOS }\end{array}$ & 100 & 35.9 & 35.9 & & $\$ 12543,461$ \\
\hline
\end{tabular}




\section{Tabla 12}

Continuación...

\begin{tabular}{|c|c|c|c|c|c|c|c|c|c|}
\hline $\begin{array}{l}\text { PRO- } \\
\text { GRAMA }\end{array}$ & $\begin{array}{l}\text { PROYECTO } \\
\text { O PROCESO }\end{array}$ & OBJETIVO & $\begin{array}{c}\text { RESULTADO } \\
\text { ESPERADO }\end{array}$ & $\begin{array}{l}\text { NOMBRE } \\
\text { DEL INDI- } \\
\text { CADOR }\end{array}$ & $\begin{array}{l}\text { META } \\
\text { ANUAL }\end{array}$ & $\begin{array}{l}\text { MODI- } \\
\text { FICA- } \\
\text { CIÓN }\end{array}$ & $\begin{array}{l}\text { RE- } \\
\text { SUL- } \\
\text { TADO }\end{array}$ & $\begin{array}{l}\text { SEMÁ- } \\
\text { FORO }\end{array}$ & $\begin{array}{c}\text { PRESUPUES- } \\
\text { TO OTORGA- } \\
\text { DO }\end{array}$ \\
\hline $\begin{array}{l}\text { MODER- } \\
\text { NIZACION } \\
\text { COMER- } \\
\text { CIAL }\end{array}$ & $\begin{array}{l}\text { INCUBACION } \\
\text { EMPRESA- } \\
\text { RIAL }\end{array}$ & $\begin{array}{l}\text { CREAR NUEVAS EMPRESAS A } \\
\text { TRAVÉS DE UNA POLÍTICA DE } \\
\text { INCUBACIÓN, CON LA APLICA- } \\
\text { CIÓN DE UNA METODOLOGÍA } \\
\text { QUE PERMITA CREAR, FORTALE- } \\
\text { CER Y DAR PERMANENCIA A LAS } \\
\text { EMPRESAS A TRAVÉS DEL TIEM- } \\
\text { PO }\end{array}$ & $\begin{array}{l}\text { GENERACIÓN } \\
\text { DE NUEVAS } \\
\text { EMPRESAS }\end{array}$ & $\begin{array}{l}\text { INDICE DE } \\
\text { EMPRESAS } \\
\text { GENERADAS }\end{array}$ & 100 & 0 & 0 & & $\$ 12543,461$ \\
\hline
\end{tabular}




\section{Tabla 12}

Continuación...

\begin{tabular}{|c|c|c|c|c|c|c|c|c|c|}
\hline $\begin{array}{l}\text { PRO- } \\
\text { GRAMA }\end{array}$ & $\begin{array}{l}\text { PROYECTO } \\
\text { O PROCESO }\end{array}$ & OBJETIVO & $\begin{array}{l}\text { RESULTADO } \\
\text { ESPERADO }\end{array}$ & $\begin{array}{l}\text { NOMBRE } \\
\text { DEL INDI- } \\
\text { CADOR }\end{array}$ & $\begin{array}{l}\text { META } \\
\text { ANUAL }\end{array}$ & $\begin{array}{l}\text { MODI- } \\
\text { FICA- } \\
\text { CIÓN }\end{array}$ & $\begin{array}{l}\text { RE- } \\
\text { SUL- } \\
\text { TADO }\end{array}$ & $\begin{array}{l}\text { SEMÁ- } \\
\text { FORO }\end{array}$ & $\begin{array}{c}\text { PRESUPUES- } \\
\text { TO OTORGA- } \\
\text { DO }\end{array}$ \\
\hline \multirow[b]{2}{*}{$\begin{array}{l}\text { MODER- } \\
\text { NIZACION } \\
\text { COMER- } \\
\text { CIAL }\end{array}$} & \multirow[b]{2}{*}{$\begin{array}{l}\text { IMPULSO AL } \\
\text { DESARRO- } \\
\text { LLO CO- } \\
\text { MERCIAL }\end{array}$} & \multirow[b]{2}{*}{$\begin{array}{l}\text { DESARROLLAR E INNOVAR PRO- } \\
\text { DUCTOS SONORENSES, ASÍ COMO } \\
\text { LOGRAR SU POSICIONAMIENTO } \\
\text { EN EL MERCADO MODERNO }\end{array}$} & \multirow{2}{*}{\begin{tabular}{|l} 
SE LOGRA \\
APOYAR IN- \\
TEGRALMEN- \\
TE A MIPYMES \\
SONORENSES \\
EN SU POSI- \\
CIONAMIENTO \\
EN EL MER- \\
CADO MO- \\
DERNO
\end{tabular}} & $\begin{array}{l}\text { INDICE DE } \\
\text { EMPRESAS } \\
\text { APOYADAS } \\
\text { EN REINGE- } \\
\text { NIERIA DEL } \\
\text { PRODUCTO }\end{array}$ & 100 & 154.8 & 154.8 & & \multirow[b]{2}{*}{$\$ 2,631,721$} \\
\hline & & & & $\begin{array}{l}\text { INDICE DE } \\
\text { EMPRESAS } \\
\text { BENEFICIA- } \\
\text { DAS CON } \\
\text { ENLACES } \\
\text { COMERCIA- } \\
\text { LES Y/O EN- } \\
\text { CUENTROS } \\
\text { DE NEGO- } \\
\text { CIOS }\end{array}$ & 100 & 113.3 & 113.3 & & \\
\hline
\end{tabular}

Fuente: Elaboración propia en base Secretaría de Hacienda y Credito Público Sonora (2016). 
Se otorgaron aproximadamente $\$ 12$ millones de pesos para apoyar a los pequeños empresarios, gracias a que se impulsó una política de desarrollo económico y productivo, entre empresarios mediante proyectos que impulsan el crecimiento. Sin embargo, sólo se alcanzó a lograr 35.9\% del indicador "Empresas Beneficiadas de todos los Sectores Productivos" beneficiando a un total de 147 empresas, la falta de cumplimiento de esta meta es debido a la variación del presupuesto a esta unidad administrativa dirigidos al capítulo 3000 "Servicios Generales" por Comunicación Social y Difusión de Programas Gubernamentales. Consideramos que dicha modificación es una mala decisión ya que el impacto que generan las empresas, es altamente positivo en generación de empleos, aumento de la economía, etc. mientras que la difusión de programas gubernamentales no tiene un alto valor agregado e impacto en la sociedad. El proyecto incubación empresarial tuvo un 0\% de alcance. Esto no es bueno ya que las personas que tenían nuevos proyectos para crear una nueva empresa se quedaron en la espera de hacer su proyecto realidad y eso afecta económicamente. El proyecto impulso al desarrollo comercial cumplió con su meta establecida con un presupuesto de aproximadamente \$2 millones de pesos, con esto se logra la creación y posicionamiento de productos regionales. Así mismo, podemos observar que los indicadores relacionados con la asesoría a las empresas alcanzaron sus metas. Tabla 13. 


\section{Tabla 13}

Impulso a la diversificación de mercados

\begin{tabular}{|c|c|c|c|c|c|c|c|c|}
\hline $\begin{array}{l}\text { PROYECTO O } \\
\text { PROCESO }\end{array}$ & OBJETIVO & $\begin{array}{l}\text { RESULTADO } \\
\text { ESPERADO }\end{array}$ & $\begin{array}{l}\text { NOMBRE DEL IN- } \\
\text { DICADOR }\end{array}$ & $\begin{array}{l}\text { META } \\
\text { ANUAL }\end{array}$ & $\begin{array}{l}\text { MODI- } \\
\text { FICA- } \\
\text { CIÓN }\end{array}$ & $\begin{array}{l}\text { RESUL- } \\
\text { TADO }\end{array}$ & $\begin{array}{l}\text { SEMÁ- } \\
\text { FORO }\end{array}$ & $\begin{array}{c}\text { PRESU- } \\
\text { PUESTO } \\
\text { OTORGA- } \\
\text { DO }\end{array}$ \\
\hline $\begin{array}{l}\text { PROGRAMA ES- } \\
\text { TATAL PARA EL } \\
\text { FORTALECI- } \\
\text { MIENTO DE EM- } \\
\text { PRESAS DE TEC- } \\
\text { NOLOGÍAS DE LA } \\
\text { INFORMACIÓN }\end{array}$ & $\begin{array}{l}\text { EL ESTADO DE SONORA SERÁ } \\
\text { LIIDER NACIONAL EN GENERA- } \\
\text { CIÓN DE EMPLEOS, CRECIMIEN- } \\
\text { TO SOSTENIDO Y DESARROLLO } \\
\text { ECONÓMICO SUSTENTABLE A } \\
\text { TRAVÉS DEL DESARROLLO } \\
\text { TECNOLÓGICO Y DE LA INNO- } \\
\text { VACIÓN QUE INCREMENTEN LA } \\
\text { COMPETITIVIDAD DE LAS UNI- } \\
\text { DADES ECONÓMICAS Y GENE- } \\
\text { REN UN ENTORNO ATRACTIVO } \\
\text { Y FACILITADOR DE NEGOCIOS }\end{array}$ & $\begin{array}{l}\text { EMPRESAS APO- } \\
\text { YADAS EN EL } \\
\text { SECTOR DE TEC- } \\
\text { NOLOGÍAS DE LA } \\
\text { INFORMACIÓN } \\
\text { CON IMPLÍCITO } \\
\text { DESARROLLO } \\
\text { TECNOLÓGICO, } \\
\text { INNOVACIÓN Y } \\
\text { COMPETITIVI- } \\
\text { DAD }\end{array}$ & $\begin{array}{l}\text { INDICE DE EMPRE- } \\
\text { SAS APOYADAS } \\
\text { DEL SECTOR DE } \\
\text { TECNOLOGÍAS DE } \\
\text { LA INFORMACIÓN }\end{array}$ & 100 & 316.6 & 316.6 & & $\$ 1,545,863$ \\
\hline
\end{tabular}




\section{Tabla 13}

Continuación...

\begin{tabular}{|c|c|c|c|c|c|c|c|c|}
\hline $\begin{array}{l}\text { PROYECTO O } \\
\text { PROCESO }\end{array}$ & OBJETIVO & $\begin{array}{l}\text { RESULTADO } \\
\text { ESPERADO }\end{array}$ & $\begin{array}{l}\text { NOMBRE DEL IN- } \\
\text { DICADOR }\end{array}$ & $\begin{array}{l}\text { META } \\
\text { ANUAL }\end{array}$ & $\begin{array}{l}\text { MODI- } \\
\text { FICA- } \\
\text { CIÓN }\end{array}$ & $\begin{array}{l}\text { RESUL- } \\
\text { TADO }\end{array}$ & $\begin{array}{l}\text { SEMÁ- } \\
\text { FORO }\end{array}$ & $\begin{array}{l}\text { PRESU- } \\
\text { PUESTO } \\
\text { OTORGA- } \\
\text { DO }\end{array}$ \\
\hline $\begin{array}{l}\text { ATENCIÓN A SO- } \\
\text { LICITUDES DE } \\
\text { APOYO AL FON- } \\
\text { DO MIXTO DE } \\
\text { FOMENTO A LA } \\
\text { INVESTIGACIÓN } \\
\text { CIENTÍFICA Y } \\
\text { TECNOLÓGICA } \\
\text { CONACYT- } \\
\text { GOBIERNO DEL } \\
\text { ESTADO DE SO- } \\
\text { NORA. / FOMEN- } \\
\text { TO A LA INVES- } \\
\text { TIGACIÓN CIEN- } \\
\text { TÍFICA Y TECNO- } \\
\text { LÓGICA CONA- } \\
\text { CYT }\end{array}$ & $\begin{array}{l}\text { RECEPCIÓN, ANÁLISIS Y APOYO } \\
\text { A SOLICITUDES DE PROYECTOS } \\
\text { AL FONDO MIXTO }\end{array}$ & $\begin{array}{l}\text { SE RECIBEN, } \\
\text { ANALIZAN Y } \\
\text { APOYAN SOLICI- } \\
\text { TUDES DE PRO- } \\
\text { YECTOS DEL } \\
\text { FONDO MIXTO; } \\
\text { APOYO A TODOS } \\
\text { LOS PROYECTOS } \\
\text { VIABLES Y DE } \\
\text { IMPACTO PARA } \\
\text { EL ESTADO }\end{array}$ & $\begin{array}{l}\text { INDICE DE APOYOS } \\
\text { OTORGADOS / FO- } \\
\text { MENTO A LA IN- } \\
\text { VESTIGACIÓN } \\
\text { TECNOLÓGICA }\end{array}$ & 100 & 0 & 0 & & $\$ 11,742,710$ \\
\hline
\end{tabular}




\section{Tabla 13}

Continuación...

\begin{tabular}{|c|c|c|c|c|c|c|c|c|}
\hline $\begin{array}{l}\text { PROYECTO O } \\
\text { PROCESO }\end{array}$ & OBJETIVO & $\begin{array}{l}\text { RESULTADO } \\
\text { ESPERADO }\end{array}$ & $\begin{array}{l}\text { NOMBRE DEL IN- } \\
\text { DICADOR }\end{array}$ & $\begin{array}{l}\text { META } \\
\text { ANUAL }\end{array}$ & $\begin{array}{l}\text { MODI- } \\
\text { FICA- } \\
\text { CIÓN }\end{array}$ & $\begin{array}{l}\text { RESUL- } \\
\text { TADO }\end{array}$ & $\begin{array}{l}\text { SEMÁ- } \\
\text { FORO }\end{array}$ & $\begin{array}{c}\text { PRESU- } \\
\text { PUESTO } \\
\text { OTORGA- } \\
\text { DO }\end{array}$ \\
\hline $\begin{array}{l}\text { PROGRAMA ES- } \\
\text { TATAL PARA EL } \\
\text { FORTALECI- } \\
\text { MIENTO DE EM- } \\
\text { PRESAS DE TEC- } \\
\text { NOLOGÍAS DE LA } \\
\text { INFORMACIÓN } \\
\text { (PROSOFT) }\end{array}$ & $\begin{array}{l}\text { EL ESTADO DE SONORA SERÁ } \\
\text { LIIDER NACIONAL EN GENERA- } \\
\text { CIÓN DE EMPLEOS, CRECIMIEN- } \\
\text { TO SOSTENIDO Y DESARROLLO } \\
\text { ECONÓMICO SUSTENTABLE A } \\
\text { TRAVÉS DEL DESARROLLO } \\
\text { TECNOLÓGICO Y DE LA INNO- } \\
\text { VACIÓN QUE INCREMENTEN LA } \\
\text { COMPETITIVIDAD DE LAS UNI- } \\
\text { DADES ECONÓMICAS Y GENE- } \\
\text { REN UN ENTORNO ATRACTIVO } \\
\text { Y FACILITADOR DE NEGOCIOS }\end{array}$ & $\begin{array}{l}\text { EMPRESAS APO- } \\
\text { YADAS EN EL } \\
\text { SECTOR DE TEC- } \\
\text { NOLOGÍAS DE LA } \\
\text { INFORMACIÓN } \\
\text { CON IMPLÍCITO } \\
\text { DESARROLLO } \\
\text { TECNOLÓGICO, } \\
\text { INNOVACIÓN Y } \\
\text { COMPETITIVI- } \\
\text { DAD }\end{array}$ & $\begin{array}{l}\text { FORTALECIMIEN- } \\
\text { TO A EMPRESAS } \\
\text { TECNOLÓGICAS } \\
\text { DE LA INFORMA- } \\
\text { CIÓN }\end{array}$ & 100 & 0 & 0 & & $\$ 11,742,710$ \\
\hline
\end{tabular}

Fuente: Elaboración propia en base Secretaría de Hacienda y Credito Público Sonora (2016). 


\section{Programa 3: Innovación y desarrollo tecnológico}

El programa Innovación y Desarrollo Tecnológico no pudo alcanzar la meta de 2 de sus indicadores relacionados con apoyos a proyectos viables y de impacto para el estado, la evaluación cualitativa del indicador menciona que la totalidad de los recursos para ser asignados al proyecto fueron cancelados por la SHCP. Sin embargo, podemos observar en el reporte de Avance Presupuestal por Procesos y Proyectos que el programa tiene presupuesto asignado y hasta en el momento Pagado. Estos resultados pueden deberse a que no se recibieron proyectos, como estado debemos impulsar la investigación, ya que estas nos favorecen como estado. Debemos administrar bien los recursos de cada proyecto y ver si no está funcionando para el próximo año aprovechar el recurso en un mejor proyecto de si de resultados.

$\checkmark$ Programa 4: Impulso a la diversificación de mercados, tabla 14. 


\section{Tabla 14}

Impulso a la diversificación de mercados

\begin{tabular}{|c|c|c|c|c|c|c|c|c|}
\hline $\begin{array}{l}\text { PROYECTO O } \\
\text { PROCESO }\end{array}$ & OBJETIVO & $\begin{array}{l}\text { RESULTADO ESPE- } \\
\text { RADO }\end{array}$ & $\begin{array}{l}\text { NOMBRE DEL INDI- } \\
\text { CADOR }\end{array}$ & $\begin{array}{l}\text { META } \\
\text { ANUAL }\end{array}$ & $\begin{array}{l}\text { MODIFI- } \\
\text { CACIÓN }\end{array}$ & $\begin{array}{c}\text { RE- } \\
\text { SUL- } \\
\text { TADO }\end{array}$ & $\begin{array}{l}\text { SEMÁ- } \\
\text { FORO }\end{array}$ & $\begin{array}{l}\text { PRESU- } \\
\text { PUESTO } \\
\text { OTOR- } \\
\text { GADO }\end{array}$ \\
\hline \multirow[b]{2}{*}{$\begin{array}{l}\text { IMPULSO A LA } \\
\text { DIVERSIFICA- } \\
\text { CIÓN DE MER- } \\
\text { CADOS }\end{array}$} & \multirow{2}{*}{$\begin{array}{l}\text { FOMENTAR E IMPULSAR LA } \\
\text { COMERCIALIZACIÓN DE } \\
\text { PRODUCTOS SONORENSES A } \\
\text { TRAVES DE ACCIONES QUE } \\
\text { INCREMENTEN EL INTER- } \\
\text { CAMBIO COMERCIAL DEL } \\
\text { ESTADO CON EL MERCADO } \\
\text { REGIONAL, NACIONAL E } \\
\text { INTERNACIONAL, TALES } \\
\text { COMO: LA ORGANIZACIÓN Y } \\
\text { PARTICIPACIÓN EN FERIAS Y } \\
\text { EVENTOS, MISIONES CO- } \\
\text { MERCIALES Y AGENDAS DE } \\
\text { NEGOCIOS, ASÍ COMO LA } \\
\text { PROMOCIÓN Y DESARROLLO } \\
\text { DE FRANQUICIAS SONOREN- } \\
\text { SES }\end{array}$} & \multirow[b]{2}{*}{$\begin{array}{l}\text { GENERAR UN MA- } \\
\text { YOR NÚMERO DE } \\
\text { EMPRESAS SONO- } \\
\text { RENSES CON MÁS } \\
\text { PRODUCTOS EN LOS } \\
\text { ANAQUELES Y DI- } \\
\text { VERSIFICACIÓN DE } \\
\text { SUS MERCADOS }\end{array}$} & $\begin{array}{l}\text { INDICE DE EMPRESAS } \\
\text { POTENCIALES A PRO- } \\
\text { MOVER EN FERIAS Y } \\
\text { EVENTOS NACIONALES } \\
\text { E INTERNACIONALES }\end{array}$ & 100 & 100 & 100 & & \multirow[b]{2}{*}{$\$ 3,943,361$} \\
\hline & & & $\begin{array}{l}\text { INDICE DE EMPRESAS } \\
\text { POTENCIALES A FOR- } \\
\text { TALECER E INTERNA- } \\
\text { CIONALIZAR EN EL } \\
\text { CAMPO DE LAS FRAN- } \\
\text { QUICIAS }\end{array}$ & 100 & 0 & 0 & & \\
\hline
\end{tabular}

Fuente: Elaboración propia en base Secretaría de Hacienda y Credito Público Sonora (2016). 
El programa Promoción Internacional y Comercio Exterior sólo logró apoyar la participación de 7 empresas sonorenses y requirió de \$3 millones de pesos para lograrlo. En cuanto al Índice de Empresas Potenciales a Fortalecer e Internacionalizar en el Campo de las Franquicias se solicitó su eliminación por falta de presupuesto, sin embargo, consideramos importante que se incentive y ayude a los empresarios a expandir sus mercados. Debemos hacer una buena planeación del presupuesto año con año y comprometer únicamente lo que se va a cumplir para no dejar indicadores inconclusos y metan sin cumplir. Debemos ser eficientes y eficaces con los recursos para poder abarcar lo mayor posible y poder hacer que la economía del estado crezca.

$\checkmark$ Programa 5: Fomento a la Minería, tabla 15.

\section{Tabla 15}

Fomento a la minería

\begin{tabular}{|c|c|c|c|c|c|c|c|c|}
\hline $\begin{array}{l}\text { PROYEC- } \\
\text { TO O } \\
\text { PROCESO }\end{array}$ & OBJETIVO & RESULTADO ESPERADO & $\begin{array}{l}\text { NOMBRE } \\
\text { DEL INDI- } \\
\text { CADOR }\end{array}$ & $\begin{array}{l}\text { META } \\
\text { ANUAL }\end{array}$ & $\begin{array}{l}\text { MODI- } \\
\text { FICA- } \\
\text { CIÓN }\end{array}$ & $\begin{array}{c}\text { RE- } \\
\text { SUL- } \\
\text { TADO }\end{array}$ & $\begin{array}{l}\text { SEMÁ- } \\
\text { FORO }\end{array}$ & $\begin{array}{c}\text { PRESU- } \\
\text { PUESTO } \\
\text { OTORGADO }\end{array}$ \\
\hline $\begin{array}{l}\text { ACCIONES } \\
\text { DE GES- } \\
\text { TION }\end{array}$ & $\begin{array}{l}\text { PROMOVER EL DESARROLLO REGIO- } \\
\text { NAL, ATENDIENDO LAS VENTAJAS } \\
\text { COMPETITIVAS DEL ESTADO, QUE } \\
\text { CONLLEVE A LA ATRACCIÓN DE IN- } \\
\text { VERSIÓN Y LA GENERACIÓN DE } \\
\text { FUENTES DE EMPLEO }\end{array}$ & $\begin{array}{l}\text { SE CONSERVA LA BASE } \\
\text { LABORAL Y SE PROMUEVE } \\
\text { EL DESARROLLO REGIO- } \\
\text { NAL, QUE CONLLEVA A LA } \\
\text { ATRACCIÓN DE INVERSIÓN } \\
\text { Y LA GENERACIÓN DE EM- } \\
\text { PLEOS }\end{array}$ & $\begin{array}{l}\text { EMPRESA } \\
\text { ATENDIDA }\end{array}$ & 100 & 300 & 300 & & $\$ 4,717,757$ \\
\hline
\end{tabular}




\section{Tabla 15}

Continuación...

\begin{tabular}{|c|c|c|c|c|c|c|c|c|}
\hline $\begin{array}{l}\text { PROYEC- } \\
\text { TO O } \\
\text { PROCESO }\end{array}$ & OBJETIVO & RESULTADO ESPERADO & $\begin{array}{l}\text { NOMBRE } \\
\text { DEL INDI- } \\
\text { CADOR }\end{array}$ & $\begin{array}{c}\text { META } \\
\text { ANUAL }\end{array}$ & $\begin{array}{l}\text { MODI- } \\
\text { FICA- } \\
\text { CIÓN }\end{array}$ & $\begin{array}{l}\text { RE- } \\
\text { SUL- } \\
\text { TADO }\end{array}$ & $\begin{array}{l}\text { SEMÁ- } \\
\text { FORO }\end{array}$ & $\begin{array}{c}\text { PRESU- } \\
\text { PUESTO } \\
\text { OTORGADO }\end{array}$ \\
\hline $\begin{array}{l}\text { ASISTEN- } \\
\text { CIA TEC- } \\
\text { NICA A } \\
\text { PEQUE- } \\
\text { ÑOS MI- } \\
\text { NEROS }\end{array}$ & $\begin{array}{l}\text { PROMOVER EL DESARROLLO REGIO- } \\
\text { NAL, ATENDIENDO LAS VENTAJAS } \\
\text { COMPETITIVAS DEL ESTADO, QUE } \\
\text { CONLLEVEN A LA ATRACCIÓN DE } \\
\text { INVERSIÓN Y LA GENERACIÓN DE } \\
\text { FUENTES DE EMPLEO }\end{array}$ & $\begin{array}{l}\text { SE PROMUEVE EL DESA- } \\
\text { RROLLO REGIONAL QUE } \\
\text { CONLLEVA A LA ATRAC- } \\
\text { CIÓN DE INVERSIÓN Y LA } \\
\text { GENERACIÓN DE FUENTES } \\
\text { DE EMPLEO }\end{array}$ & $\begin{array}{l}\text { INDICE DE } \\
\text { PROSPEC- } \\
\text { TOS MINE- } \\
\text { ROS ATEN- } \\
\text { DIDOS }\end{array}$ & 100 & 60 & 60 & & \multirow{2}{*}{$\$ 4,717,757$} \\
\hline $\begin{array}{l}\text { IMPULSO } \\
\text { A LA MI- } \\
\text { NERÍA }\end{array}$ & $\begin{array}{l}\text { PROMOVER EL DESARROLLO REGIO- } \\
\text { NAL, ATENDIENDO LAS VENTAJAS } \\
\text { COMPETITIVAS DEL ESTADO, QUE } \\
\text { CONLLEVEN A LA ATRACCIÓN DE } \\
\text { INVERSIÓN Y LA GENERACIÓN DE } \\
\text { FUENTES DE EMPLEO }\end{array}$ & $\begin{array}{l}\text { PROMOCIÓN MINERA DEL } \\
\text { ESTADO EN EVENTOS DE } \\
\text { TALLA INTERNACIONAL }\end{array}$ & $\begin{array}{l}\text { ÍNDICE DE } \\
\text { DIFUSIÓN } \\
\text { DE INFOR- } \\
\text { MACIÓN } \\
\text { MINERA }\end{array}$ & 100 & 300 & 300 & & \\
\hline
\end{tabular}




\section{Tabla 15}

Continuación...

\begin{tabular}{|c|c|c|c|c|c|c|c|c|}
\hline $\begin{array}{l}\text { PROYEC- } \\
\text { TO O } \\
\text { PROCESO }\end{array}$ & OBJETIVO & RESULTADO ESPERADO & $\begin{array}{l}\text { NOMBRE } \\
\text { DEL INDI- } \\
\text { CADOR }\end{array}$ & $\begin{array}{c}\text { META } \\
\text { ANUAL }\end{array}$ & $\begin{array}{l}\text { MODI- } \\
\text { FICA- } \\
\text { CIÓN }\end{array}$ & $\begin{array}{l}\text { RE- } \\
\text { SUL- } \\
\text { TADO }\end{array}$ & $\begin{array}{l}\text { SEMÁ- } \\
\text { FORO }\end{array}$ & $\begin{array}{l}\text { PRESU- } \\
\text { PUESTO } \\
\text { OTORGADO }\end{array}$ \\
\hline $\begin{array}{l}\text { IMPULSO } \\
\text { A LA MI- } \\
\text { NERÍA }\end{array}$ & $\begin{array}{l}\text { PROMOVER EL DESARROLLO REGIO- } \\
\text { NAL, ATENDIENDO LAS VENTAJAS } \\
\text { COMPETITIVAS DEL ESTADO, QUE } \\
\text { CONLLEVEN A LA ATRACCIÓN DE } \\
\text { INVERSIÓN Y LA GENERACIÓN DE } \\
\text { FUENTES DE EMPLEO }\end{array}$ & $\begin{array}{l}\text { PROMOCIÓN MINERA DEL } \\
\text { ESTADO EN EVENTOS DE } \\
\text { TALLA INTERNACIONAL }\end{array}$ & $\begin{array}{l}\text { ÍNDICE DE } \\
\text { EMPRESAS } \\
\text { ATENDI- } \\
\text { DAS }\end{array}$ & 100 & 0 & 0 & & \\
\hline $\begin{array}{l}\text { IMPULSO } \\
\text { A LA MI- } \\
\text { NERÍA } \\
\text { CURSO DE } \\
\text { CAPACI- } \\
\text { TACIÓN }\end{array}$ & $\begin{array}{l}\text { PROMOVER EL DESARROLLO REGIO- } \\
\text { NAL, ATENDIENDO LAS VENTAJAS } \\
\text { COMPETITIVAS DEL ESTADO, QUE } \\
\text { CONLLEVEN A LA ATRACCIÓN DE } \\
\text { INVERSIÓN Y LA GENERACIÓN DE } \\
\text { FUENTES DE EMPLEO. } \\
\text { PROMOVER EL DESARROLLO REGIO- } \\
\text { NAL, ATENDIENDO LAS VENTAJAS } \\
\text { COMPETITIVAS DEL ESTADO, QUE } \\
\text { CONLLEVEN A LA ATRACCIÓN DE } \\
\text { INVERSIÓN Y LA GENERACIÓN DE } \\
\text { FUENTES DE EMPLEO }\end{array}$ & $\begin{array}{l}\text { PROMOCIÓN MINERA DEL } \\
\text { ESTADO EN EVENTOS DE } \\
\text { TALLA INTERNACIONAL. } \\
\text { PERSONAS CON MAYOR } \\
\text { CALIDAD DE CONOCIMIEN- } \\
\text { TOS Y PRÁCTICAS TÉCNI- } \\
\text { CAS EN SU ÁREA DE } \\
\text { DESEMPEÑO, DENTRO DEL } \\
\text { CAMPO DE LA MINERÍA }\end{array}$ & $\begin{array}{l}\text { ÍNDICE DE } \\
\text { PERSONAS } \\
\text { CAPACI- } \\
\text { TADAS }\end{array}$ & 100 & 80 & 80 & & $\$ 4,717,757$ \\
\hline
\end{tabular}

Fuente: Elaboración propia en base Secretaría de Hacienda y Credito Público Sonora (2016). 
El programa fomento minero tiene poco recurso asignado este es por tan sólo $\$ 4$ millones de pesos aunado a ello se realizaron ajustes para darle suficiencia al capítulo 1000 este está relacionado con los gastos que se hacen por concepto de Servicios Personales, a este desembolso se le dio prioridad ya que están los sueldos o prestaciones del trabajador. La minería es un sector no explotado por los mismos mexicanos, se debe apoyar y brindar mejores herramientas a prospectos mineros de nuestro país, ya que esto mejora la economía de nuestro estado. Sólo 2 indicadores de 5 con los que cuenta el programa lograron cumplirse.

A parte de los programas antes descritos la SE cuenta con otros cuyo presupuesto ascendió a \$575 millones de pesos. Es difícil dar como conclusión la eliminación de un programa, meta o indicador, para aseverar algo así se debe hacer un análisis más profundo e investigar y cruzar información para contar con mayores soportes para tomar decisiones o emitir recomendaciones.

\section{Secretaría de Hacienda (SH)}

Como ya lo mencionamos para evaluar la gestión de una Dependencia primeramente es necesario conocer su razón de ser y las aspiraciones de la misma.

Misión: Crear políticas económicas en Sonora para la mejor administración de los recursos financieros, velar por los intereses del estado, cuidar los ingresos y disminuir los gastos.
Visión: Administrar eficaz y eficientemente los recursos del estado para que los sonorenses tengan una buena calidad de vida.

A continuación, analizaremos los programas 2015 de la SH:

Programa 1: Fortalecimiento de los Ingresos

- Proyecto/procesos 1: Cumplimiento de la aplicación de la Ley de Ingresos

- Proyecto/procesos 2: Captación y recaudación de ingresos fiscales

- Proyecto/procesos 3: Expedición, control y vigilancia de licencias y trámites de establecimientos destinados a la fabricación, envasado, distribución, guarda, transportación, venta y consumo de bebidas con contenido alcohólico.

- Proyecto/procesos 4: Atención al contribuyente en materia fiscal estatal

- Proyecto/procesos 5: Dirección supervisión y evaluación de la fiscalización

- Proyecto/procesos 6: Coordinación y seguimiento de las auditorias fiscales 
Programa 2: Justicia Administrativa y Laboral

- Proyecto/procesos 1: Formación del marco jurídico fiscal de los ingresos estatales

- Proyecto/procesos 2: Atención de asuntos jurídicos fiscales

Programa 3: Modernización de la Administración y Pasión por el Servicio Público

- Proyecto/procesos 1: Control y seguimiento administrativo de los recursos para el funcionamiento de la $\mathrm{SH}$

- Proyecto/procesos 2: Supervisión a unidades administrativas de la Subsecretaría de Ingresos y a los municipios con convenios de colaboración administrativa

- Proyecto/procesos 3: Operación correcta del sistema integral de información administrativa financiera

Programa 4: Seguridad Pública

- Proyecto/procesos 1: Inteligencia e investigación para la prevención de delitos fiscales
Programa 5: Administración de las Finanzas Públicas

- Proyecto/procesos 1: Registro y control de caja y tesorería

- Proyecto/procesos 2: Administración de la deuda publica

Programa 6: Consolidación de la Gestión Pública Para Resultados

- Proyecto/procesos 1: Participar en la vigilancia del cumplimiento de observaciones de entes fiscalizados $\mathrm{y}$ actos fiscalizados por disposiciones legales

- Proyecto/procesos 2: Modernización de la administración y pasión por el servidor publico

- Proyecto/procesos 3: Administración de las finanzas publicas

$\checkmark$ Fortalecimiento de los Ingresos, tabla 16 y tabla 17. 


\section{Tabla 16}

Dirigir y controlar la ejecución de la política hacendaria del Gobierno del Estado de Sonora

\begin{tabular}{|c|c|c|c|c|c|c|c|c|}
\hline $\begin{array}{c}\text { PROYECTO O } \\
\text { PROCESO }\end{array}$ & OBJETIVO & $\begin{array}{l}\text { RESULTADO } \\
\text { ESPERADO }\end{array}$ & $\begin{array}{l}\text { NOMBRE DEL } \\
\text { INDICADOR }\end{array}$ & $\begin{array}{l}\text { META } \\
\text { ANUAL }\end{array}$ & $\begin{array}{l}\text { MODIFI- } \\
\text { CACIÓN }\end{array}$ & $\begin{array}{l}\text { RESUL- } \\
\text { TADO }\end{array}$ & $\begin{array}{l}\text { SEMÁ- } \\
\text { FORO }\end{array}$ & $\begin{array}{c}\text { PRESUPUESTO } \\
\text { OTORGADO }\end{array}$ \\
\hline $\begin{array}{l}\text { DIRIGIR Y CON- } \\
\text { TROLAR LA EJE- } \\
\text { CUCIÓN DE LA } \\
\text { POLÍTICA HA- } \\
\text { CENDARIA DEL } \\
\text { GOBIERNO DEL } \\
\text { ESTADO DE SO- } \\
\text { NORA }\end{array}$ & $\begin{array}{l}\text { ASEGURAR EL CUMPLI- } \\
\text { MIENTO DE LOS OBJETIVOS } \\
\text { Y METAS DE LA POLÍTICA } \\
\text { FISCAL Y FINANCIERA DEL } \\
\text { ESTADO PARA EL EJERCI- } \\
\text { CIO FISCAL } 2015\end{array}$ & $\begin{array}{l}\text { ASISTENCIA AL } \\
\text { TOTAL DE } \\
\text { REUNIONES } \\
\text { PROGRAMADAS }\end{array}$ & $\begin{array}{l}\text { REUNIÓN CON } \\
\text { FUNCIONARIOS } \\
\text { FISCALES }\end{array}$ & 100 & 0 & 100 & & $\$ 111,649,858.00$ \\
\hline
\end{tabular}

Fuente: Elaboración propia en base Secretaría de Hacienda y Credito Público Sonora (2016).

El presupuesto aprobado para ejercer este proyecto "Dirigir y controlar la ejecución de la política hacendaria del Gobierno del Estado de Sonora” fue de
\$111 millones de pesos, este indicador si cumplió con su meta porque si se realizaron las reuniones con funcionarios fiscales que se tenían programadas. 


\section{Tabla 17}

Cumplimiento de la Aplicación de la Ley de Ingresos y Captación y Recaudación de Ingresos Fiscales

\begin{tabular}{|c|c|c|c|c|c|c|c|c|}
\hline $\begin{array}{l}\text { PROYECTO O } \\
\text { PROCESO }\end{array}$ & OBJETIVO & $\begin{array}{l}\text { RESULTADO ESPE- } \\
\text { RADO }\end{array}$ & $\begin{array}{l}\text { NOMBRE DEL } \\
\text { INDICADOR }\end{array}$ & $\begin{array}{r}\text { META } \\
\text { ANUAL }\end{array}$ & $\begin{array}{l}\text { MODIFI- } \\
\text { CACIÓN }\end{array}$ & $\begin{array}{l}\text { RESUL- } \\
\text { TADO }\end{array}$ & $\begin{array}{l}\text { SE- } \\
\text { MÁ- } \\
\text { FO- } \\
\text { RO }\end{array}$ & $\begin{array}{l}\text { PRESUPUESTO } \\
\text { OTORGADO }\end{array}$ \\
\hline $\begin{array}{l}\text { CUMPLIMIEN- } \\
\text { TO DE LA } \\
\text { APLICACIÓN } \\
\text { DE LA LEY DE } \\
\text { INGRESOS }\end{array}$ & $\begin{array}{l}\text { ASEGURAR EL CUMPLIMIENTO } \\
\text { DE LAS ESTRATEGIAS PARA LA } \\
\text { CAPTACIÓN DE LOS INGRESOS } \\
\text { PÚBLICOS QUE MARCAN LAS } \\
\text { DISPOSICIONES LEGALES PA- } \\
\text { RA FINANCIAR EL DESARRO- } \\
\text { LLO DEL ESTADO }\end{array}$ & $\begin{array}{l}\text { CUMPLIR CON LAS } \\
\text { METAS DE INGRE- } \\
\text { SOS ESTABLECIDAS } \\
\text { EN LA LEY DE IN- } \\
\text { GRESOS }\end{array}$ & $\begin{array}{l}\text { ÍNDICE DEL } \\
\text { CUMPLIMIENTO } \\
\text { DE LA META DE } \\
\text { INGRESOS }\end{array}$ & 100 & 0 & 89.4 & & $\$ 21,215,762.00$ \\
\hline $\begin{array}{l}\text { CAPTACIÓN Y } \\
\text { RECAUDA- } \\
\text { CIÓN DE IN- } \\
\text { GRESOS FIS- } \\
\text { CALES }\end{array}$ & $\begin{array}{l}\text { REALIZAR LA RECUPERACIÓN } \\
\text { TOTAL DE ADEUDOS INCUM- } \\
\text { PLIDOS POR CONVENIOS DE } \\
\text { PAGOS EN PARCIALIDADES }\end{array}$ & $\begin{array}{l}\text { CUMPLIR CON LAS } \\
\text { METAS PROGRA- } \\
\text { MADAS EN PRO- } \\
\text { GRAMA OPERATIVO } \\
\text { ANUAL }\end{array}$ & $\begin{array}{l}\text { INDICE DE CUM- } \\
\text { PLIMIENTO DEL } \\
\text { PROGRAMA DE } \\
\text { RECAUDACION } \\
\text { FISCAL }\end{array}$ & 100 & 0 & 36.7 & & \\
\hline
\end{tabular}




\section{Tabla 17}

Continuación...

\begin{tabular}{|c|c|c|c|c|c|c|c|c|}
\hline $\begin{array}{l}\text { PROYECTO O } \\
\text { PROCESO }\end{array}$ & OBJETIVO & $\begin{array}{l}\text { RESULTADO ESPE- } \\
\text { RADO }\end{array}$ & $\begin{array}{l}\text { NOMBRE DEL } \\
\text { INDICADOR }\end{array}$ & $\begin{array}{l}\text { META } \\
\text { ANUAL }\end{array}$ & $\begin{array}{l}\text { MODIFI- } \\
\text { CACIÓN }\end{array}$ & $\begin{array}{l}\text { RESUL- } \\
\text { TADO }\end{array}$ & $\begin{array}{l}\text { SE- } \\
\text { MÁ- } \\
\text { FO- } \\
\text { RO }\end{array}$ & $\begin{array}{l}\text { PRESUPUESTO } \\
\text { OTORGADO }\end{array}$ \\
\hline $\begin{array}{l}\text { CAPTACIÓN Y } \\
\text { RECAUDA- } \\
\text { CIÓN DE IN- } \\
\text { GRESOS FIS- } \\
\text { CALES }\end{array}$ & $\begin{array}{l}\text { REALIZAR LA RECUPERACIÓN } \\
\text { TOTAL DE ADEUDOS INCUM- } \\
\text { PLIDOS POR CONVENIOS DE } \\
\text { PAGOS EN PARCIALIDADES }\end{array}$ & $\begin{array}{l}\text { LOGRAR UN CUM- } \\
\text { PLIMIENTO DEL } \\
\text { 100\% DE LA META } \\
\text { PROGRAMADA }\end{array}$ & $\begin{array}{l}\text { INDICE DEL } \\
\text { CUMPLIMIENTO } \\
\text { DE CONVENIOS } \\
\text { DE COORDINA- } \\
\text { CION FISCAL }\end{array}$ & 100 & 0 & 9.84 & & $\$ 21,215,762.00$ \\
\hline
\end{tabular}

Fuente: Elaboración propia en base Secretaría de Hacienda y Credito Público Sonora (2016). 
El presupuesto aprobado para ejercer los proyectos "Cumplimiento de la Aplicación de la Ley de Ingresos” y "Captación y Recaudación de Ingresos Fiscales” (tabla 18) es de \$21 millones de pesos. El primer proyecto es aceptable aunque el indicador únicamente alcanzo 89.4/100 por debajo de la meta anual.

El segundo proyecto no se está ejerciendo como se debería, ya que no se está cumpliendo con las metas. Los dos indicadores están en estado crítico (rojo), el primero "índice de cumplimiento del programa de recaudación fiscal" no se está cumpliendo por:

1. En el primer trimestre de 2015 se estaba implementando el nuevo sistema contable debido a eso no se pudieron realizar ni cobros ni pagos.

2. No había presupuesto por causa del cambio de administración, así que no se contaba con dinero para viáticos. Pasó un percance que no servían impresoras y además no tenían internet, eso causó que no hicieran algunos cobros y afectó económicamente a la dependencia. Se sugiere que la dependencia esté preparada para cualquier percance en el futuro ya que estas fallas perjudican con los cobros y no se tendrán ingresos.

El segundo indicador "índice del cumplimiento de convenios de coordinación fiscal” no se cumplió por:

1. Convenios sin firma y sin firma prácticamente no se cumple con la meta.

2. Por el cambio de administración se retrasaron las firmas de los convenios.

En estos casos se solicita poner más atención y que el personal actúe con eficiencia y eficacia ante cualquier circunstancia, porque si se dejan de recaudar ingresos perjudica al presupuesto y al ente. 


\section{Tabla 18}

Captación y Recaudación de Ingresos

\begin{tabular}{|c|c|c|c|c|c|c|c|c|}
\hline $\begin{array}{l}\text { PROYECTO O } \\
\text { PROCESO }\end{array}$ & OBJETIVO & $\begin{array}{l}\text { RESULTADO ES- } \\
\text { PERADO }\end{array}$ & $\begin{array}{l}\text { NOMBRE DEL IN- } \\
\text { DICADOR }\end{array}$ & $\begin{array}{l}\text { META } \\
\text { ANUAL }\end{array}$ & $\begin{array}{l}\text { MODI- } \\
\text { FICA- } \\
\text { CIÓN }\end{array}$ & $\begin{array}{l}\text { RESUL- } \\
\text { TADO }\end{array}$ & $\begin{array}{l}\text { SEMÁ- } \\
\text { FORO }\end{array}$ & $\begin{array}{l}\text { PRESUPUES- } \\
\text { TO OTORGA- } \\
\text { DO }\end{array}$ \\
\hline \multirow{2}{*}{$\begin{array}{l}\text { CAPTACIÓN Y } \\
\text { RECAUDA- } \\
\text { CIÓN DE IN- } \\
\text { GRESOS }\end{array}$} & \multirow{2}{*}{$\begin{array}{l}\text { INCREMENTAR LOS NIVELES DE } \\
\text { RECAUDACIÓN APLICANDO ES- } \\
\text { QUEMAS PARA EL SEGUIMIENTO } \\
\text { Y PROMOCIÓN DE REGULARIZA- } \\
\text { CIÓN DEL PAGO DE CONTRIBU- } \\
\text { CIONES ESTATALES Y FEDERA- } \\
\text { LES COORDINADAS, CON EL FIN } \\
\text { DE QUE EL EJECUTIVO CUENTE } \\
\text { CON LOS RECURSOS NECESA- } \\
\text { RIOS PARA EL DESARROLLO DEL } \\
\text { ESTADO }\end{array}$} & $\begin{array}{l}\text { CUMPLIR CON EL } \\
\text { NIVEL DE RECAU- } \\
\text { DACIÓN ESTABLE- } \\
\text { CIDO EN LA LEY } \\
\text { DE INGRESOS }\end{array}$ & $\begin{array}{l}\text { ÍNDICE DE CUM- } \\
\text { PLIMIENTO DEL } \\
\text { PROGRAMA DE } \\
\text { RECAUDACIÓN }\end{array}$ & 100 & 0 & 113.9 & & \multirow{2}{*}{$\$ 50,231,866.00$} \\
\hline & & $\begin{array}{l}\text { MANTENER AC- } \\
\text { TUALIZADO EL } \\
\text { REGISTRO DE } \\
\text { CONTRIBUYENTES }\end{array}$ & $\begin{array}{l}\text { AUMENTO DEL } \\
\text { UNIVERSO DE } \\
\text { CONTRIBUYENTES }\end{array}$ & 100 & 0 & 373.25 & & \\
\hline
\end{tabular}




\section{Tabla 18}

Continuación...

\begin{tabular}{|c|c|c|c|c|c|c|c|c|}
\hline $\begin{array}{c}\text { PROYECTO O } \\
\text { PROCESO }\end{array}$ & OBJETIVO & $\begin{array}{l}\text { RESULTADO ES- } \\
\text { PERADO }\end{array}$ & $\begin{array}{l}\text { NOMBRE DEL IN- } \\
\text { DICADOR }\end{array}$ & $\begin{array}{l}\text { META } \\
\text { ANUAL }\end{array}$ & $\begin{array}{l}\text { MODI- } \\
\text { FICA- } \\
\text { CIÓN }\end{array}$ & $\begin{array}{l}\text { RESUL- } \\
\text { TADO }\end{array}$ & $\begin{array}{l}\text { SEMÁ- } \\
\text { FORO }\end{array}$ & $\begin{array}{c}\text { PRESUPUES- } \\
\text { TO OTORGA- } \\
\text { DO }\end{array}$ \\
\hline \multirow{3}{*}{$\begin{array}{l}\text { CAPTACIÓN Y } \\
\text { RECAUDA- } \\
\text { CIÓN DE IN- } \\
\text { GRESOS }\end{array}$} & \multirow{3}{*}{$\begin{array}{l}\text { INCREMENTAR LOS NIVELES DE } \\
\text { RECAUDACIÓN APLICANDO ES- } \\
\text { QUEMAS PARA EL SEGUIMIENTO } \\
\text { Y PROMOCIÓN DE REGULARIZA- } \\
\text { CIÓN DEL PAGO DE CONTRIBU- } \\
\text { CIONES ESTATALES Y FEDERA- } \\
\text { LES COORDINADAS, CON EL FIN } \\
\text { DE QUE EL EJECUTIVO CUENTE } \\
\text { CON LOS RECURSOS NECESA- } \\
\text { RIOS PARA EL DESARROLLO DEL } \\
\text { ESTADO }\end{array}$} & $\begin{array}{l}\text { MANTENER AC- } \\
\text { TUALIZADO EL } \\
\text { REGISTRO ESTA- } \\
\text { TAL VEHICULAR Y } \\
\text { DE LICENCIAS }\end{array}$ & $\begin{array}{l}\text { INCREMENTO AL } \\
\text { NIVEL DE RECAU- } \\
\text { DACIÓN POR CON- } \\
\text { CEPTOS VEHICU- } \\
\text { LARES }\end{array}$ & 100 & 0 & 75.27 & & \multirow{3}{*}{$\$ 50,231,866.00$} \\
\hline & & $\begin{array}{l}\text { COADYUVAR A LA } \\
\text { DISMINUCIÓN DE } \\
\text { REZAGO DE LAS } \\
\text { CONTRIBUCIONES } \\
\text { QUE SE TRATE }\end{array}$ & $\begin{array}{l}\text { SEGUIMIENTO Y } \\
\text { CONTROL DE } \\
\text { CONTRIBUCIONES } \\
\text { NO VEHICULARES } \\
\text { ESTATALES Y FE- } \\
\text { DERALES COOR- } \\
\text { DINADAS }\end{array}$ & 100 & 0 & 126.07 & & \\
\hline & & $\begin{array}{l}\text { DISMINUIR LA } \\
\text { EVASIÓN FISCAL }\end{array}$ & $\begin{array}{l}\text { COBRANZA COAC- } \\
\text { TIVA }\end{array}$ & 100 & 0 & 97.08 & & \\
\hline
\end{tabular}




\section{Tabla 18}

Continuación...

\begin{tabular}{|c|c|c|c|c|c|c|c|c|}
\hline $\begin{array}{l}\text { PROYECTO O } \\
\text { PROCESO }\end{array}$ & OBJETIVO & $\begin{array}{l}\text { RESULTADO ES- } \\
\text { PERADO }\end{array}$ & $\begin{array}{l}\text { NOMBRE DEL IN- } \\
\text { DICADOR }\end{array}$ & $\begin{array}{l}\text { META } \\
\text { ANUAL }\end{array}$ & $\begin{array}{l}\text { MODI- } \\
\text { FICA- } \\
\text { CIÓN }\end{array}$ & $\begin{array}{l}\text { RESUL- } \\
\text { TADO }\end{array}$ & $\begin{array}{l}\text { SEMÁ- } \\
\text { FORO }\end{array}$ & $\begin{array}{c}\text { PRESUPUES- } \\
\text { TO OTORGA- } \\
\text { DO }\end{array}$ \\
\hline $\begin{array}{l}\text { CAPTACIÓN Y } \\
\text { RECAUDA- } \\
\text { CIÓN DE IN- } \\
\text { GRESOS }\end{array}$ & $\begin{array}{l}\text { INCREMENTAR LOS NIVELES DE } \\
\text { RECAUDACIÓN APLICANDO ES- } \\
\text { QUEMAS PARA EL SEGUIMIENTO } \\
\text { Y PROMOCIÓN DE REGULARIZA- } \\
\text { CIÓN DEL PAGO DE CONTRIBU- } \\
\text { CIONES ESTATALES Y FEDERA- } \\
\text { LES COORDINADAS, CON EL FIN } \\
\text { DE QUE EL EJECUTIVO CUENTE } \\
\text { CON LOS RECURSOS NECESA- } \\
\text { RIOS PARA EL DESARROLLO DEL } \\
\text { ESTADO }\end{array}$ & $\begin{array}{l}\text { FORMULAR EL } \\
\text { TOTAL DE INFOR- } \\
\text { MES PROYECTA- } \\
\text { DOS }\end{array}$ & $\begin{array}{l}\text { RENDICIÓN DE } \\
\text { CUENTAS }\end{array}$ & 100 & 0 & 100 & & $\$ 50,231,866.00$ \\
\hline
\end{tabular}

Fuente: Elaboración propia en base Secretaría de Hacienda y Credito Público Sonora (2016). 
El presupuesto aprobado para este proyecto "Captación y Recaudación de Ingresos” es de \$50 millones de pesos, el cual tiene 6 indicadores de los cuales se cumplieron satisfactoriamente 5 , de los cuales solo uno no cumplió con la meta y solo obtuvo un resultado de 97.08/100.

El indicador "Incremento al nivel de recaudación por conceptos vehiculares" está en riesgo (amarillo) por la implementación del sistema contable, esto retraso la captura de los ingresos además de que los contribuyentes no cumplieron con sus pagos.

El indicador de tramites cumplió con su meta. El indicador de documentación no se cumplió el presupuesto aprobado de $\$ 50$ millones de pesos para este proyecto está en riesgo (Amarillo) ya que no se está cumpliendo cada trimestre con la meta establecida, ya que no se cuenta con documentación. Tabla 19.

\section{Tabla 19}

Expedición, control y vigilancia de licencias y tramites de establecimientos destinados a la fabricación, envasado, distribución, guarda, transportación, venta y consumo de bebidas con contenido alcohólico" es de \$50, 231,866.00. El indicador "Documentar la circunstancia del establecimiento

\begin{tabular}{|c|c|c|c|c|c|c|c|c|}
\hline PROYECTO O PROCESO & OBJETIVO & $\begin{array}{l}\text { RESULTADO } \\
\text { ESPERADO }\end{array}$ & $\begin{array}{l}\text { NOMBRE } \\
\text { DEL INDI- } \\
\text { CADOR }\end{array}$ & $\begin{array}{l}\text { META } \\
\text { ANUAL }\end{array}$ & $\begin{array}{l}\text { MODI- } \\
\text { FICA- } \\
\text { CIÓN }\end{array}$ & $\begin{array}{l}\text { RE- } \\
\text { SUL- } \\
\text { TADO }\end{array}$ & $\begin{array}{l}\text { SEMÁ- } \\
\text { FORO }\end{array}$ & $\begin{array}{c}\text { PRESUPUES- } \\
\text { TO OTORGA- } \\
\text { DO }\end{array}$ \\
\hline \multirow[b]{2}{*}{$\begin{array}{l}\text { EXPEDICIÓN , CONTROL Y VIGI- } \\
\text { LANCIA DE LICENCIAS Y TRAMI- } \\
\text { TES DE ESTABLECIMIENTOS DES- } \\
\text { TINADOS A LA FABRICACIÓN, } \\
\text { EMVASAMIENTO, DISTRIBUCIÓN, } \\
\text { GUARDA, TRANSPORTACIÓN, } \\
\text { VENTA Y CONSUMO DE BEBIDAS } \\
\text { CON CONTENIDO ALCOHÓLICO }\end{array}$} & \multirow[b]{2}{*}{$\begin{array}{l}\text { REGISTRAR Y CONTRO- } \\
\text { LAR A LOS ESTABLECI- } \\
\text { MIENTOS QUE CUENTAN } \\
\text { CON LICENCIA PARA } \\
\text { FABRICACIÓN, EMVA- } \\
\text { SAMIENTO, DISTRIBU- } \\
\text { CIÓN, GUARDA, TRANS- } \\
\text { PORTACIÓN, VENTA Y } \\
\text { CONSUMO DE BEBIDAS } \\
\text { CON CONTENIDO AL- } \\
\text { COHÓLICO }\end{array}$} & \multirow[b]{2}{*}{$\begin{array}{l}\text { CUMPLIR AL } \\
\text { 100\% LA META } \\
\text { PROGRAMA- } \\
\text { DA }\end{array}$} & TRAMITES & 100 & 0 & 134.66 & & \\
\hline & & & $\begin{array}{l}\text { DOCUMEN- } \\
\text { TAR LA CIR- } \\
\text { CUNSTAN- } \\
\text { CIA DEL ES- } \\
\text { TABLECI- } \\
\text { MIENTO }\end{array}$ & 100 & 0 & 57.99 & & $\$ 50,231,866.00$ \\
\hline
\end{tabular}

Fuente: Elaboración propia en base Secretaría de Hacienda y Credito Público Sonora (2016). 
El presupuesto aprobado para este proyecto "atención al contribuyente en materia fiscal estatal” (tabla 20) es de \$5 millones de pesos. Este proyecto tiene seis indicadores y no se está ejecutando como debe ser, ya que únicamente se están cumpliendo las metas de dos indicadores. Está en riesgo la capacitación para el fortalecimiento de una cultura fiscal eficaz y oportuna con un resultado de 78.33/100. y tres indicadores están en estado crítico (rojo): este indicador es el más preocupante, ya que no se obtuvieron resultados "Elaboración y distribución de material de difusión fiscal” se debe a que por falta de organización y seguimiento no se imprimieron los trípticos de información, esto se retrasó para el final del año pero ya no se logró por falta de logos, se pide que sean más responsables y que cumplan con las metas establecidas. 


\section{Tabla 20}

Atención al contribuyente en materia fiscal estatal

\begin{tabular}{|c|c|c|c|c|c|c|c|c|}
\hline $\begin{array}{l}\text { PROYECTO } \\
\text { O PROCESO }\end{array}$ & OBJETIVO & $\begin{array}{l}\text { RESULTADO } \\
\text { ESPERADO }\end{array}$ & NOMIBRE DEL INDICADOR & $\begin{array}{l}\text { META } \\
\text { ANUAL }\end{array}$ & $\begin{array}{l}\text { MODIFI- } \\
\text { CACIÓN }\end{array}$ & $\begin{array}{l}\text { RESUL- } \\
\text { TADO }\end{array}$ & $\begin{array}{l}\text { SEMÁ- } \\
\text { FORO }\end{array}$ & $\begin{array}{l}\text { PRESUPUES- } \\
\text { TO OTORGA- } \\
\text { DO }\end{array}$ \\
\hline \multirow{3}{*}{$\begin{array}{l}\text { ATENCION } \\
\text { AL CONTRI- } \\
\text { BUYENTE EN } \\
\text { MATERIA } \\
\text { FISCAL ES- } \\
\text { TATAL }\end{array}$} & \multirow{3}{*}{$\begin{array}{l}\text { PROPORCIONAR ORIEN- } \\
\text { TACION Y ASISTENCIA } \\
\text { AL CONTRIBUYENTE, } \\
\text { INSTANCIAS RECAUDA- } \\
\text { DORAS Y DEPENDEN- } \\
\text { CIAS, A TRAVES DE CA- } \\
\text { PACITACION Y DIFUSION } \\
\text { DE PROGRAMAS PARA } \\
\text { EL FORTALECIMIENTO } \\
\text { DE UNA CULTURA FIS- } \\
\text { CAL EFICAZ Y OPORTU- } \\
\text { NA }\end{array}$} & \multirow{3}{*}{$\begin{array}{l}\text { CUMPLIR CON } \\
\text { LAS METAS Y } \\
\text { OBJETIVOS } \\
\text { ESTABLECI- } \\
\text { DOS EN EL } \\
\text { PROGRAMA } \\
\text { OPERATIVO } \\
\text { ANUAL }\end{array}$} & $\begin{array}{l}\text { CAPACITACION PARA EL } \\
\text { FORTALECIMIENTO DE UNA } \\
\text { CULTURA FISCAL EFICAZ Y } \\
\text { OPORTUNA }\end{array}$ & 100 & 0 & 73.33 & & \multirow{3}{*}{$\$ 5,869,662.00$} \\
\hline & & & $\begin{array}{l}\text { ASESORIA TELEFONICA, } \\
\text { ELECTRONICA Y PERSONA- } \\
\text { LIZADA }\end{array}$ & 100 & 0 & 107.6 & & \\
\hline & & & $\begin{array}{l}\text { REUNIONES CON CONTRI- } \\
\text { BUYENTES, CAMARAS EM- } \\
\text { PRESARIALES Y COLEGIOS } \\
\text { DE PROFESIONALES }\end{array}$ & 100 & 0 & 41.67 & & \\
\hline
\end{tabular}




\section{Tabla 20}

Continuación...

\begin{tabular}{|c|c|c|c|c|c|c|c|c|}
\hline $\begin{array}{l}\text { PROYECTO } \\
\text { O PROCESO }\end{array}$ & OBJETIVO & $\begin{array}{l}\text { RESULTADO } \\
\text { ESPERADO }\end{array}$ & NOMBRE DEL INDICADOR & $\begin{array}{l}\text { META } \\
\text { ANUAL }\end{array}$ & $\begin{array}{l}\text { MODIFI- } \\
\text { CACIÓN }\end{array}$ & $\begin{array}{l}\text { RESUL- } \\
\text { TADO }\end{array}$ & $\begin{array}{l}\text { SEMÁ- } \\
\text { FORO }\end{array}$ & $\begin{array}{c}\text { PRESUPUES- } \\
\text { TO OTORGA- } \\
\text { DO }\end{array}$ \\
\hline \multirow{3}{*}{$\begin{array}{l}\text { ATENCION } \\
\text { AL CONTRI- } \\
\text { BUYENTE EN } \\
\text { MATERIA } \\
\text { FISCAL ES- } \\
\text { TATAL }\end{array}$} & \multirow{3}{*}{$\begin{array}{l}\text { PROPORCIONAR ORIEN- } \\
\text { TACION Y ASISTENCIA } \\
\text { AL CONTRIBUYENTE, } \\
\text { INSTANCIAS RECAUDA- } \\
\text { DORAS Y DEPENDEN- } \\
\text { CIAS, A TRAVES DE CA- } \\
\text { PACITACION Y DIFUSION } \\
\text { DE PROGRAMAS PARA } \\
\text { EL FORTALECIMIENTO } \\
\text { DE UNA CULTURA FIS- } \\
\text { CAL EFICAZ Y OPORTU- } \\
\text { NA }\end{array}$} & \multirow{3}{*}{$\begin{array}{l}\text { CUMPLIR CON } \\
\text { LAS METAS Y } \\
\text { OBJETIVOS } \\
\text { ESTABLECI- } \\
\text { DOS EN EL } \\
\text { PROGRAMA } \\
\text { OPERATIVO } \\
\text { ANUAL }\end{array}$} & $\begin{array}{l}\text { ELABORACION Y DISTRI- } \\
\text { BUCION DE MATERIAL DE } \\
\text { DIFUSION FISCAL }\end{array}$ & 100 & 0 & 50 & & \multirow{3}{*}{$\$ 5,869,662.00$} \\
\hline & & & $\begin{array}{l}\text { ELABORACION Y DISTRI- } \\
\text { BUCION DE MATERIAL DE } \\
\text { DIFUSION FISCAL }\end{array}$ & 100 & 0 & 0 & & \\
\hline & & & $\begin{array}{l}\text { ALUMNOS SENSIBILIZADOS } \\
\text { A TRAVES DEL PROGRAMA } \\
\text { DE CULTURA FISCAL }\end{array}$ & 100 & 0 & 104.12 & & \\
\hline
\end{tabular}

Fuente: Elaboración propia en base Secretaría de Hacienda y Credito Público Sonora (2016). 


\section{Tabla 21}

Dirección, supervisión y evaluación de la fiscalización

\begin{tabular}{|c|c|c|c|c|c|c|c|c|}
\hline $\begin{array}{l}\text { PROYECTO } \\
\text { O PROCESO }\end{array}$ & OBJETIVO & RESULTADO ESPERADO & $\begin{array}{l}\text { NOMBRE DEL IN- } \\
\text { DICADOR }\end{array}$ & $\begin{array}{l}\text { META } \\
\text { ANUAL }\end{array}$ & $\begin{array}{l}\text { MODI- } \\
\text { FICA- } \\
\text { CIÓN }\end{array}$ & $\begin{array}{l}\text { RE- } \\
\text { SUL- } \\
\text { TADO }\end{array}$ & $\begin{array}{l}\text { SE } \\
\text { MÁ } \\
\text { FO- } \\
\text { RO }\end{array}$ & $\begin{array}{c}\text { PRESUPUES- } \\
\text { TO OTORGA- } \\
\text { DO }\end{array}$ \\
\hline \multirow{3}{*}{$\begin{array}{l}\text { DIRECCIÓN, } \\
\text { SUPERVI- } \\
\text { SIÓN Y EVA- } \\
\text { LUACIÓN DE } \\
\text { LA FISCALI- } \\
\text { ZACIÓN }\end{array}$} & \multirow{3}{*}{$\begin{array}{l}\text { REALIZAR SUPERVI- } \\
\text { SIÓN CONSTANTE EN } \\
\text { LOS ACTOS DE VERI- } \\
\text { FICACIÓN Y FISCALI- } \\
\text { ZACIÓN QUE SE } \\
\text { EFECTÚEN, CUM- } \\
\text { PLIENDO CON ELLO } \\
\text { EN LA DETECCIÓN DE } \\
\text { ELEMENTOS DE OMI- } \\
\text { SIÓN Y EVASIÓN CO- } \\
\text { METIDA A LAS LEYES } \\
\text { FISCALES }\end{array}$} & $\begin{array}{l}\text { DISMINUIR EL NÚMERO DE } \\
\text { VEHÍCULOS DE PROCEDENCIA EX- } \\
\text { TRANJERA QUE CIRCULAN DE } \\
\text { FORMA IRREGULAR EN EL TERRI- } \\
\text { TORIO DEL ESTADO }\end{array}$ & $\begin{array}{l}\text { ÍNDICE DE } \\
\text { VEHÍCULOS DE } \\
\text { PROCEDENCIA } \\
\text { EXTRANJERA EN } \\
\text { EL ESTADO }\end{array}$ & 100 & 0 & 124.39 & & \multirow{3}{*}{$\$ 65,580,728.00$} \\
\hline & & $\begin{array}{l}\text { EVITAR QUE LOS VEHÍCULOS IN- } \\
\text { TERNADOS TEMPORALMENTE AL } \\
\text { AMPARO DEL PROGRAMA ONLY } \\
\text { SONORA SALGAN DEL ESTADO DE } \\
\text { SONORA HACIA EL INTERIOR DEL } \\
\text { PAÍS }\end{array}$ & $\begin{array}{l}\text { PORCENTAJE DE } \\
\text { HOLOGRAMAS DE } \\
\text { PERMISO DE IM- } \\
\text { PORTACIÓN TEM- } \\
\text { PORAL EXPEDIDOS }\end{array}$ & 100 & 0 & 80.79 & & \\
\hline & & $\begin{array}{l}\text { DISMINUIR EL NÚMERO DE MER- } \\
\text { CANCÍA DE PROCEDENCIA EX- } \\
\text { TRANJERA QUE SE INTRODUCE DE } \\
\text { FORMA IRREGULAR EN EL TERRI- } \\
\text { TORIO DEL ESTADO }\end{array}$ & $\begin{array}{l}\text { PORCENTAJE DE } \\
\text { VEHÍCULOS CON } \\
\text { MERCANCÍA DE } \\
\text { PROCEDENCIA } \\
\text { EXTRANJERA }\end{array}$ & 100 & 0 & 63.67 & & \\
\hline
\end{tabular}




\section{Tabla 21}

Continuación...

\begin{tabular}{|c|c|c|c|c|c|c|c|c|}
\hline $\begin{array}{l}\text { PROYECTO } \\
\text { O PROCESO }\end{array}$ & OBJETIVO & RESULTADO ESPERADO & $\begin{array}{l}\text { NOMBRE DEL IN- } \\
\text { DICADOR }\end{array}$ & $\begin{array}{l}\text { META } \\
\text { ANUAL }\end{array}$ & $\begin{array}{l}\text { MODI- } \\
\text { FICA- } \\
\text { CIÓN }\end{array}$ & $\begin{array}{l}\text { RE- } \\
\text { SUL- } \\
\text { TADO }\end{array}$ & $\begin{array}{l}\text { SE } \\
\text { MÁ } \\
\text { FO- } \\
\text { RO }\end{array}$ & $\begin{array}{c}\text { PRESUPUES- } \\
\text { TO OTORGA- } \\
\text { DO }\end{array}$ \\
\hline \multirow{2}{*}{$\begin{array}{l}\text { DIRECCIÓN, } \\
\text { SUPERVI- } \\
\text { SIÓN Y EVA- } \\
\text { LUACIÓN DE } \\
\text { LA FISCALI- } \\
\text { ZACIÓN }\end{array}$} & \multirow{2}{*}{$\begin{array}{l}\text { REALIZAR SUPERVI- } \\
\text { SIÓN CONSTANTE EN } \\
\text { LOS ACTOS DE VERI- } \\
\text { FICACIÓN Y FISCALI- } \\
\text { ZACIÓN QUE SE } \\
\text { EFECTÚEN, CUM- } \\
\text { PLIENDO CON ELLO } \\
\text { EN LA DETECCIÓN DE } \\
\text { ELEMENTOS DE OMI- } \\
\text { SIÓN Y EVASIÓN CO- } \\
\text { METIDA A LAS LEYES } \\
\text { FISCALES }\end{array}$} & $\begin{array}{l}\text { DISMINUIR EL NÚMERO DE NEGO- } \\
\text { CIOS CON MERCANCÍA DE PROCE- } \\
\text { DENCIA EXTRANJERA QUE ES IN- } \\
\text { TRODUCIDA EN FORMA IRREGU- } \\
\text { LAR, A TRAVÉS DE ACTOS DE FIS- } \\
\text { CALIZACIÓN CON LA MAYOR EFI- } \\
\text { CIENCIA Y CALIDAD }\end{array}$ & $\begin{array}{l}\text { VISITAS DOMICI- } \\
\text { LIARIAS }\end{array}$ & 100 & 0 & 41.48 & & \multirow{2}{*}{$\$ 65,580,728.00$} \\
\hline & & $\begin{array}{l}\text { DISMINUIR EL NÚMERO DE MER- } \\
\text { CANCÍA DONADA DE PROCEDEN- } \\
\text { CIA EXTRANJERA INTERNADA EN } \\
\text { EL ESTADO DE MANERA ILÍCITA }\end{array}$ & $\begin{array}{l}\text { GESTIÓN EN LOS } \\
\text { TRAMITES DE DO- } \\
\text { NACIONES LIBRES } \\
\text { DE IMPUESTOS DE } \\
\text { MERCANCÍAS DO- } \\
\text { NADAS DEL EX- } \\
\text { TRANJERO }\end{array}$ & 100 & 0 & 38.1 & & \\
\hline
\end{tabular}

Fuente: Elaboración propia en base Secretaría de Hacienda y Credito Público Sonora (2016). 
El presupuesto aprobado para este proyecto "Dirección, supervisión y evaluación de la fiscalización” (tabla 21) es de \$65, 580,728.00. El presupuesto que se está destinando para este proyecto no se está ejecutando de manera correcta, ya que casi ninguna de las metas se está cumpliendo según a lo que se había establecido.

\section{Tabla 22}

Coordinación y seguimiento de las auditorias fiscales

\begin{tabular}{|c|c|c|c|c|c|c|c|c|}
\hline $\begin{array}{l}\text { PROYECTO O } \\
\text { PROCESO }\end{array}$ & OBJETIVO & $\begin{array}{l}\text { RESULTADO ESPE- } \\
\text { RADO }\end{array}$ & $\begin{array}{l}\text { NOMBRE DEL IN- } \\
\text { DICADOR }\end{array}$ & $\begin{array}{l}\text { META } \\
\text { ANUAL }\end{array}$ & $\begin{array}{l}\text { MODI- } \\
\text { FICA- } \\
\text { CIÓN }\end{array}$ & $\begin{array}{c}\text { RE- } \\
\text { SUL- } \\
\text { TADO }\end{array}$ & $\begin{array}{l}\text { SEMÁ- } \\
\text { FORO }\end{array}$ & $\begin{array}{l}\text { PRESUPUESTO } \\
\text { OTORGADO }\end{array}$ \\
\hline $\begin{array}{l}\text { COORDINACION } \\
\text { Y SEGUIMIENTO } \\
\text { DE LAS AUDITO- } \\
\text { RIAS FISCALES }\end{array}$ & $\begin{array}{l}\text { EVITAR Y REDUCIR LA } \\
\text { EVASIÓN FISCAL AUMEN- } \\
\text { TANDO LA RECAUDACIÓN } \\
\text { PRIMARIA MEDIANTE LA } \\
\text { VERIFICACIÓN DEL CO- } \\
\text { RRECTO CUMPLIMIENTO DE } \\
\text { LAS DISPOSICIONES FISCA- } \\
\text { LES VIGENTES }\end{array}$ & $\begin{array}{l}\text { CUMPLIR AL 100\% } \\
\text { CON LA RECAUDA- } \\
\text { CIÓN POR ACTOS DE } \\
\text { FISCALIZACIÓN QUE } \\
\text { MARCA LA LEY DE } \\
\text { INGRESOS PARA EL } \\
\text { GOBIERNO DEL ES- } \\
\text { TADO }\end{array}$ & $\begin{array}{l}\text { ÍNDICE DE AVAN- } \\
\text { CE DE CUMPLI- } \\
\text { MIENTO DE LA } \\
\text { LEY DE INGRESOS }\end{array}$ & 100 & 0 & 125.56 & & $\$ 164,074,712.00$ \\
\hline
\end{tabular}

Fuente: Elaboración propia en base Secretaría de Hacienda y Credito Público Sonora (2016).
Los indicadores que están en estado crítico (rojo) son:

"Visitas Domiciliarias" y esto se debe a fallas que se debieron a la entrega/recepción, a la falta de personal y por rotación (Falta de capacidad en los trabajadores)

"Gestión en los tramites de donaciones libres de impuestos de Mercancías donadas del Extranjero” y esto se debe a que algunas fueron canceladas, otras en espera de validación y otras quedaron en espera. 
El presupuesto aprobado para este proyecto “Coordinación y seguimiento de las auditorias fiscales” (tabla 23) es de \$164 millones de pesos cumplió con su meta, superándola, alcanzando un resultado de 125.56.

\section{Tabla 23}

Formulación del Marco Jurídico Fiscal de los Ingresos Estatales y Atención de Asuntos Jurídicos Fiscales

\begin{tabular}{|c|c|c|c|c|c|c|c|c|}
\hline $\begin{array}{l}\text { PROYECTO } \\
\text { O PROCESO }\end{array}$ & OBJETIVO & RESULTADO ESPERADO & $\begin{array}{l}\text { NOMBRE DEL IN- } \\
\text { DICADOR }\end{array}$ & $\begin{array}{l}\text { META } \\
\text { ANUAL }\end{array}$ & $\begin{array}{l}\text { MODI- } \\
\text { FICA- } \\
\text { CIÓN }\end{array}$ & $\begin{array}{l}\text { RESUL- } \\
\text { TADO }\end{array}$ & $\begin{array}{l}\text { SEMÁ- } \\
\text { FORO }\end{array}$ & $\begin{array}{c}\text { PRESUPUES- } \\
\text { TO OTORGA- } \\
\text { DO }\end{array}$ \\
\hline \multirow{2}{*}{$\begin{array}{l}\text { FORMULA- } \\
\text { CIÓN DEL } \\
\text { MARCO JU- } \\
\text { RÍDICO FIS- } \\
\text { CAL DE LOS } \\
\text { INGRESOS } \\
\text { ESTATALES }\end{array}$} & \multirow{2}{*}{$\begin{array}{l}\text { PROMOVER MEDIDAS E } \\
\text { INICIATIVAS DE LEY QUE } \\
\text { FAVOREZCAN EL FORTA- } \\
\text { LECIMIENTO DE LA HA- } \\
\text { CIENDA ESTATAL Y CON- } \\
\text { TRIBUYAN A DAR CUM- } \\
\text { PLIMIENTO A LAS RES- } \\
\text { PONSABILIDADES DERI- } \\
\text { VADAS DE LA ADHESIÓN } \\
\text { DEL ESTADO AL } \\
\text { SISTEMA NACIONAL DE } \\
\text { COORDINACIÓN FISCAL }\end{array}$} & $\begin{array}{l}\text { INGRESOS FEDERALES A } \\
\text { FAVOR DEL ESTADO }\end{array}$ & $\begin{array}{l}\text { ESTIMACIÓN DE } \\
\text { INGRESOS FEDE- } \\
\text { RALES A FAVOR } \\
\text { DEL ESTADO }\end{array}$ & 100 & 0 & 100 & & \\
\hline & & $\begin{array}{l}\text { ASISTENCIA A REUNIONES } \\
\text { DE LOS GRUPOS DE TRA- } \\
\text { BAJO DEL SISTEMA NA- } \\
\text { CIONAL DE COORDINA- } \\
\text { CIÓN FISCAL Y DEL CO- } \\
\text { MITÉ DE VIGILANCIA DE } \\
\text { PARTICIPACIONES }\end{array}$ & $\begin{array}{l}\text { GRUPO DE TRABA- } \\
\text { JO DEL SISTEMA } \\
\text { NACIONAL DE } \\
\text { COORDINACIÓN } \\
\text { FISCAL Y COMITÉ } \\
\text { DE VIGILANCIA DE } \\
\text { PARTICIPACIONES }\end{array}$ & 100 & 0 & 50 & & $\$ 17,895,959.00$ \\
\hline
\end{tabular}




\section{Tabla 23}

Continuación...

\begin{tabular}{|c|c|c|c|c|c|c|c|c|}
\hline $\begin{array}{l}\text { PROYECTO } \\
\text { O PROCESO }\end{array}$ & OBJETIVO & RESULTADO ESPERADO & $\begin{array}{l}\text { NOMBRE DEL IN- } \\
\text { DICADOR }\end{array}$ & $\begin{array}{l}\text { META } \\
\text { ANUAL }\end{array}$ & $\begin{array}{l}\text { MODI- } \\
\text { FICA- } \\
\text { CIÓN }\end{array}$ & $\begin{array}{l}\text { RESUL- } \\
\text { TADO }\end{array}$ & $\begin{array}{l}\text { SEMÁ- } \\
\text { FORO }\end{array}$ & $\begin{array}{l}\text { PRESUPUES- } \\
\text { TO OTORGA- } \\
\text { DO }\end{array}$ \\
\hline \multirow{2}{*}{$\begin{array}{l}\text { FORMULA- } \\
\text { CIÓN DEL } \\
\text { MARCO JU- } \\
\text { RÍDICO FIS- } \\
\text { CAL DE LOS } \\
\text { INGRESOS } \\
\text { ESTATALES }\end{array}$} & \multirow{2}{*}{$\begin{array}{l}\text { PROMOVER MEDIDAS E } \\
\text { INICIATIVAS DE LEY QUE } \\
\text { FAVOREZCAN EL FORTA- } \\
\text { LECIMIENTO DE LA HA- } \\
\text { CIENDA ESTATAL Y CON- } \\
\text { TRIBUYAN A DAR CUM- } \\
\text { PLIMIENTO A LAS RES- } \\
\text { PONSABILIDADES DERI- } \\
\text { VADAS DE LA ADHESIÓN } \\
\text { DEL ESTADO AL } \\
\text { SISTEMA NACIONAL DE } \\
\text { COORDINACIÓN FISCAL }\end{array}$} & $\begin{array}{l}\text { PARTICIPACIÓN EN LOS } \\
\text { ÓRGANOS DEL SISTEMA } \\
\text { NACIONAL DE COORDI- } \\
\text { NACIÓN FISCAL }\end{array}$ & $\begin{array}{l}\text { COORDINACIÓN } \\
\text { HACENDARIA CON } \\
\text { EL GOBIERNO FE- } \\
\text { DERAL }\end{array}$ & 100 & 0 & 87.5 & & \multirow{3}{*}{$\$ 17,895,959.00$} \\
\hline & & $\begin{array}{l}\text { INGRESOS PERCIBI- } \\
\text { DOS/INGRESOS PERCIBI- } \\
\text { DOS EN EL AÑO ANTE- } \\
\text { RIOR X100 }\end{array}$ & $\begin{array}{l}\text { SUSCRIPCIÓN DE } \\
\text { ACUERDOS EN } \\
\text { COORDINACIÓN } \\
\text { FISCAL DE MUNI- } \\
\text { CIPIOS Y FEDERA- } \\
\text { CIÓN }\end{array}$ & 100 & 0 & 100 & & \\
\hline $\begin{array}{l}\text { ATENCIÓN } \\
\text { DE ASUNTOS } \\
\text { JURÍDICOS } \\
\text { FISCALES }\end{array}$ & $\begin{array}{l}\text { REPRESENTAR Y DEFEN- } \\
\text { DER LOS INTERESES DE LA } \\
\text { HACIENDA PÚBLICA DEL } \\
\text { ESTADO CON APEGO AL } \\
\text { MARCO LEGAL APLICABLE }\end{array}$ & $\begin{array}{l}\text { PROYECTO } \\
\text { RESULTADO ESPERADO } \\
\text { DETERMINA EL CUMPLI- } \\
\text { MIENTO DE LAS ACCIO- } \\
\text { NES PROGRAMADAS }\end{array}$ & $\begin{array}{l}\text { RESOLUCIÓN DE } \\
\text { CONSULTAS }\end{array}$ & 100 & 0 & 53.33 & & \\
\hline
\end{tabular}




\section{Tabla 23}

Continuación...

\begin{tabular}{|c|c|c|c|c|c|c|c|c|}
\hline $\begin{array}{l}\text { PROYECTO } \\
\text { O PROCESO }\end{array}$ & OBJETIVO & RESULTADO ESPERADO & $\begin{array}{l}\text { NOMBRE DEL IN- } \\
\text { DICADOR }\end{array}$ & $\begin{array}{l}\text { META } \\
\text { ANUAL }\end{array}$ & $\begin{array}{l}\text { MODI- } \\
\text { FICA- } \\
\text { CIÓN }\end{array}$ & $\begin{array}{l}\text { RESUL- } \\
\text { TADO }\end{array}$ & $\begin{array}{l}\text { SEMÁ- } \\
\text { FORO }\end{array}$ & $\begin{array}{l}\text { PRESUPUES- } \\
\text { TO OTORGA- } \\
\text { DO }\end{array}$ \\
\hline \multirow{3}{*}{$\begin{array}{l}\text { ATENCIÓN } \\
\text { DE ASUNTOS } \\
\text { JURÍDICOS } \\
\text { FISCALES }\end{array}$} & \multirow{3}{*}{$\begin{array}{l}\text { REPRESENTAR Y DEFEN- } \\
\text { DER LOS INTERESES DE LA } \\
\text { HACIENDA PÚBLICA DEL } \\
\text { ESTADO CON APEGO AL } \\
\text { MARCO LEGAL APLICABLE }\end{array}$} & \multirow{3}{*}{$\begin{array}{l}\text { DETERMINA EL CUMPLI- } \\
\text { MIENTO DE LAS ACCIO- } \\
\text { NES PROGRAMADAS }\end{array}$} & $\begin{array}{l}\text { CUMPLIMENTA- } \\
\text { CIÓN DE SENTEN- } \\
\text { CIAS EMITIDAS EN } \\
\text { JUICIOS }\end{array}$ & 100 & 0 & 268.5 & & \multirow{3}{*}{$\$ 17,895,959.00$} \\
\hline & & & $\begin{array}{l}\text { RESOLUCIÓN DE } \\
\text { RECURSOS DE RE- } \\
\text { VOCACIÓN }\end{array}$ & 100 & 0 & 424 & & \\
\hline & & & $\begin{array}{l}\text { ATENCIÓN A RE- } \\
\text { QUERIMIENTOS DE } \\
\text { INFORMACIÓN Y } \\
\text { DOCUMENTACIÓN }\end{array}$ & 100 & 0 & 94.4 & & \\
\hline
\end{tabular}




\section{Tabla 23}

Continuación...

\begin{tabular}{|c|c|c|c|c|c|c|c|c|}
\hline $\begin{array}{l}\text { PROYECTO } \\
\text { O PROCESO }\end{array}$ & OBJETIVO & RESULTADO ESPERADO & $\begin{array}{l}\text { NOMBRE DEL IN- } \\
\text { DICADOR }\end{array}$ & $\begin{array}{l}\text { META } \\
\text { ANUAL }\end{array}$ & $\begin{array}{l}\text { MODI- } \\
\text { FICA- } \\
\text { CIÓN }\end{array}$ & $\begin{array}{l}\text { RESUL- } \\
\text { TADO }\end{array}$ & $\begin{array}{l}\text { SEMÁ- } \\
\text { FORO }\end{array}$ & $\begin{array}{l}\text { PRESUPUES- } \\
\text { TO OTORGA- } \\
\text { DO }\end{array}$ \\
\hline \multirow[t]{2}{*}{$\begin{array}{l}\text { ATENCIÓN } \\
\text { DE ASUNTOS } \\
\text { JURÍDICOS } \\
\text { FISCALES }\end{array}$} & \multirow[t]{2}{*}{$\begin{array}{l}\text { REPRESENTAR Y DEFEN- } \\
\text { DER LOS INTERESES DE LA } \\
\text { HACIENDA PÚBLICA DEL } \\
\text { ESTADO CON APEGO AL } \\
\text { MARCO LEGAL APLICABLE }\end{array}$} & $\begin{array}{l}\text { FORMULA Y PROPONE } \\
\text { PROYECTOS DE REFOR- } \\
\text { MAS FISCALES O ADMI- } \\
\text { NISTRATIVAS QUE PRO- } \\
\text { PORCIONEN CERTEZA } \\
\text { JURÍDICA A LOS CONTRI- } \\
\text { BUYENTES Y GENEREN } \\
\text { RESULTADOS ECONÓMI- } \\
\text { COS RELEVANTES ACOR- } \\
\text { DE A LAS POLÍTICAS } \\
\text { ESTABLECIDAS }\end{array}$ & $\begin{array}{l}\text { FORMULACIÓN DE } \\
\text { INICIATIVAS DE } \\
\text { LEYES O DECRE- } \\
\text { TOS, REGLAMEN- } \\
\text { TOS Y ACUERDOS } \\
\text { FISCALES }\end{array}$ & 100 & 0 & 240 & & \multirow[t]{2}{*}{$\$ 17,895,959.00$} \\
\hline & & $\begin{array}{l}\text { TOTAL DE INFORMES Y } \\
\text { CONTESTACIÓN DE DE- } \\
\text { MANDAS INTERPUESTAS } \\
\text { POR LOS CONTRIBUYEN- } \\
\text { TES }\end{array}$ & $\begin{array}{l}\text { INFORMES Y CON- } \\
\text { TESTACIÓN DE } \\
\text { DEMANDAS }\end{array}$ & 100 & 0 & 168.73 & & \\
\hline
\end{tabular}




\section{Tabla 23}

Continuación...

\begin{tabular}{|c|c|c|c|c|c|c|c|c|}
\hline $\begin{array}{l}\text { PROYECTO } \\
\text { O PROCESO }\end{array}$ & OBJETIVO & RESULTADO ESPERADO & $\begin{array}{l}\text { NOMBRE DEL IN- } \\
\text { DICADOR }\end{array}$ & $\begin{array}{l}\text { META } \\
\text { ANUAL }\end{array}$ & $\begin{array}{l}\text { MODI- } \\
\text { FICA- } \\
\text { CIÓN }\end{array}$ & $\begin{array}{l}\text { RESUL- } \\
\text { TADO }\end{array}$ & $\begin{array}{l}\text { SEMÁ- } \\
\text { FORO }\end{array}$ & $\begin{array}{c}\text { PRESUPUES- } \\
\text { TO OTORGA- } \\
\text { DO }\end{array}$ \\
\hline $\begin{array}{l}\text { ATENCIÓN } \\
\text { DE ASUNTOS } \\
\text { JURÍDICOS } \\
\text { FISCALES }\end{array}$ & $\begin{array}{l}\text { REPRESENTAR Y DEFEN- } \\
\text { DER LOS INTERESES DE LA } \\
\text { HACIENDA PÚBLICA DEL } \\
\text { ESTADO CON APEGO AL } \\
\text { MARCO LEGAL APLICABLE }\end{array}$ & $\begin{array}{l}\text { TOTAL DE TRÁMITES EN } \\
\text { MATERIA PENAL ANTE } \\
\text { AUTORIDADES EN LAS } \\
\text { QUE INTERVIENE EL SE- } \\
\text { CRETARIO DE HACIENDA } \\
\text { Y SUS UNIDADES }\end{array}$ & $\begin{array}{l}\text { TRÁMITES EN MA- } \\
\text { TERIA PENAL }\end{array}$ & 100 & 0 & 122 & & $\$ 17,895,959.00$ \\
\hline
\end{tabular}

Fuente: Elaboración propia en base Secretaría de Hacienda y Credito Público Sonora (2016).

\section{Programa 2: Justicia Administrativa y Laboral}

El presupuesto aprobado para ejercer los proyectos "Formulación del Marco Jurídico Fiscal de los Ingresos Estatales” y “Atención de Asuntos Jurídicos Fiscales” fue de \$17 millones de pesos. En el primer proyecto seis indicadores fueron satisfactorios (verde) (de los cuales tres rebasaron la meta anual y uno quedo por debajo de la meta anual). Además de que el indicador resolución de consultas está en riesgo (amarillo) esto se debe a que las citas solicitadas no fueron suficientes para cumplir la meta, ya que no se necesitaron casi asesorías jurídicas.

El indicador Grupo de Trabajo del Sistema Nacional de Coordinación Fiscal y Comité de Vigilancia de Participaciones esta critico (rojo), esto se debe a que 
no fueron convocadas las reuniones por el secretario de hacienda.

El segundo proyecto se cumplió satisfactoriamente rebasando la meta anual, esto es muy importante ya que es uno de los proyectos a los que debe de ponerse atención ya que es de atención jurídica fiscal. $\checkmark$ Programa 3: Modernización de la Administración y Pasión por el $\underline{\text { Servicio Público }}$

\section{Tabla 24}

Control y seguimiento administrativo de los recursos para el funcionamiento de la Secretaría de Hacienda

\begin{tabular}{|c|c|c|c|c|c|c|c|c|}
\hline $\begin{array}{c}\text { PROYECTO O } \\
\text { PROCESO }\end{array}$ & OBJETIVO & RESULTADO ESPERADO & $\begin{array}{l}\text { NOMBRE DEL } \\
\text { INDICADOR }\end{array}$ & $\begin{array}{l}\text { META } \\
\text { ANUAL }\end{array}$ & $\begin{array}{l}\text { MODIFI- } \\
\text { CACIÓN }\end{array}$ & $\begin{array}{l}\text { RESUL- } \\
\text { TADO }\end{array}$ & $\begin{array}{l}\text { SEMÁ- } \\
\text { FORO }\end{array}$ & $\begin{array}{c}\text { PRESU- } \\
\text { PUESTO } \\
\text { OTORGADO }\end{array}$ \\
\hline \multirow{2}{*}{$\begin{array}{l}\text { CONTROL Y } \\
\text { SEGUIMIENTO } \\
\text { ADMINISTRATI- } \\
\text { VO DE LOS RE- } \\
\text { CURSOS PARA } \\
\text { EL FUNCIONA- } \\
\text { MIENTO DE LA } \\
\text { SECRETARÍA DE } \\
\text { HACIENDA }\end{array}$} & \multirow{2}{*}{$\begin{array}{l}\text { ADMINISTRAR LOS RE- } \\
\text { CURSOS HUMANOS, MA- } \\
\text { TERIALES Y FINANCIE- } \\
\text { ROS DE LA SECRETARÍA } \\
\text { DE HACIENDA, ESTA- } \\
\text { BLECIENDO MECANIS- } \\
\text { MOS E INSTRUMENTOS } \\
\text { DE CONTROL QUE PER- } \\
\text { MITAN DAR CUMPLI- } \\
\text { MIENTO A POLÍTICAS, } \\
\text { NORMAS Y DISPOSICIO- } \\
\text { NES LEGALES DENTRO } \\
\text { DE LAS ATRIBUCIONES } \\
\text { QUE LE HAN SIDO CON- } \\
\text { FERIDAS }\end{array}$} & $\begin{array}{l}\text { CUMPLIMIENTO EN LA } \\
\text { PRESENTACIÓN DE LOS } \\
\text { INFORMES Y CUENTA PÚ- } \\
\text { BLICA }\end{array}$ & $\begin{array}{l}\text { COORDINAR LA } \\
\text { INTEGRACIÓN Y } \\
\text { ELABORACIÓN } \\
\text { DE INFORMES } \\
\text { TRIMESTRALES Y } \\
\text { CUENTA PÚBLI- } \\
\text { CA }\end{array}$ & 100 & 0 & 100 & & \multirow{2}{*}{$\$ 1,199,983.00$} \\
\hline & & $\begin{array}{l}\text { LLEVAR A CABO UN ADE- } \\
\text { CUADO CONTROL DEL } \\
\text { PRESUPUESTO EJERCIDO } \\
\text { Y LOS INFORMES REALI- } \\
\text { ZADOS }\end{array}$ & $\begin{array}{l}\text { INFORMES DE } \\
\text { AVANCE PRESU- } \\
\text { PUESTAL Y RE- } \\
\text { PORTES OPERA- } \\
\text { TIVOS GENERA- } \\
\text { DOS }\end{array}$ & 100 & 0 & 100 & & \\
\hline
\end{tabular}




\section{Tabla 24}

Continuación...

\begin{tabular}{|c|c|c|c|c|c|c|c|c|}
\hline $\begin{array}{l}\text { PROYECTO O } \\
\text { PROCESO }\end{array}$ & OBJETIVO & RESULTADO ESPERADO & $\begin{array}{l}\text { NOMBRE DEL } \\
\text { INDICADOR }\end{array}$ & $\begin{array}{l}\text { META } \\
\text { ANUAL }\end{array}$ & $\begin{array}{l}\text { MODIFI- } \\
\text { CACIÓN }\end{array}$ & $\begin{array}{l}\text { RESUL- } \\
\text { TADO }\end{array}$ & $\begin{array}{l}\text { SEMÁ- } \\
\text { FORO }\end{array}$ & $\begin{array}{c}\text { PRESU- } \\
\text { PUESTO } \\
\text { OTORGADO }\end{array}$ \\
\hline \multirow{3}{*}{$\begin{array}{l}\text { CONTROL Y } \\
\text { SEGUIMIENTO } \\
\text { ADMINISTRATI- } \\
\text { VO DE LOS RE- } \\
\text { CURSOS PARA } \\
\text { EL FUNCIONA- } \\
\text { MIENTO DE LA } \\
\text { SECRETARÍA DE } \\
\text { HACIENDA }\end{array}$} & \multirow{3}{*}{$\begin{array}{l}\text { ADMINISTRAR LOS RE- } \\
\text { CURSOS HUMANOS, MA- } \\
\text { TERIALES Y FINANCIE- } \\
\text { ROS DE LA SECRETARÍA } \\
\text { DE HACIENDA, ESTA- } \\
\text { BLECIENDO MECANIS- } \\
\text { MOS E INSTRUMENTOS } \\
\text { DE CONTROL QUE PER- } \\
\text { MITAN DAR CUMPLI- } \\
\text { MIENTO A POLÍTICAS, } \\
\text { NORMAS Y DISPOSICIO- } \\
\text { NES LEGALES DENTRO } \\
\text { DE LAS ATRIBUCIONES } \\
\text { QUE LE HAN SIDO CON- } \\
\text { FERIDAS }\end{array}$} & $\begin{array}{l}\text { PROVEER EN TIEMPO Y } \\
\text { FORMA LOS REQUERI- } \\
\text { MIENTOS DE LAS UNIDA- } \\
\text { DES ADMINISTRATIVAS } \\
\text { DE LA DEPENDENCIA }\end{array}$ & $\begin{array}{l}\text { REPORTE DE AD- } \\
\text { QUISICIONES Y } \\
\text { SERVICIOS REA- } \\
\text { LIZADOS }\end{array}$ & 100 & 0 & 100 & & \multirow{3}{*}{$\$ 1,199,983.00$} \\
\hline & & $\begin{array}{l}\text { QUE LOS USUARIOS DE } \\
\text { LAS UNIDADES ADMINIS- } \\
\text { TRATIVAS CUMPLAN CON } \\
\text { LA NORMATIVIDAD ES- } \\
\text { TABLECIDA EN LOS MA- } \\
\text { NUALES DE PROCEDI- } \\
\text { MIENTOS }\end{array}$ & $\begin{array}{l}\text { VERIFICACIONES } \\
\text { INTERNAS }\end{array}$ & 100 & 0 & 100 & & \\
\hline & & $\begin{array}{l}\text { QUE EL PERSONAL DE } \\
\text { BASE EVALUADO MEJORE } \\
\text { LA CALIDAD DEL SERVI- } \\
\text { CIO QUE PRESTA EN LA } \\
\text { DEPENDENCIA }\end{array}$ & $\begin{array}{l}\text { EVALUACIÓN } \\
\text { DEL DESEMPEÑO }\end{array}$ & 100 & 0 & 44.62 & & \\
\hline
\end{tabular}

Fuente: Elaboración propia en base Secretaría de Hacienda y Credito Público Sonora (2016). 
Para el proyecto "Control y seguimiento administrativo de los recursos para el funcionamiento de la Secretaría de Hacienda” (tabla 24) se otorgó un presupuesto de \$1 millón de pesos el cual está integrado por cinco indicadores, de los cuales cuatro fueron satisfactorios (verdes) y un indicador "Evaluación de desempeño" está en riesgo (rojo) con un resultado de 44.62/100, esto se debe que en el primer trimestre no se cumplieron con las evaluaciones, para los siguientes trimestres si se aplicaron las evaluaciones pero algunas no se entregaron en tiempo y forma lo que hizo que no se cumpliera la meta.

\section{Tabla 25}

Supervisión a Unidades administrativas de la Subsecretaria de Ingresos y a los Municipios con convenio de Colaboración Administrativa

\begin{tabular}{|c|c|c|c|c|c|c|c|c|}
\hline $\begin{array}{c}\text { PROYECTO O } \\
\text { PROCESO }\end{array}$ & OBJETIVO & $\begin{array}{c}\text { RESUL- } \\
\text { TADO } \\
\text { ESPERA- } \\
\text { DO }\end{array}$ & $\begin{array}{l}\text { NOMBRE } \\
\text { DEL INDI- } \\
\text { CADOR }\end{array}$ & $\begin{array}{l}\text { META } \\
\text { ANUAL }\end{array}$ & $\begin{array}{l}\text { MODI- } \\
\text { FICA- } \\
\text { CIÓN }\end{array}$ & $\begin{array}{l}\text { RE- } \\
\text { SUL- } \\
\text { TADO }\end{array}$ & $\begin{array}{l}\text { SEMÁ- } \\
\text { FORO }\end{array}$ & $\begin{array}{c}\text { PRESU- } \\
\text { PUESTO } \\
\text { OTORGADO }\end{array}$ \\
\hline $\begin{array}{l}\text { SUPERVISIÓN A } \\
\text { UNIDADES ADMI- } \\
\text { NISTRATIVAS DE } \\
\text { LA SUBSECRETA- } \\
\text { RIA DE INGRESOS } \\
\text { Y A LOS MUNICI- } \\
\text { PIOS CON CONVE- } \\
\text { NIO DE } \\
\text { COLABORACIÓN } \\
\text { ADMINISTRATIVA }\end{array}$ & $\begin{array}{l}\text { SUPERVISAR EL CUMPLIMIENTO DE LAS OBLI- } \\
\text { GACIONES A CARGO DE LAS UNIDADES ADMI- } \\
\text { NISTRATIVAS DE LA SUBSECRETARIA DE IN- } \\
\text { GRESOS, DERIVADAS DE LOS CONVENIOS O } \\
\text { ACUERDOS DE COORDINACIÓN CELEBRADOS } \\
\text { ENTRE EL GOBIERNO DEL ESTADO Y LA SE- } \\
\text { CRETARIA DE HACIENDA Y CRÉDITO PÚBLICO } \\
\text { EN MATERIA FISCAL FEDERAL O CON LOS MU- } \\
\text { NICIPIOS DEL ESTADO EN MATERIA FISCAL } \\
\text { ESTATAL }\end{array}$ & $100 \%$ & $\begin{array}{l}\text { ÍNDICE DE } \\
\text { CUMPLI- } \\
\text { MIENTO DEL } \\
\text { PROGRAMA } \\
\text { DE SUPERVI- } \\
\text { SIONES }\end{array}$ & 100 & 0 & 66.67 & & $\$ 8,205,702.00$ \\
\hline
\end{tabular}

Fuente: Elaboración propia en base Secretaría de Hacienda y Credito Público Sonora (2016). 
Para el proyecto "Supervisión a Unidades administrativas de la Subsecretaría de Ingresos y a los Municipios con convenio de Colaboración Administrativa” (tabla 25) se tiene un presupuesto otorgado de \$8 millones de pesos el cual no se está ejerciendo como se debería ya que está en riesgo (amarillo) esto se debe a que no se llevaron a cabo las revisiones que se tenían contempladas desde un principio esto fue por carga de trabajo y mala administración de las revisiones.

\section{Tabla 26}

Operación correcta del sistema integral de información y administración financiera

\begin{tabular}{|c|c|c|c|c|c|c|c|c|}
\hline $\begin{array}{l}\text { PROYECTO O } \\
\text { PROCESO }\end{array}$ & OBJETIVO & RESULTADO ESPERADO & $\begin{array}{l}\text { NOMBRE DEL INDI- } \\
\text { CADOR }\end{array}$ & $\begin{array}{l}\text { META } \\
\text { ANUAL }\end{array}$ & $\begin{array}{l}\text { MODI- } \\
\text { FICA- } \\
\text { CIÓN }\end{array}$ & $\begin{array}{l}\text { RE- } \\
\text { SUL- } \\
\text { TADO }\end{array}$ & $\begin{array}{l}\text { SEMÁ- } \\
\text { FORO }\end{array}$ & $\begin{array}{l}\text { PRESUPUESTO } \\
\text { OTORGADO }\end{array}$ \\
\hline \multirow{3}{*}{$\begin{array}{l}\text { OPERACION } \\
\text { CORRECTA } \\
\text { DEL SISTEMA } \\
\text { INTEGRAL DE } \\
\text { INFORMACION } \\
\text { Y ADMINIS- } \\
\text { TRACION FI- } \\
\text { NANCIERA }\end{array}$} & \multirow{3}{*}{$\begin{array}{l}\text { GARANTIZAR EL CUM- } \\
\text { PLIMIENTO A LOS LI- } \\
\text { NEAMIENTOS Y POLÍ- } \\
\text { TICAS EN MATERIA DE } \\
\text { ADMINISTRACIÓN FI- } \\
\text { NANCIERA DEL GO- } \\
\text { BIERNO DEL ESTADO } \\
\text { DE SONORA, A TRAVÉS } \\
\text { DEL SISTEMA INTE- } \\
\text { GRAL DE INFORMA- } \\
\text { CIÓN Y ADMINISTRA- } \\
\text { CIÓN FINANCIERA A } \\
\text { FIN DE GARANTIZAR } \\
\text { LA CORRECTA OPERA- } \\
\text { CIÓN DEL MISMO }\end{array}$} & $\begin{array}{l}\text { DOCUMENTAR EL HIS- } \\
\text { TORIAL DE LOS MOVI- } \\
\text { MIENTOS EFECTUADOS } \\
\text { EN EL SISTEMA PARA } \\
\text { UNA MEJORA CONTINUA }\end{array}$ & $\begin{array}{l}\text { NUMERO DE PRUEBAS } \\
\text { DE SOFTWARE }\end{array}$ & 100 & 0 & 338.75 & & \multirow{3}{*}{$\$ 289,284,033.00$} \\
\hline & & $\begin{array}{l}\text { QUE EL USUARIO CUM- } \\
\text { PLA EN TIEMPO Y FOR- } \\
\text { MA CON SUS FUNCIONES }\end{array}$ & $\begin{array}{l}\text { SOLICITUDES DE SO- } \\
\text { PORTE TECNICO } \\
\text { (USUARIOS GOBIERNO, } \\
\text { CONTRIBUYENTE Y } \\
\text { PROVEEDORES) }\end{array}$ & 100 & 0 & 148.07 & & \\
\hline & & $\begin{array}{l}\text { CORRECTA OPERACION } \\
\text { DEL SISTEMA }\end{array}$ & $\begin{array}{l}\text { MOVIMIENTOS DE } \\
\text { USUARIOS DE SIIAF }\end{array}$ & 100 & 0 & 203.8 & & \\
\hline
\end{tabular}




\section{Tabla 26}

Continuación...

\begin{tabular}{|c|c|c|c|c|c|c|c|c|}
\hline $\begin{array}{l}\text { PROYECTO O } \\
\text { PROCESO }\end{array}$ & OBJETIVO & RESULTADO ESPERADO & $\begin{array}{l}\text { NOMBRE DEL INDI- } \\
\text { CADOR }\end{array}$ & $\begin{array}{l}\text { META } \\
\text { ANUAL }\end{array}$ & $\begin{array}{l}\text { MODI- } \\
\text { FICA- } \\
\text { CIÓN }\end{array}$ & $\begin{array}{l}\text { RE- } \\
\text { SUL- } \\
\text { TADO }\end{array}$ & $\begin{array}{l}\text { SEMÁ- } \\
\text { FORO }\end{array}$ & $\begin{array}{l}\text { PRESUPUESTO } \\
\text { OTORGADO }\end{array}$ \\
\hline \multirow{4}{*}{$\begin{array}{l}\text { OPERACION } \\
\text { CORRECTA } \\
\text { DEL SISTEMA } \\
\text { INTEGRAL DE } \\
\text { INFORMACION } \\
\text { Y ADMINIS- } \\
\text { TRACION FI- } \\
\text { NANCIERA }\end{array}$} & \multirow{4}{*}{$\begin{array}{l}\text { GARANTIZAR EL CUM- } \\
\text { PLIMIENTO A LOS LI- } \\
\text { NEAMIENTOS Y POLÍ- } \\
\text { TICAS EN MATERIA DE } \\
\text { ADMINISTRACIÓN FI- } \\
\text { NANCIERA DEL GO- } \\
\text { BIERNO DEL ESTADO } \\
\text { DE SONORA, A TRAVÉS } \\
\text { DEL SISTEMA INTE- } \\
\text { GRAL DE INFORMA- } \\
\text { CIÓN Y ADMINISTRA- } \\
\text { CIÓN FINANCIERA A } \\
\text { FIN DE GARANTIZAR } \\
\text { LA CORRECTA OPERA- } \\
\text { CIÓN DEL MISMO }\end{array}$} & $\begin{array}{l}\text { USUARIOS CON AMPLIO } \\
\text { CONOCIMIENTO SOBRE } \\
\text { USO DEL SISTEMA }\end{array}$ & $\begin{array}{l}\text { NUMERO CAPACITA- } \\
\text { CION A USUARIOS }\end{array}$ & 100 & 0 & 137.32 & & \multirow{4}{*}{$\$ 289,284,033.00$} \\
\hline & & $\begin{array}{l}\text { DOCUMENTAR EL HIS- } \\
\text { TORIAL DE LOS MOVI- } \\
\text { MIENTOS REALIZADOS } \\
\text { EN EL SISTEMA PARA } \\
\text { UNA MEJORA CONTINUA }\end{array}$ & $\begin{array}{l}\text { NUMERO DE LIBERA- } \\
\text { CIONES }\end{array}$ & 100 & 0 & 8280.39 & & \\
\hline & & $\begin{array}{l}\text { PROPORCIONAR AL } \\
\text { USUARIO UNA HERRA- } \\
\text { MIENTA SENCILLA Y DE } \\
\text { FACIL MANEJO }\end{array}$ & $\begin{array}{l}\text { REPORTES DE LAS AC- } \\
\text { TUALIZACIONES DE } \\
\text { LOS SISTEMAS ELEC- } \\
\text { TRONICOS }\end{array}$ & 100 & 0 & 75.89 & & \\
\hline & & $\begin{array}{l}\text { FACILITAR EL TRABAJO } \\
\text { DIARIO Y ATENCION AL } \\
\text { CONTRIBUYENTE }\end{array}$ & $\begin{array}{l}\text { NUMERO DE USUARIOS } \\
\text { WEB }\end{array}$ & 100 & 0 & 87.15 & & \\
\hline
\end{tabular}




\section{Tabla 26}

Continuación...

\begin{tabular}{|c|c|c|c|c|c|c|c|c|}
\hline $\begin{array}{l}\text { PROYECTO O } \\
\text { PROCESO }\end{array}$ & OBJETIVO & RESULTADO ESPERADO & $\begin{array}{l}\text { NOMBRE DEL INDI- } \\
\text { CADOR }\end{array}$ & $\begin{array}{l}\text { META } \\
\text { ANUAL }\end{array}$ & $\begin{array}{l}\text { MODI- } \\
\text { FICA- } \\
\text { CIÓN }\end{array}$ & $\begin{array}{c}\text { RE- } \\
\text { SUL- } \\
\text { TADO }\end{array}$ & $\begin{array}{l}\text { SEMÁ- } \\
\text { FORO }\end{array}$ & $\begin{array}{l}\text { PRESUPUESTO } \\
\text { OTORGADO }\end{array}$ \\
\hline $\begin{array}{l}\text { OPERACION } \\
\text { CORRECTA } \\
\text { DEL SISTEMA } \\
\text { INTEGRAL DE } \\
\text { INFORMACION } \\
\text { Y ADMINIS- } \\
\text { TRACION FI- } \\
\text { NANCIERA }\end{array}$ & $\begin{array}{l}\text { GARANTIZAR EL CUM- } \\
\text { PLIMIENTO A LOS LI- } \\
\text { NEAMIENTOS Y POLÍ- } \\
\text { TICAS EN MATERIA DE } \\
\text { ADMINISTRACIÓN FI- } \\
\text { NANCIERA DEL GO- } \\
\text { BIERNO DEL ESTADO } \\
\text { DE SONORA, A TRAVÉS } \\
\text { DEL SISTEMA INTE- } \\
\text { GRAL DE INFORMA- } \\
\text { CIÓN Y ADMINISTRA- } \\
\text { CIÓN FINANCIERA A } \\
\text { FIN DE GARANTIZAR } \\
\text { LA CORRECTA OPERA- } \\
\text { CIÓN DEL MISMO }\end{array}$ & $\begin{array}{l}\text { PARA EL COBRO DE IM- } \\
\text { PUESTOS Y DERECHOS } \\
\text { QUE COMPETAN AL GO- } \\
\text { BIERNO DEL ESTADO DE } \\
\text { SONORA Y DE ESTA MA- } \\
\text { NERA TENER UNA RE- } \\
\text { CAUDACION MAS AGIL }\end{array}$ & $\begin{array}{l}\text { NUMERO DE PROYEC- } \\
\text { TOS WEB }\end{array}$ & 100 & 0 & 0 & & $\$ 289,284,033.00$ \\
\hline
\end{tabular}

Fuente: Elaboración propia en base Secretaría de Hacienda y Credito Público Sonora (2016). 
El presupuesto aprobado para este proyecto "Operación correcta del sistema integral de información y administración financiera” (tabla 26) es de \$289 millones de pesos el proyecto tiene ocho indicadores de los cuales seis si cumplieron, cinco rebasando el 100\% y 1 al 87.15/100. El indicador "reportes de las actualizaciones de los sistemas electrónicos” está en riesgo (Amarillo) esto es porque algunos servidores se dieron de baja y otros reportes no se pudieron realizar porque las plataformas estaban en mantenimiento.

El indicador “número de proyectos web” está en estado crítico (Rojo) esto es por la implementación de sistema contable e incorporación de nuevas tecnologías, lo que afecta y hace que no se cumpla con las metas.

\section{Tabla 27}

Inteligencia e investigación para la prevención de delitos fiscales

\begin{tabular}{|c|c|c|c|c|c|c|c|c|}
\hline $\begin{array}{l}\text { PROYECTO O } \\
\text { PROCESO }\end{array}$ & OBJETIVO & $\begin{array}{l}\text { RESULTADO ES- } \\
\text { PERADO }\end{array}$ & NOMBRE DEL INDICADOR & $\begin{array}{l}\text { META } \\
\text { ANUAL }\end{array}$ & $\begin{array}{l}\text { MODI- } \\
\text { FICA- } \\
\text { CIÓN }\end{array}$ & $\begin{array}{l}\text { RE- } \\
\text { SUL- } \\
\text { TADO }\end{array}$ & $\begin{array}{l}\text { SE- } \\
\text { MÁ- } \\
\text { FO- } \\
\text { RO }\end{array}$ & $\begin{array}{c}\text { PRESUPUES- } \\
\text { TO OTORGA- } \\
\text { DO }\end{array}$ \\
\hline \multirow{2}{*}{$\begin{array}{l}\text { INTELIGENCIA } \\
\text { E INVESTIGA- } \\
\text { CIÓN PARA LA } \\
\text { PREVENCIÓN } \\
\text { DE DELITOS } \\
\text { FISCALES }\end{array}$} & \multirow{2}{*}{$\begin{array}{l}\text { CONTRIBUIR A } \\
\text { REDUCIR LOS DE- } \\
\text { LITOS CON RE- } \\
\text { CURSOS DE PRO- } \\
\text { CEDENCIA ILÍCITA, } \\
\text { MEDIANTE LA GE- } \\
\text { NERACIÓN Y ANÁ- } \\
\text { LISIS DE INFOR- } \\
\text { MACIÓN RELE- } \\
\text { VANTE SOBRE } \\
\text { ESTE TEMA }\end{array}$} & $\begin{array}{l}\text { DISMINUCIÓN DE } \\
\text { OPERACIONES } \\
\text { CON RECURSOS DE } \\
\text { PROCEDENCIA } \\
\text { ILÍCITA EN EL ES- } \\
\text { TADO DE SONORA }\end{array}$ & $\begin{array}{l}\text { ÍNDICE DE CUMPLIMIENTO EN LA } \\
\text { ELABORACIÓN DEL INFORME ES- } \\
\text { TADÍSTICO SEMESTRAL DE LA } \\
\text { UNIDAD DE INTELIGENCIA PATRI- } \\
\text { MONIAL Y ECONÓMICA DEL ESTA- } \\
\text { DO DE SONORA }\end{array}$ & 100 & 0 & 0 & & \multirow[t]{2}{*}{$\$ 21,215,762.00$} \\
\hline & & $\begin{array}{l}\text { CUMPLIMIENTO } \\
\text { AL 100\% DEL PRO- } \\
\text { GRAMA }\end{array}$ & $\begin{array}{l}\text { ÍNDICE DE CUMPLIMIENTO EN LA } \\
\text { ELABORACIÓN DEL REPORTE TRI- } \\
\text { MESTRAL DE ACTIVIDADES }\end{array}$ & 100 & 0 & 100 & & \\
\hline
\end{tabular}




\section{Tabla 27}

Continuación...

\begin{tabular}{|c|c|c|c|c|c|c|c|c|}
\hline $\begin{array}{c}\text { PROYECTO O } \\
\text { PROCESO }\end{array}$ & OBJETIVO & $\begin{array}{l}\text { RESULTADO ES- } \\
\text { PERADO }\end{array}$ & NOMBRE DEL INDICADOR & $\begin{array}{r}\text { META } \\
\text { ANUAL }\end{array}$ & $\begin{array}{l}\text { MODI- } \\
\text { FICA- } \\
\text { CIÓN }\end{array}$ & $\begin{array}{l}\text { RE- } \\
\text { SUL- } \\
\text { TADO }\end{array}$ & $\begin{array}{l}\text { SE- } \\
\text { MÁ- } \\
\text { FO- } \\
\text { RO }\end{array}$ & $\begin{array}{l}\text { PRESUPUES- } \\
\text { TO OTORGA- } \\
\text { DO }\end{array}$ \\
\hline $\begin{array}{l}\text { INTELIGENCIA } \\
\text { E INVESTIGA- } \\
\text { CIÓN PARA LA } \\
\text { PREVENCIÓN } \\
\text { DE DELITOS } \\
\text { FISCALES }\end{array}$ & $\begin{array}{l}\text { CONTRIBUIR A } \\
\text { REDUCIR LOS DE- } \\
\text { LITOS CON RE- } \\
\text { CURSOS DE PRO- } \\
\text { CEDENCIA ILÍCITA, } \\
\text { MEDIANTE LA GE- } \\
\text { NERACIÓN Y ANÁ- } \\
\text { LISIS DE INFOR- } \\
\text { MACIÓN RELE- } \\
\text { VANTE SOBRE } \\
\text { ESTE TEMA }\end{array}$ & $\begin{array}{l}\text { ASISTIR AL TOTAL } \\
\text { DE EVENTOS PRO- } \\
\text { GRAMADOS }\end{array}$ & $\begin{array}{l}\text { ÍNDICE DE CUMPLIMIENTO DE } \\
\text { ASISTENCIA A CURSOS DE CAPA- } \\
\text { CITACIÓN E INTERCAMBIO DE IN- } \\
\text { FORMACIÓN INSTITUCIONAL }\end{array}$ & 100 & 0 & 0 & & $\$ 21,215,762.00$ \\
\hline
\end{tabular}




\section{Tabla 27}

Continuación...

\begin{tabular}{|c|c|c|c|c|c|c|c|c|}
\hline $\begin{array}{l}\text { PROYECTO O } \\
\text { PROCESO }\end{array}$ & OBJETIVO & $\begin{array}{l}\text { RESULTADO ES- } \\
\text { PERADO }\end{array}$ & NOMBRE DEL INDICADOR & $\begin{array}{l}\text { META } \\
\text { ANUAL }\end{array}$ & $\begin{array}{l}\text { MODI- } \\
\text { FICA- } \\
\text { CIÓN }\end{array}$ & $\begin{array}{l}\text { RE- } \\
\text { SUL- } \\
\text { TADO }\end{array}$ & $\begin{array}{l}\text { SE- } \\
\text { MÁ- } \\
\text { FO- } \\
\text { RO }\end{array}$ & $\begin{array}{l}\text { PRESUPUES- } \\
\text { TO OTORGA- } \\
\text { DO }\end{array}$ \\
\hline $\begin{array}{l}\text { INTELIGENCIA } \\
\text { E INVESTIGA- } \\
\text { CIÓN PARA LA } \\
\text { PREVENCIÓN } \\
\text { DE DELITOS } \\
\text { FISCALES }\end{array}$ & $\begin{array}{l}\text { CONTRIBUIR A } \\
\text { REDUCIR LOS DE- } \\
\text { LITOS CON RE- } \\
\text { CURSOS DE PRO- } \\
\text { CEDENCIA ILÍCITA, } \\
\text { MEDIANTE LA GE- } \\
\text { NERACIÓN Y ANÁ- } \\
\text { LISIS DE INFOR- } \\
\text { MACIÓN RELE- } \\
\text { VANTE SOBRE } \\
\text { ESTE TEMA }\end{array}$ & $\begin{array}{l}\text { ASISTIR AL TOTAL } \\
\text { DE EVENTOS PRO- } \\
\text { GRAMADOS }\end{array}$ & $\begin{array}{l}\text { ÍNDICE DE CUMPLIMIENTO DE } \\
\text { ASISTENCIA A CURSOS DE CAPA- } \\
\text { CITACIÓN E INTERCAMBIO DE IN- } \\
\text { FORMACIÓN INSTITUCIONAL }\end{array}$ & 100 & 0 & 0 & & $\$ 21,215,762.00$ \\
\hline
\end{tabular}

Fuente: Elaboración propia en base Secretaría de Hacienda y Credito Público Sonora (2016). 


\section{$\checkmark \quad$ Programa 4: Seguridad Pública}

El presupuesto otorgado para el proyecto "Inteligencia e investigación para la prevención de delitos fiscales” (tabla 27) fue de \$21 millones de pesos el cual no se está ejerciendo como se debería, ya que no se están cumpliendo las metas que se establecieron, esto afecta, ya que el programa de seguridad es muy importante. De tres indicadores que tiene el programa únicamente fue satisfactorio (verde) "Índice de cumplimiento en la elaboración del Reporte Trimestral de Actividades”, los otros dos están en riesgo (rojo) por lo siguiente:

Indicador “Índice de cumplimiento en la elaboración del Informe estadístico semestral de la Unidad de Inteligencia Patrimonial y Económica del Estado de Sonora" no se cumplió por que se iba a contratar nuevo personal por lo tanto no tenían información suficiente como para tener estadísticas.

Indicador "Índice de cumplimiento de asistencia a Cursos de Capacitación e Intercambio de Información Institucional” La meta no pudo cumplirse en virtud de que no se autorizaron los recursos para pagar los cursos o por la entrega/recepción o cambio de nueva administración no se pudo asistir a los cursos de capacitación, por esos motivos no se cumplió con la meta. 


\section{Tabla 28}

Registro y control de caja y tesorería 1

\begin{tabular}{|c|c|c|c|c|c|c|c|c|}
\hline $\begin{array}{c}\text { PROYECTO } \\
\text { O PROCE- } \\
\text { SO }\end{array}$ & OBJETIVO & $\begin{array}{l}\text { RESULTADO ESPE- } \\
\text { RADO }\end{array}$ & $\begin{array}{c}\text { NOMBRE DEL INDI- } \\
\text { CADOR }\end{array}$ & $\begin{array}{r}\text { META } \\
\text { ANUAL }\end{array}$ & $\begin{array}{l}\text { MO- } \\
\text { DIIFI- } \\
\text { CA- } \\
\text { CIÓN }\end{array}$ & $\begin{array}{c}\text { RE- } \\
\text { SUL- } \\
\text { TA- } \\
\text { DO }\end{array}$ & $\begin{array}{l}\text { SE- } \\
\text { MÁ- } \\
\text { FO- } \\
\text { RO }\end{array}$ & $\begin{array}{l}\text { PRESUPUESTO } \\
\text { OTORGADO }\end{array}$ \\
\hline $\begin{array}{l}\text { REGISTRO } \\
\text { Y CONTROL } \\
\text { DE CAJA Y } \\
\text { TESORERIA }\end{array}$ & $\begin{array}{l}\text { PROPORCIONAR LOS MEDIOS PARA } \\
\text { UNA ADECUADA DISPONIBILIDAD } \\
\text { Y CUSTODIA EN LOS FONDOS PÚ- } \\
\text { BLICOS CON EL FIN DE CONTRI- } \\
\text { BUIR A UNA MAYOR LIQUIDEZ EN } \\
\text { OPERACIONES ADMINISTRATIVAS } \\
\text { DIARIAMENTE. } \\
\text { 2.- IMPULSAR } \\
\text { LA MEJORA CONTINUA DE LOS } \\
\text { PROCESOS EN REVISIÓN Y VALI- } \\
\text { DACIÓN, IDENTIFICANDO MÉTO- } \\
\text { DOS QUE AYUDEN A ALCANZAR } \\
\text { UNA MEJOR DISTRIBUCIÓN EN } \\
\text { TIEMPO MAXIMIZANDO EL REN- } \\
\text { DIMIENTO ADMINISTRATIVO Y } \\
\text { MINIMIZANDO EL COSTE PARA } \\
\text { CON EL CONTRIBUYENTE }\end{array}$ & $\begin{array}{l}\text { LOGRAR LA VALIDA- } \\
\text { CIÓN DEL } 100 \% \text { DE } \\
\text { ORDENES DE PAGO } \\
\text { PRESENTADAS POR } \\
\text { LAS DEPENDENCIAS } \\
\text { Y QUE CUMPLAN CON } \\
\text { LA NORMATIVIDAD } \\
\text { CORRESPONDIENTE }\end{array}$ & $\begin{array}{l}\text { INDICE DE VALIDA- } \\
\text { CIÓN DE ORDENES DE } \\
\text { PAGO EMITIDAS POR } \\
\text { LAS DIFERENTES DE- } \\
\text { PENDENCIAS DE GO- } \\
\text { BIERNO }\end{array}$ & 100 & 0 & 100 & & $\$ 104,059,498.00$ \\
\hline
\end{tabular}

Fuente: Elaboración propia en base Secretaría de Hacienda y Credito Público Sonora (2016). 
$\checkmark \quad$ Programa 5: Administración de las Finanzas Públicas

El presupuesto aprobado para este proyecto "registro y control de caja y tesorería” (tabla 28) es de \$104 millones de pesos. El Resultado de este indicador cumplió al 100\% respecto a la Meta programada para 2015.

\section{Tabla 29}

Registro y control de caja y tesorería 2

\begin{tabular}{|c|c|c|c|c|c|c|c|c|}
\hline $\begin{array}{l}\text { PROYECTO } \\
\text { O PROCESO }\end{array}$ & OBJETIVO & RESULTADO ESPERADO & NOMBRE DEL INDICADOR & $\begin{array}{l}\text { META } \\
\text { ANUAL }\end{array}$ & $\begin{array}{l}\text { MODI- } \\
\text { FICA- } \\
\text { CIÓN }\end{array}$ & $\begin{array}{l}\text { RE- } \\
\text { SUL- } \\
\text { TADO }\end{array}$ & $\begin{array}{l}\text { SEMÁ- } \\
\text { FORO }\end{array}$ & $\begin{array}{l}\text { PRESUPUES- } \\
\text { TO OTORGA- } \\
\text { DO }\end{array}$ \\
\hline \multirow{2}{*}{$\begin{array}{l}\text { REGISTRO Y } \\
\text { CONTROL DE } \\
\text { CAJA Y TE- } \\
\text { SORERIA }\end{array}$} & \multirow{2}{*}{$\begin{array}{l}\text { CONTRO- } \\
\text { LAR Y SU- } \\
\text { PERVISAR } \\
\text { EL PAGO } \\
\text { DEL GASTO } \\
\text { PUBLICO }\end{array}$} & $\begin{array}{l}\text { CUBRIR EL PAGO TOTAL DE OR- } \\
\text { DENES DE PAGO PROGRAMADAS }\end{array}$ & $\begin{array}{l}\text { INDICE DE EFICIENCIA EN } \\
\text { EL PAGO DE ORDENES DE } \\
\text { PAGO }\end{array}$ & 100 & 0 & 78.85 & & \multirow[b]{2}{*}{$\$ 16,361,920.00$} \\
\hline & & $\begin{array}{l}\text { GARANTIZAR DISPONIBILIDAD DE } \\
\text { LIQUIDEZ PARA LA OPERACIÓN DE } \\
\text { LOS PROGRAMAS DE GOBIERNO }\end{array}$ & $\begin{array}{l}\text { REPORTE DE CONCILIA- } \\
\text { CIONES BANCARIAS DE LAS } \\
\text { CUENTAS DE CHEQUE A } \\
\text { NOMBRE DEL GOBIERNO } \\
\text { DEL ESTADO DE SONORA }\end{array}$ & 100 & 0 & 100 & & \\
\hline
\end{tabular}

Fuente: Elaboración propia en base Secretaría de Hacienda y Credito Público Sonora (2016). 
El presupuesto aprobado para este proyecto "Registro y control de caja y tesorería” (tabla 29) es de \$16 millones de pesos. El proyecto tiene dos indicadores, de los cuales uno si se cumplió de acuerdo a la meta establecida.
El otro no alcanzo la meta establecida quedando en estado crítico (amarillo) debido a que no hay eficiencia, ni pago.

\section{Tabla 30}

Administración de la Deuda Pública

\begin{tabular}{|c|c|c|c|c|c|c|c|c|}
\hline $\begin{array}{l}\text { PROYECTO O } \\
\text { PROCESO }\end{array}$ & OBJETIVO & RESULTADO ESPERADO & $\begin{array}{l}\text { NOMBRE DEL INDI- } \\
\text { CADOR }\end{array}$ & $\begin{array}{l}\text { META } \\
\text { ANUAL }\end{array}$ & $\begin{array}{l}\text { MODI- } \\
\text { FICA- } \\
\text { CIÓN }\end{array}$ & $\begin{array}{c}\text { RE- } \\
\text { SUL- } \\
\text { TADO }\end{array}$ & $\begin{array}{l}\text { SEMÁ- } \\
\text { FORO }\end{array}$ & $\begin{array}{l}\text { PRESUPUESTO } \\
\text { OTORGADO }\end{array}$ \\
\hline \multirow{3}{*}{$\begin{array}{l}\text { ADMINISTRA- } \\
\text { CIÓN DE LA } \\
\text { DEUDA PÚBLICA }\end{array}$} & \multirow{3}{*}{$\begin{array}{l}\text { DISMINUCIÓN } \\
\text { DEL MONTO } \\
\text { DE LA DEUDA } \\
\text { PÚBLICA }\end{array}$} & $\begin{array}{l}\text { DISMINUCIÓN DE LA DEUDA } \\
\text { PÚBLICA }\end{array}$ & $\begin{array}{l}\text { CARGA DE LA DEUDA } \\
\text { TOTAL }\end{array}$ & 100 & 0 & 118.49 & & \multirow{3}{*}{$\$ 6,484,217,587.00$} \\
\hline & & $\begin{array}{l}\text { INCREMENTAR LA TRANSPA- } \\
\text { RENCIA DE LAS FINANZAS } \\
\text { PÚBLICAS }\end{array}$ & $\begin{array}{l}\text { ÍNDICE DE REGISTRO } \\
\text { DE LOS CONTRATOS } \\
\text { DE CRÉDITO }\end{array}$ & 100 & 0 & 183.33 & & \\
\hline & & $\begin{array}{l}\text { MEJORAR LA CALIFICACIÓN } \\
\text { CREDITICIA POR PARTE DE } \\
\text { LAS AGENCIAS CALIFICADO- } \\
\text { RAS AL ESTADO DE SONORA }\end{array}$ & $\begin{array}{l}\text { VARIACIÓN ANUAL } \\
\text { DEL ÍNDICE DE CALI- } \\
\text { FICACIÓN CREDITICIA } \\
\text { DEL ESTADO DE SO- } \\
\text { NORA }\end{array}$ & 100 & 0 & 100 & & \\
\hline
\end{tabular}

Fuente: Elaboración propia en base Secretaría de Hacienda y Credito Público Sonora (2016). 
El presupuesto aprobado para este proyecto "Administración de la Deuda Pública” (tabla 30) es de \$6, 484 millones de pesos. El Resultado de este indicador fue muy bueno ya que rebaso el $100 \%$ de lo programado respecto a 2015.

$\checkmark \quad$ Programa 6: Consolidación de la Gestión Pública Para Resultados

\section{Tabla 31}

Participar en la vigilancia del cumplimiento de observaciones de entes fiscalizados y actos fiscalizados por disposiciones legales

\begin{tabular}{|c|c|c|c|c|c|c|c|c|}
\hline $\begin{array}{c}\text { PROYECTO O PROCE- } \\
\text { SO }\end{array}$ & OBJETIVO & $\begin{array}{l}\text { RESULTADO } \\
\text { ESPERADO }\end{array}$ & $\begin{array}{l}\text { NOMBRE DEL } \\
\text { INDICADOR }\end{array}$ & $\begin{array}{l}\text { META } \\
\text { ANUAL }\end{array}$ & $\begin{array}{l}\text { MODI- } \\
\text { FICA- } \\
\text { CIÓN }\end{array}$ & $\begin{array}{c}\text { RE- } \\
\text { SUL- } \\
\text { TADO }\end{array}$ & $\begin{array}{l}\text { SEMÁ- } \\
\text { FORO }\end{array}$ & $\begin{array}{c}\text { PRESU- } \\
\text { PUESTO } \\
\text { OTORGADO }\end{array}$ \\
\hline $\begin{array}{l}\text { PARTICIPAR EN LA VI- } \\
\text { GILANCIA DEL CUM- } \\
\text { PLIMIENTO DE OBSER- } \\
\text { VACIONES DE ENTES } \\
\text { FISCALIZADOS Y AC- } \\
\text { TOS FISCALIZADOS POR } \\
\text { DISPOSICIONES LEGA- } \\
\text { LES }\end{array}$ & $\begin{array}{l}\text { VIGILAR ACCIONES DE LOS } \\
\text { ÓRGANOS FISCALIZADOS, } \\
\text { ASESORAR, PROPONER Y OPI- } \\
\text { NAR CON EL FIN DE COADYU- } \\
\text { VAR EN LA SOLVENTACIÓN DE } \\
\text { OBSERVACIONES POR PARTE } \\
\text { DE LAS UNIDADES ADMINIS- } \\
\text { TRATIVAS }\end{array}$ & $\begin{array}{l}\text { CUMPLIMIENTO } \\
\text { DE SOLVENTA- } \\
\text { CIÓN DE OBSER- } \\
\text { VACIONES POR } \\
\text { PARTE DE LAS } \\
\text { UNIDADES AD- } \\
\text { MINISTRATIVAS }\end{array}$ & $\begin{array}{l}\text { ÍNDICE DE CO- } \\
\text { BERTURA EN LA } \\
\text { SOLVENTACIÓN } \\
\text { DE OBSERVA- } \\
\text { CIONES }\end{array}$ & 100 & 0 & 71.43 & & $\$ 1,171,730.00$ \\
\hline
\end{tabular}

Fuente: Elaboración propia en base Secretaría de Hacienda y Credito Público Sonora (2016). 
El presupuesto aprobado para este proyecto "Participar en la vigilancia del cumplimiento de observaciones de entes fiscalizados y actos fiscalizados por disposiciones legales” (tabla 31) es de \$1 millón. El Resultado de este indicador No Alcanzó el 100\% respecto a la meta anual, según los resultados informados trimestralmente en el ejercicio 2015 debido a que en el último trimestre no hubo avances para solventar las observaciones además de que en el primer trimestre se dará de baja una meta porque una observación es improcedente.

El presupuesto de \$5,534 millones de pesos se otorga a 8 proyectos de 3 programas diferentes:

El proyecto Modernización de la Administración y Pasión por el Servicio Público y Administración de las Finanzas Públicas (tabla 32) cumplen sus metas al $100 \%$.

\section{Tabla 32}

Modernización de la Administración y Pasión por el Servicio Público; administración de las Finanzas públicas y Sonora competitivo

\begin{tabular}{|c|c|c|c|c|c|c|c|c|c|}
\hline & $\begin{array}{c}\text { PROYECTO O } \\
\text { PROCESO }\end{array}$ & OBJETIVO & $\begin{array}{l}\text { RESULTA- } \\
\text { DO ESPE- } \\
\text { RADO }\end{array}$ & $\begin{array}{l}\text { NOMBRE DEL } \\
\text { INDICADOR }\end{array}$ & $\begin{array}{l}\text { META } \\
\text { ANUAL }\end{array}$ & $\begin{array}{l}\text { MODI- } \\
\text { FICA- } \\
\text { CIÓN }\end{array}$ & $\begin{array}{l}\text { RE- } \\
\text { SUL- } \\
\text { TADO }\end{array}$ & $\begin{array}{l}\text { SEMÁ- } \\
\text { FORO }\end{array}$ & $\begin{array}{c}\text { PRESUPUESTO } \\
\text { OTORGADO }\end{array}$ \\
\hline $\begin{array}{l}\text { MO- } \\
\text { DERNI- } \\
\text { ZACIÓN } \\
\text { DE LA } \\
\text { ADMI- } \\
\text { NISTRA- } \\
\text { CIÓN Y } \\
\text { PASIÓN } \\
\text { POR EL } \\
\text { SERVI- } \\
\text { CIO PU- } \\
\text { BLICO }\end{array}$ & $\begin{array}{l}\text { OPTIMIZAR LOS } \\
\text { REGISTROS DE } \\
\text { LAS OPERACIO- } \\
\text { NES FINANCIE- } \\
\text { RAS QUE REALI- } \\
\text { ZA EL GOBIERNO } \\
\text { DEL ESTADO } \\
\text { PARA OBTENER } \\
\text { ESTADOS FINAN- } \\
\text { CIEROS EN FOR- } \\
\text { MA EFICIENTE Y } \\
\text { EFICAZ }\end{array}$ & $\begin{array}{l}\text { LLEVAR A CABO TRABAJOS } \\
\text { DE ARMONIZACIÓN CONTA- } \\
\text { BLE Y ALINEAR LOS RECUR- } \\
\text { SOS DEL ESTADO Y MUNICI- } \\
\text { PIOS CON LA FEDERACIÓN, } \\
\text { MEDIANTE LOS REGISTROS } \\
\text { DE LAS OPERACIONES CON- } \\
\text { TABLES QUE REALIZA EL } \\
\text { GOBIERNO DEL ESTADO A } \\
\text { TRAVÉS DE LAS DEPENDEN- } \\
\text { CIAS QUE CONFORMAN LA } \\
\text { ESTRUCTURA DEL PODER } \\
\text { EJECUTIVO DEL ESTADO }\end{array}$ & $\begin{array}{l}\text { LLEGAR A } \\
\text { OBTENER- } \\
\text { LA INFOR- } \\
\text { MACIÓN } \\
\text { FINANCIE- } \\
\text { RA PARA } \\
\text { LA FOR- } \\
\text { MULACIÓN } \\
\text { DE LOS } \\
\text { ESTADOS } \\
\text { FINANCIE- } \\
\text { ROS }\end{array}$ & $\begin{array}{l}\text { OPTIMIZAR LOS } \\
\text { REGISTROS DE } \\
\text { LAS OPERACIO- } \\
\text { NES FINANCIE- } \\
\text { RAS QUE REALI- } \\
\text { ZA EL GOBIERNO } \\
\text { DEL ESTADO PA- } \\
\text { RA OBTENER } \\
\text { ESTADOS FINAN- } \\
\text { CIEROS EN FOR- } \\
\text { MA EFICIENTE Y } \\
\text { EFICAZ }\end{array}$ & 100 & 0 & 100 & & $\$ 5,534,018,823.00$ \\
\hline
\end{tabular}




\section{Tabla 32}

Continuación...

\begin{tabular}{|c|c|c|c|c|c|c|c|c|c|}
\hline & $\begin{array}{l}\text { PROYECTO O } \\
\text { PROCESO }\end{array}$ & OBJETIVO & $\begin{array}{c}\text { RESULTADO ESPE- } \\
\text { RADO }\end{array}$ & $\begin{array}{l}\text { NOMBRE DEL } \\
\text { INDICADOR }\end{array}$ & $\begin{array}{l}\text { META } \\
\text { ANUAL }\end{array}$ & $\begin{array}{l}\text { MODI- } \\
\text { FICA- } \\
\text { CIÓN }\end{array}$ & $\begin{array}{c}\text { RE- } \\
\text { SUL- } \\
\text { TADO }\end{array}$ & $\begin{array}{l}\text { SEMÁ- } \\
\text { FORO }\end{array}$ & $\begin{array}{l}\text { PRESUPUESTO } \\
\text { OTORGADO }\end{array}$ \\
\hline $\begin{array}{l}\text { ADMINIS- } \\
\text { TRACIÓN } \\
\text { DE LAS FI- } \\
\text { NANZAS } \\
\text { PÚBLICAS }\end{array}$ & $\begin{array}{l}\text { REGISTRAR, } \\
\text { DISTRIBUIR Y } \\
\text { CONTROLAR } \\
\text { LAS PARTICI- } \\
\text { PACIONES Y } \\
\text { APORTACIONES } \\
\text { A MUNICIPIOS }\end{array}$ & \begin{tabular}{|l} 
REMITIR A LOS \\
MUNICIPIOS LAS \\
PARTICIPACIONES \\
DE CARÁCTER \\
ESTATAL Y FEDE- \\
RAL POR CONCEP- \\
TO DE RAMO 28, \\
RAMO 33 Y FOR- \\
TAMUN
\end{tabular} & $\begin{array}{l}\text { CUMPLIR CON EL } \\
\text { PROCESO ELABO- } \\
\text { RAR EL DOCUMEN- } \\
\text { TO NECESARIO PA- } \\
\text { RA QUE SE REALICE } \\
\text { EL PAGO DE LAS } \\
\text { PARTICIPACIONES } \\
\text { MUNICIPALES A LOS } \\
\text { MUNICIPIOS DEL } \\
\text { ESTADO DE SONORA }\end{array}$ & $\begin{array}{l}\text { REGISTRAR Y } \\
\text { CONTROLAR } \\
\text { LA RECEP- } \\
\text { CIÓN DE LAS } \\
\text { PARTICIPA- } \\
\text { CIONES Y } \\
\text { APORTACIO- } \\
\text { NES A MUNI- } \\
\text { CIPIOS }\end{array}$ & 100 & 0 & 100 & & $\$ 5,534,018,823.00$ \\
\hline
\end{tabular}




\section{Tabla 32}

Continuación...

\begin{tabular}{|c|c|c|c|c|c|c|c|c|c|}
\hline & $\begin{array}{l}\text { PROYECTO O } \\
\text { PROCESO }\end{array}$ & OBJETIVO & $\begin{array}{l}\text { RESULTA- } \\
\text { DO ESPE- } \\
\text { RADO }\end{array}$ & $\begin{array}{l}\text { NOMBRE DEL IN- } \\
\text { DICADOR }\end{array}$ & $\begin{array}{l}\text { META } \\
\text { ANUAL }\end{array}$ & $\begin{array}{l}\text { MODI- } \\
\text { FICA- } \\
\text { CIÓN }\end{array}$ & $\begin{array}{l}\text { RE- } \\
\text { SUL- } \\
\text { TADO }\end{array}$ & $\begin{array}{l}\text { SEMÁ- } \\
\text { FORO }\end{array}$ & $\begin{array}{l}\text { PRESUPUESTO } \\
\text { OTORGADO }\end{array}$ \\
\hline \multirow{2}{*}{$\begin{array}{l}\text { SONORA } \\
\text { COMPETI- } \\
\text { TIVO }\end{array}$} & $\begin{array}{l}\text { OBRAS Y ACCIONES } \\
\text { CON CARGO AL } \\
\text { FIDEICOMISO } \\
\text { PUENTE COLORADO } \\
\text { EN EL MUNICIPIO } \\
\text { DE SAN LUIS RIO } \\
\text { COLORADO }\end{array}$ & $\begin{array}{l}\text { FOMENTAR EL } \\
\text { DESARROLLO DE } \\
\text { LA INFRAESTRUC- } \\
\text { TURA EN GENERAL } \\
\text { EN EL MUNICIPIO } \\
\text { DE SAN LUIS RIO } \\
\text { COLORADO }\end{array}$ & $\begin{array}{l}\text { AMPLIAR } \\
\text { LA COBER- } \\
\text { TURA DE } \\
\text { INFRAES- } \\
\text { TRUCTURA } \\
\text { INSTALA- } \\
\text { DA }\end{array}$ & $\begin{array}{l}\text { AUTORIZAR Y LI- } \\
\text { BERAR RECURSOS } \\
\text { DEL FIDEICOMISO } \\
\text { PUENTE COLORA- } \\
\text { DO A LA FRANJA } \\
\text { DE ATENCIÓN DEL } \\
\text { MISMO PUENTE }\end{array}$ & 100 & 0 & 0 & & \multirow{2}{*}{$\$ 5,534,018,823.00$} \\
\hline & $\begin{array}{l}\text { OBRAS Y ACCIONES } \\
\text { CON CARGO AL } \\
\text { FIDEICOMISO } \\
\text { PUENTE COLORADO } \\
\text { DEL MUNICIPIO DE } \\
\text { PUERTO PEÑASCO }\end{array}$ & $\begin{array}{l}\text { FOMENTAR EL } \\
\text { DESARROLLO DE } \\
\text { LA INFRAESTRUC- } \\
\text { TURA EN GENERAL } \\
\text { EN EL MUNICIPIO } \\
\text { DE PUERTO PE- } \\
\text { ÑASCO }\end{array}$ & $\begin{array}{l}\text { AMPLIAR } \\
\text { LA COBER- } \\
\text { TURA DE } \\
\text { INFRAES- } \\
\text { TRUCTURA } \\
\text { INSTALA- } \\
\text { DA }\end{array}$ & $\begin{array}{l}\text { FOMENTAR EL } \\
\text { DESARROLLO DE } \\
\text { LA INFRAESTRUC- } \\
\text { TURA EN GENE- } \\
\text { RAL EN EL MUNI- } \\
\text { CIPIO DE PUERTO } \\
\text { PEÑASCO }\end{array}$ & 100 & 0 & 0 & & \\
\hline
\end{tabular}




\section{Tabla 32}

Continuación...

\begin{tabular}{|c|c|c|c|c|c|c|c|c|c|}
\hline & $\begin{array}{c}\text { PROYECTO O } \\
\text { PROCESO }\end{array}$ & OBJETIVO & $\begin{array}{l}\text { RESULTADO } \\
\text { ESPERADO }\end{array}$ & $\begin{array}{l}\text { NOMBRE DEL } \\
\text { INDICADOR }\end{array}$ & $\begin{array}{l}\text { META } \\
\text { ANUAL }\end{array}$ & $\begin{array}{l}\text { MODI- } \\
\text { FICA- } \\
\text { CIÓN }\end{array}$ & $\begin{array}{c}\text { RE- } \\
\text { SUL- } \\
\text { TADO }\end{array}$ & $\begin{array}{l}\text { SEMÁ- } \\
\text { FORO }\end{array}$ & $\begin{array}{c}\text { PRESUPUESTO } \\
\text { OTORGADO }\end{array}$ \\
\hline $\begin{array}{l}\text { SONORA } \\
\text { COMPETI- } \\
\text { TIVO }\end{array}$ & $\begin{array}{l}\text { OBRAS Y ACCIONES } \\
\text { CON CARGO AL } \\
\text { FIDEICOMISO } \\
\text { PUENTE COLORADO } \\
\text { EN EL MUNICIPIO } \\
\text { DE PLUTARCO } \\
\text { ELÍAS CALLES }\end{array}$ & $\begin{array}{l}\text { FOMENTAR EL } \\
\text { DESARROLLO DE } \\
\text { LA INFRAESTRUC- } \\
\text { TURA EN GENERAL } \\
\text { EN EL MUNICIPIO } \\
\text { DE PLUTARCO } \\
\text { ELÍAS CALLES }\end{array}$ & $\begin{array}{l}\text { AMPLIAR LA } \\
\text { COBERTURA } \\
\text { DE INFRAES- } \\
\text { TRUCTURA } \\
\text { INSTALADA }\end{array}$ & $\begin{array}{l}\text { AUTORIZAR Y } \\
\text { LIBERAR RECUR- } \\
\text { SOS DE FIDEICO- } \\
\text { MISO PUENTE } \\
\text { COLORADO A LA } \\
\text { FRANCA DE } \\
\text { ATENCIÓN DEL } \\
\text { MISMO PUENTE }\end{array}$ & 100 & 0 & 0 & & $\$ 5,534,018,823.00$ \\
\hline
\end{tabular}




\section{Tabla 32}

Continuación...

\begin{tabular}{|c|c|c|c|c|c|c|c|c|c|}
\hline & PROYECTO O PROCESO & OBJETIVO & $\begin{array}{l}\text { RESULTADO } \\
\text { ESPERADO }\end{array}$ & $\begin{array}{l}\text { NOMBRE DEL } \\
\text { INDICADOR }\end{array}$ & $\begin{array}{l}\text { META } \\
\text { ANUAL }\end{array}$ & $\begin{array}{l}\text { MODI- } \\
\text { FICA- } \\
\text { CIÓN }\end{array}$ & $\begin{array}{l}\text { RE- } \\
\text { SUL- } \\
\text { TADO }\end{array}$ & $\begin{array}{l}\text { SEMÁ- } \\
\text { FORO }\end{array}$ & $\begin{array}{c}\text { PRESUPUESTO } \\
\text { OTORGADO }\end{array}$ \\
\hline $\begin{array}{l}\text { SONORA } \\
\text { COMPETI- } \\
\text { TIVO }\end{array}$ & $\begin{array}{l}\text { PREVISIÓN DE RECURSOS, } \\
\text { RAMO } 23 \text { PARA EL FONDO } \\
\text { DE PAVIMENTACIÓN, ES- } \\
\text { PACIOS DEPORTIVOS, } \\
\text { ALUMBRADO PÚBLICO Y } \\
\text { REHABILITACIÓN DE IN- } \\
\text { FRAESTRUCTURA DEPOR- } \\
\text { TIVA PARA LOS MUNICI- } \\
\text { PIOS Y DEMARCACIÓN TE- } \\
\text { RRITORIAL }\end{array}$ & $\begin{array}{l}\text { FOMENTAR } \\
\text { EL DESA- } \\
\text { RROLLO DE } \\
\text { INFRAES- } \\
\text { TRUCTURA } \\
\text { EN GENERAL } \\
\text { EN LOS MU- } \\
\text { NICIPIOS } \\
\text { DEL ESTADO }\end{array}$ & $\begin{array}{l}\text { AMPLIAR LA } \\
\text { COBERTURA } \\
\text { DE INFRAES- } \\
\text { TRUCTURA } \\
\text { INSTALADA }\end{array}$ & $\begin{array}{l}\text { AUTORIZAR Y } \\
\text { LIBERAR RE- } \\
\text { CURSOS DEL } \\
\text { FOPEDEP EN } \\
\text { LOS MUNICI- } \\
\text { PIOS EL ESTA- } \\
\text { DO DE SONORA }\end{array}$ & 100 & 0 & 0 & & $\$ 5,534,018,823.00$ \\
\hline
\end{tabular}




\section{Tabla 32}

Continuación...

\begin{tabular}{|c|c|c|c|c|c|c|c|c|c|}
\hline & $\begin{array}{c}\text { PROYECTO O PRO- } \\
\text { CESO }\end{array}$ & OBJETIVO & $\begin{array}{l}\text { RESULTADO } \\
\text { ESPERADO }\end{array}$ & $\begin{array}{l}\text { NOMBRE DEL } \\
\text { INDICADOR }\end{array}$ & $\begin{array}{l}\text { META } \\
\text { ANUAL }\end{array}$ & $\begin{array}{l}\text { MODI- } \\
\text { FICA- } \\
\text { CIÓN }\end{array}$ & $\begin{array}{c}\text { RE- } \\
\text { SUL- } \\
\text { TADO }\end{array}$ & $\begin{array}{l}\text { SEMÁ- } \\
\text { FORO }\end{array}$ & $\begin{array}{l}\text { PRESUPUESTO } \\
\text { OTORGADO }\end{array}$ \\
\hline \multirow{2}{*}{$\begin{array}{l}\text { SONORA } \\
\text { COMPETI- } \\
\text { TIVO }\end{array}$} & $\begin{array}{l}\text { PREVISIÓN DE RE- } \\
\text { CURSOS DEL RAMO } \\
\text { 23 PARA EL FONDO } \\
\text { DE INFRAESTRUCTU- } \\
\text { RA DEPORTIVA PARA } \\
\text { LOS MUNICIPIOS DEL } \\
\text { ESTADO }\end{array}$ & $\begin{array}{l}\text { FOMENTAR EL } \\
\text { DESARROLLO DE } \\
\text { INFRAESTRUC- } \\
\text { TURA EN GENE- } \\
\text { RAL EN LOS MU- } \\
\text { NICIPIOS DEL } \\
\text { ESTADO }\end{array}$ & $\begin{array}{l}\text { AMPLIAR LA } \\
\text { COBERTURA } \\
\text { DE INFRAES- } \\
\text { TRUCTURA } \\
\text { INSTALADA }\end{array}$ & $\begin{array}{l}\text { AUTORIZAR Y } \\
\text { LIBERAR RECUR- } \\
\text { SOS DEL FONDO } \\
\text { DE INFRAES- } \\
\text { TRUCTURA DE- } \\
\text { PORTIVA }\end{array}$ & 100 & 0 & 0 & & \multirow{2}{*}{$\$ 5,534,018,823.00$} \\
\hline & $\begin{array}{l}\text { PREVISIÓN DE RE- } \\
\text { CURSOS DEL RAMO } \\
\text { 23 PARA EL FONDO } \\
\text { DE CULTURA PARA } \\
\text { LOS MUNICIPIOS }\end{array}$ & $\begin{array}{l}\text { FOMENTAR EL } \\
\text { DESARROLLO DE } \\
\text { INFRAESTRUC- } \\
\text { TURA EN GENE- } \\
\text { RAL EN LOS MU- } \\
\text { NICIPIOS DEL } \\
\text { ESTADO }\end{array}$ & $\begin{array}{l}\text { AMPLIAR LA } \\
\text { COBERTURA } \\
\text { DE INFRAES- } \\
\text { TRUCTURA } \\
\text { INSTALADA }\end{array}$ & $\begin{array}{l}\text { AUTORIZAR Y } \\
\text { LIBERAR RECUR- } \\
\text { SOS DEL FONDO } \\
\text { DE CULTURA A } \\
\text { LOS MUNICIPIOS } \\
\text { DEL ESTADO }\end{array}$ & 100 & 0 & 0 & & \\
\hline
\end{tabular}

Fuente: Elaboración propia en base Secretaría de Hacienda y Credito Público Sonora (2016). 
El proyecto Sonora Competitivo con seis indicadores no se cumple quedando al $0 \%$ no se cumplió debido a que los recursos eran para el capítulo 4000 de la SHCP de Sonora y se han estado transfiriendo al capítulo 8000 de las instancias ejecutoras de obra. Se debe poner mucho cuidado porque esto tiene consecuencias a futuro.

\section{Tabla 33}

Protección Jurídica a los Sonorenses y sus Bienes; Operación Registral y; Protección Jurídica a los Sonorenses y sus Bienes

\begin{tabular}{|c|c|c|c|c|c|c|c|c|c|}
\hline & $\begin{array}{c}\text { PRO- } \\
\text { YECTO O } \\
\text { PROCE- } \\
\text { SO }\end{array}$ & OBJETIVO & $\begin{array}{l}\text { RESUL- } \\
\text { TADO } \\
\text { ESPE- } \\
\text { RADO }\end{array}$ & $\begin{array}{l}\text { NOMBRE } \\
\text { DEL INDI- } \\
\text { CADOR }\end{array}$ & $\begin{array}{l}\text { META } \\
\text { ANUAL }\end{array}$ & $\begin{array}{l}\text { MODI- } \\
\text { FICA- } \\
\text { CIÓN }\end{array}$ & $\begin{array}{l}\text { RE- } \\
\text { SUL- } \\
\text { TADO }\end{array}$ & $\begin{array}{l}\text { SEMÁ- } \\
\text { FORO }\end{array}$ & $\begin{array}{c}\text { PRESUPUES- } \\
\text { TO OTORGA- } \\
\text { DO }\end{array}$ \\
\hline $\begin{array}{l}\text { PROTEC- } \\
\text { CIÓN JU- } \\
\text { RÍDICA A } \\
\text { LOS SO- } \\
\text { NORENSES } \\
\text { Y SUS } \\
\text { BIENES }\end{array}$ & $\begin{array}{l}\text { OPERA- } \\
\text { CIÓN } \\
\text { REGIS- } \\
\text { TRAL }\end{array}$ & $\begin{array}{l}\text { LOGRAR QUE LA OPERACIÓN DE LA FUN- } \\
\text { CIÓN REGISTRAL SEA EFICIENTE, OPOR- } \\
\text { TUNA Y SISTEMÁTICA; A TRAVÉS DE LA } \\
\text { SUPERVISIÓN Y CONTROL DE LAS OFICI- } \\
\text { NAS REGISTRALES, DE LA CONSERVACIÓN } \\
\text { DE SU ACERVO DOCUMENTAL, ASÍ COMO } \\
\text { A TRAVÉS DEL APEGO A LA LEGALIDAD } \\
\text { EN TODOS SUS PROCEDIMIENTOS CIVILES. } \\
\text { DOCUMENTAL, ASÍ COMO A TRAVÉS DEL } \\
\text { APEGO A LA LEGALIDAD DE TODOS SUS } \\
\text { PROCEDIMIENTOS CIVILES. }\end{array}$ & \begin{tabular}{|l} 
DISMI- \\
NUIR EL \\
PRO- \\
DUCTO \\
INCO- \\
RRECTO
\end{tabular} & $\begin{array}{l}\text { ÍNDICE DE } \\
\text { SEGURIDAD } \\
\text { JURÍDICA EN } \\
\text { LA EMISIÓN } \\
\text { DE CERTIFI- } \\
\text { CADOS DE } \\
\text { INFORMA- } \\
\text { CIÓN REGIS- } \\
\text { TRAL }\end{array}$ & 100 & 0 & 100.5 & & $\$ 117,044,169.0$ \\
\hline
\end{tabular}




\section{Tabla 33}

Continuación...

\begin{tabular}{|c|c|c|c|c|c|c|c|c|c|}
\hline & $\begin{array}{l}\text { PROYECTO } \\
\text { O PROCESO }\end{array}$ & OBJETIVO & $\begin{array}{l}\text { RESULTADO } \\
\text { ESPERADO }\end{array}$ & $\begin{array}{l}\text { NOMBRE } \\
\text { DEL INDI- } \\
\text { CADOR }\end{array}$ & $\begin{array}{l}\text { META } \\
\text { ANUAL }\end{array}$ & $\begin{array}{l}\text { MODI- } \\
\text { FICA- } \\
\text { CIÓN }\end{array}$ & $\begin{array}{l}\text { RE- } \\
\text { SUL- } \\
\text { TADO }\end{array}$ & $\begin{array}{l}\text { SEMÁ- } \\
\text { FORO }\end{array}$ & $\begin{array}{c}\text { PRESUPUES- } \\
\text { TO OTORGA- } \\
\text { DO }\end{array}$ \\
\hline $\begin{array}{l}\text { LEGISLA- } \\
\text { TIVO }\end{array}$ & $\begin{array}{l}\text { DIRECCIÓN } \\
\text { Y COORDI- } \\
\text { NACIÓN DE } \\
\text { LAS POLITTI- } \\
\text { CAS Y FUN- } \\
\text { CIONES DEL } \\
\text { INSTITUTO }\end{array}$ & $\begin{array}{l}\text { ESTABLECER MECANISMOS Y } \\
\text { DIRECTRICES PARA DESARRO- } \\
\text { LLAR LOS PROCESOS DE GESTIÓN } \\
\text { CATASTRAL, REGISTRAL, TÉCNI- } \\
\text { CA Y ADMINISTRATIVA DEL INS- } \\
\text { TITUTO }\end{array}$ & $\begin{array}{l}\text { EFICIENCIA EN } \\
\text { LAS ACCIONES } \\
\text { Y ACTIVIDADES } \\
\text { DE LAS DISTIN- } \\
\text { TAS ÁREAS DEL } \\
\text { INSTITUTO }\end{array}$ & $\begin{array}{l}\text { ÍNDICE DE } \\
\text { EFICIENCIA } \\
\text { EN LAS } \\
\text { ACCIONES } \\
\text { ESTRATÉ- } \\
\text { GICAS }\end{array}$ & 100 & 0 & 87.8 & & \\
\hline $\begin{array}{l}\text { PROTEC- } \\
\text { CIÓN JU- } \\
\text { RÍDICA A } \\
\text { LOS SO- } \\
\text { NORENSES } \\
\text { Y SUS } \\
\text { BIENES }\end{array}$ & $\begin{array}{l}\text { OPERACIÓN } \\
\text { CATASTRAL }\end{array}$ & $\begin{array}{l}\text { COORDINAR LA CORRECTA APLI- } \\
\text { CACIÓN Y OPERACIÓN DE LA LEY } \\
\text { EN MATERIA CATASTRAL, QUE } \\
\text { PERMITA AL INSTITUTO OPERAR } \\
\text { CON EFICIENCIA Y EFICACIA PA- } \\
\text { RA OFRECER PRODUCTOS Y SER- } \\
\text { VICIOS, Y MANTENER UN EFI- } \\
\text { CIENTE INVENTARIO DE LA PRO- } \\
\text { PIEDAD PÚBLICA Y PRIVADA EN } \\
\text { LA ENTIDAD }\end{array}$ & $\begin{array}{l}\text { PADRÓN DE } \\
\text { PREDIOS AC- } \\
\text { TUALIZADOS }\end{array}$ & $\begin{array}{l}\text { ÍNDICE DE } \\
\text { ACTUALI- } \\
\text { ZACIÓN } \\
\text { DEL PA- } \\
\text { DRÓN CA- } \\
\text { TASTRAL }\end{array}$ & 100 & 0 & 175.5 & & $\$ 117,044,169.0$ \\
\hline
\end{tabular}

Fuente: Elaboración propia en base Secretaría de Hacienda y Credito Público Sonora (2016). 
El presupuesto otorgado de \$117 millones de pesos fue otorgado a tres diferentes programas, cada uno con su respectivo proyecto, el cual quedo como se observa en la tabla 33. El resultado de todos los indicadores fue igual al $100 \%$ o superó la meta programada, según la cuenta pública 2015.

\section{Gráfica 2}

\section{Comparación metas}

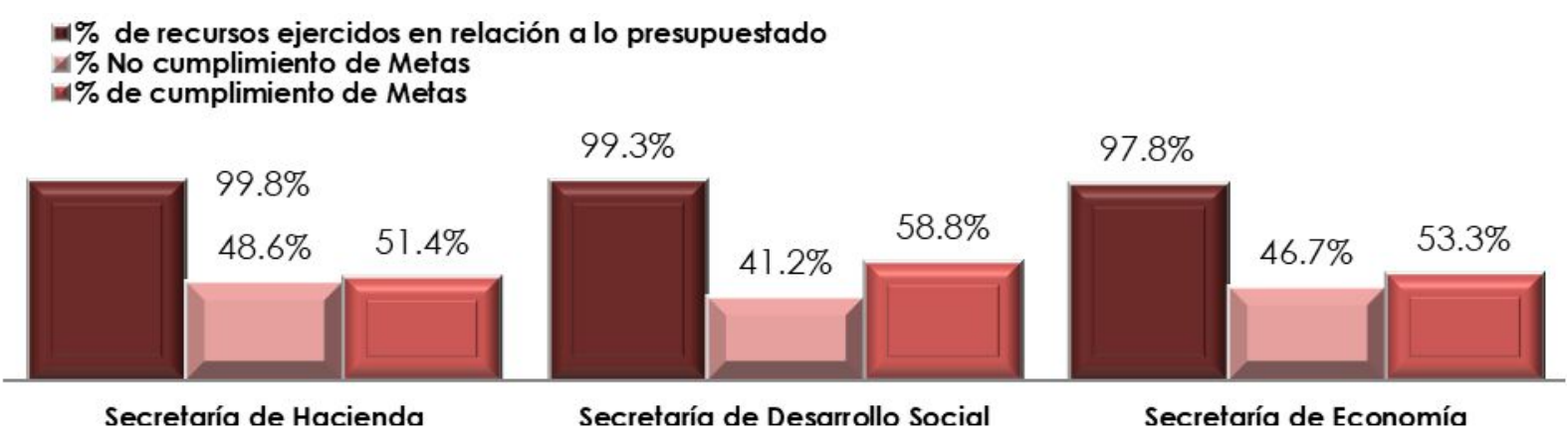

Fuente: Elaboración propia.

\section{Comparación con las metas cumplidas}

Por otro lado analizaremos el presupuesto en comparación con las metas cumplidas por las tres Dependencias analizadas a detalle en el presente estudio, gráfica 2.
Analizando el porcentaje de recursos ejercidos en relación a lo presupuestado, podemos observar que la Secretaría de Hacienda gastó el 98.8\% de su presupuesto asignado de 2015, las metas que no cumplió fueron el $48.6 \%$ de las establecidas, cumpliendo únicamente con el 51.4\%. La Secretaría de Desarrollo Social gastó el 99.3\% de su presupuesto asignado de 2015, las metas que no cumplió fueron el $41.2 \%$ de las establecidas, cumpliendo únicamente con el 58.8\%. La Secretaría de Economía gastó el $97.8 \%$ de su presupuesto asignado de 2015, las metas que no cumplió fueron el $46.7 \%$ de las establecidas, cumpliendo únicamente con el 53.3\%. De las 3 dependencias evaluadas la que mejor cumplió fue la Secretaría de Desarrollo Social al cumplir con más metas cumplidas alcanzando el 58.8\% de cumplimiento, aunque esto no es suficiente ya que esto no representa una calificación aprobatoria, aunque a las entidades se les asigne presupuesto y se lo gasten, eso no significa que se cumplirán con las metas establecidas.

\section{Conclusiones}

Como conclusión podemos decir que cumplimos con el objetivo general y con el objetivo específico, el cual era evaluar el cumplimiento de metas del año 2015 de la Secretaría de Desarrollo Social(DEDESOL), Secretaría de Economía(SE) y Secretaría de Hacienda(SH). Toda la información analizada fue extraída de la cuenta pública del año 2015 del poder ejecutivo de la sección información programática, esta información es toda la relacionada a los programas públicos que son establecidos por las mismas dependencias, estas incluyen proyectos, metas, indicadores, presupuesto 
asignado, objetivo y resultado.

En este análisis podemos observar cómo se distribuye el presupuesto del poder ejecutivo a las Dependencias del sector Público, y como éstas, crean programas en relación a dicho presupuesto con la implementación de objetivos para cumplimento de metas y los diversos indicadores de evaluación para cada programa. El Ejecutivo del Estado es el que logró cumplir un mayor porcentaje de metas con un $78 \%$ equivalente a 29 . En total el Poder Ejecutivo estableció 477 metas. La Secretaría de Agricultura, Ganadería, Recursos Hidráulicos, Pesca y Acuacultura, es la Dependencia con menor porcentaje de metas cumplidas apenas alcanzó el 37\% de ellas.

$\mathrm{Al}$ analizar las 3 dependencias pudimos observar que:

La Secretaría de Desarrollo Social tuvo un presupuesto asignado (modificado) para el año 2015 por \$381 millones de pesos; tuvo un subejercicio por $\$ 2$ millones de pesos, este recurso es el que no se alcanzó a gastar durante 2015 el cual en porcentaje representa un remanente de $0.7 \%$ basándose en el presupuesto total; esta dependencia estableció 17 metas, de las cuales solo 10 alcanzaron una calificación a más del 100\% representando el $59 \%$ del total de las metas, las que cumplieron a más del $80 \%$ y menos del $100 \%$ fueron 2 metas representando el $12 \%$ del total y las que cumplieron a menos del $80 \%$ fueron 5 metas que representan el $29 \%$ del total de metas establecidas. En general el porcentaje de metas que no cumplieron fueron el $41 \%$ ejerciendo el 98.5 de su presupuesto.

La Secretaría de Economía tuvo un presupuesto asignado (modificado) para el año 2015 por $\$ 662$ millones de pesos; tuvo un subejercicio por \$14 millones de pesos, este recurso es el que no se alcanzó a gastar durante 2015 el cual en porcentaje representa un remanente de $2.2 \%$ basándose en el presupuesto total; esta dependencia estableció 30 metas, de las cuales solo 16 alcanzaron una calificación a más del 100\% representando el 53\% del total de las metas, las que cumplieron a más del $80 \%$ y menos del $100 \%$ fueron 2 metas representando el $7 \%$ del total $y$ las que cumplieron a menos del $80 \%$ fueron 12 metas que representan el $40 \%$ del total de metas establecidas. En general el porcentaje de metas que no cumplieron fueron el $47 \%$ ejerciendo el 97.8 de su presupuesto.

La Secretaría de Hacienda tuvo un presupuesto asignado (modificado) para el año 2015 por \$16,620 millones de pesos; tuvo un subejercicio por $\$ 22$ millones de pesos, este recurso es el que no se alcanzó a gastar durante 2015 el cual en porcentaje representa un remanente de $0.2 \%$ basándose en el presupuesto total; esta dependencia estableció 70 metas, de las cuales solo 36 alcanzaron una calificación a más del 100\% representando el $51 \%$ del total de las metas, las que cumplieron a más del $80 \%$ y menos del $100 \%$ fueron 7 metas representando el $10 \%$ del total y las que cumplieron a menos del $80 \%$ fueron 17 metas que representan el 30\% del total de metas establecidas. En general el porcentaje de metas que no cumplieron fueron el $49 \%$ ejerciendo el 99.8 de su presupuesto.

En relación a estas tres dependencias analizadas podemos decir que no tienen sus objetivos muy claros, lo que hace que no cumplan sus metas establecidas, lo que se analizó de información relacionada al no cumplimiento de metas siempre hubo excusas por parte de los trabajadores para no llevar a cabo los indicadores y metas, creo que es necesario sancionar a las personas 
que no estén cumpliendo bien con su trabajo, ya que todo esto repercute en la economía y en la sociedad, estamos estancando programas de mucha utilidad, también es importante que con anticipación planeemos bien los programas, metas e indicadores, los cuales sean favorecedores para los sonorenses. Los programas tenían su recurso establecido algunas dependencias con más y otras con menos y eso no quiere decir o asegura que cumplirán con sus metas, además las dependencias se gastaron más del $98 \%$ de su presupuesto y no alcanzaron a lograr ni el 60\% de cumplimiento.

Por otra parte, según los programas que se analizaron de Secretaría de Desarrollo Social (Sonora Solidario, Impulso al Federalismo y al Desarrollo Municipal), Secretaría de Economía (Sonora Competitivo, Sonora Competitivo y Modernización Comercial, Innovación y Desarrollo Tecnológico, Promoción Internacional y Comercio Exterior, Fomento a la Minería) y Secretaría de Hacienda (Fortalecimiento de los Ingresos, Justicia Administrativa y Laboral, Modernización de la Administración y Pasión por el Servicio Público, Seguridad Pública, Administración de las Finanzas Públicas, Consolidación de la Gestión Pública Para Resultados, Modernización de la Administración y Pasión por el Servicio Público:, Protección Jurídica a los Sonorenses y sus Bienes, Legislativo). Podemos concluir que existe una deficiencia en los indicadores aplicados a los programas ya que existen muchas metas inconclusas en las dependencias gubernamentales. Algunos de éstos programas no fueron efectuados debido a cancelaciones de recursos por parte de la Secretaría de Hacienda, sin quedar claro a donde se redistribuyó dicho recurso. Aunado a esto los subejercicios registrados son de especial observancia, puesto que la sociedad siempre tendrá necesidades ilimitadas que cubrir, y se ve limitada de dicho recurso presupuestario.

Se recomienda que cada una de las secretarías tenga sus objetivos claros para que pueda cumplir con la meta de cada uno de los indicadores, ya que el recurso que se está destinando a cada proyecto se puede aprovechar en otro programa en el que en verdad si se necesita y que actualmente si está cumpliendo sus metas o para programas nuevo. También se recomienda darle seguimiento a cada uno de los indicadores para poder ver las fallas que están obstruyendo el alcance de dicha meta y así poder corregirlo cada trimestre o para que el próximo año no se vuelva a repetir. También hay varios proyectos a los que no se les debería asignar mucho recurso, como por ejemplo: El proyecto de la Secretaría de Desarrollo "Impulsar al Desarrollo Social” el cual establece 4 indicadores, los cuales ninguno logró alcanzar la meta; 2 de ellos el Índice de Cobertura del Programa de Apoyo a Adultos Mayores (asignación aprobada 50 millones de pesos, padrón de beneficiarios 32,880 personas adultas)y el Programa de Apoyo a Madres Jefas de Familia no tienen ningún avance, debido a la implementación de una serie de medidas de racionalidad y contención en la administración de los recursos presupuestarios por parte de Secretaría de Hacienda ante la presentación de problemas de liquidez. Los $\$ 37,385,981$ pesos otorgados a este proyecto se destinaron a cubrir el indicador Índice de Cumplimiento de la Realización de Brigadas Comunitarias. 


\section{Referencias}

\section{Páginas web}

Ballar, X. (1993). Evaluación de políticas. Marco conceptual y organización institucional.

https://dialnet.unirioja.es/descarga/articulo/27215.pdf

Ejecutivo del Estado. (2016). Cuenta de la Hacienda Pública Estatal 2015. Tomo del Ejecutivo, 265-1006. https://hacienda.sonora.gob.mx/media/3368/ctapub201 5-ejecutivo.pdf

H. Congreso del Estado. (2008). Plan estatal de desarrollo 2009-2015. PED 2009-2015, 1-98.

https://hacienda.sonora.gob.mx/media/3785/ped_20092015.pdf
Oficialía Mayor. (2014). Manual de Programación y Presupuestación 2015. Manual de programación y presupuestación, 1-56.

https://hacienda.sonora.gob.mx/media/2982/mpp2015. pdf

Roth, A. (2009). Políticas Públicas, formulación, implementación y evaluación. Aurora. http://uca.edu.sv/mcp/media/archivo/f5abaa_evaluacio npoliticaspublicasroth.pdf

Roth, A. (2004). Políticas Públicas, formulación, implementación y evaluación. Aurora. https://es.scribd.com/document/317185012/PoliticasPublicas-Andre-Noel-Roth 